\title{
CAPACIDADE FUNCIONAL E ANÁLISE DE MARCHA NO PÓS- OPERATÓRIO E ARTROPLASIA TOTAL DO QUADRIL, DE ACORDO COM NÍVEIS DE 25-HIDROXIVITAMINA D
}

\author{
Tese apresentada à Pós-Graduação em Ciências Médicas da \\ Universidade de Brasília para obtenção do título de Doutor
}

Orientador: Prof. Dr. Leopoldo Luiz dos Santos-Neto - Professor Associado de Clínica Médica da Faculdade de Medicina da Universidade de Brasília

Co-orientadora: Prof. Dra. Ana Cristina de David - Professora Associada da Faculdade de Educação Física da Universidade de Brasília

\section{Brasília}





\section{Dedicatória}

À minha esposa Camila Sodré, que ainda me faz acreditar na Humanidade. 


\section{AGRADECIMENTOS}

Ao Professor Leopoldo Luiz dos Santos-Neto, pela orientação prestimosa e atenta em todos esses anos.

À Professora Ana Cristina de David, pela inestimável orientação e análise crítica acerca da análise de marcha.

À minha liderança no SARAH, Dr. Sérgio Henrique Rodolpho Ramalho, pelo incessante apoio, permitindo e facilitando a realização desta pesquisa.

À equipe de fisioterapeutas do programa de Ortopedia do hospital SARAH-Brasília, que realizaram algumas das avaliações que utilizei neste estudo.

À equipe do Centro Nacional de Controle de Qualidade da Rede SARAH, particularmente ao estatístico Sandro Barbosa de Oliveira, pelo inestimável auxílio em todas as fases da estatística, desde o planejamento até a execução.

À equipe do Laboratório de Movimento da Rede SARAH, em especial à fisioterapeuta Aline Dalfito Gava, que me prestou consultoria em todas as fases do estudo.

Aos médicos da equipe de Ortopedia, que permitiram a realização deste estudo com seus pacientes.

Aos meus pais, que investiram em mim e facilitaram a minha vida estudantil de todas as formas.

Aos pacientes que aceitaram fazer parte do estudo. 



\section{RESUMO}

Objetivos: Verificar a hipótese de associação entre níveis basais de 25-hidroxivitamina D (25OHD) e mudanças da capacidade funcional e análise de marcha em artroplastia total do quadril (ATQ) e identificar quais variáveis apresentariam diferenças entre o pré e pósoperatório. Métodos: Coorte prospectiva de pacientes submetidos à primeira ATQ da articulação acometida, analisada em dois cortes transversais. Os níveis séricos de 25OHD foram dosados na admissão hospitalar. Os pacientes foram avaliados com o Western Ontario and MacMaster University Osteoarthritis Index (WOMAC) e com análise de marcha, incluindo sistemas de captura de movimento e plataforma de força. As avaliações foram realizadas no pré-operatório e após 3 meses. Resultados: Dados completos de WOMAC, cinemática e cinética estiveram disponíveis em 104, 93 e 66 pacientes, respectivamente. Houve melhora significativa nos domínios "dor", "rigidez" e "atividade física" em 3 meses de pós-operatório. ( $\mathrm{p}<0,001$ em todas as análises). Não foi encontrada correlação entre os níveis de 25OHD e a variação no WOMAC total e seus domínios. Não foram identificadas diferenças significativas da média do WOMAC total e seus domínios, entre os grupos de 25OHD basal. Foi identificada melhora do tempo de apoio simples, comprimento do passo, passada, velocidade de marcha (todos $\mathrm{p}<0,001$ ), extensão máxima e abdução máxima $(\mathrm{p}<0,001)$, flexão máxima $(\mathrm{p}=0,01)$, momento extensor máximo $(\mathrm{p}=0,002)$, potência máxima de geração $(p<0,001)$ e absorção de energia $(p=0,001)$ dos flexores do quadril. Foi identificada correlação de $25 \mathrm{OHD}$ com a variação da extensão máxima $(\mathrm{R}=0,25, \mathrm{p}=0,017)$ e com a potência máxima de geração de energia $(R=0,25, \mathrm{p}=0,04)$. No subgrupo de pacientes idosos, não foi encontrada nenhuma correlação significativa. Foi realizada regressão linear múltipla, incluindo como varáveis dependentes a variação do pico de extensão (modelo 1) e da potência máxima de geração de energia (modelo 2). No modelo 1, 25OHD e variação da velocidade de marcha tiveram efeito na variabilidade ( $R 2$ ajustado $=0,1, p=0,004)$. No modelo 2, apenas $25 \mathrm{OHD}$ explicou a variabilidade $(\mathrm{R} 2$ ajustado $=0,05, \mathrm{p}=0,044)$. Conclusões: Não foi observada relação entre os níveis de 25OHD e a variação dos escores WOMAC. Houve melhora do WOMAC total e seus domínios, mais acentuada do que previamente relatado em outros estudos, em pacientes submetidos a ATQ. Foi encontrada correlação entre a 25OHD basal e a extensão máxima e a potência máxima de geração dos flexores do quadril. O efeito da 25OHD na variabilidade de ambas as variáveis foi modesto. Houve melhora significativa de parâmetros espaço-temporais, cinemáticos e cinéticos no terceiro mês de pós-operatório de ATQ. 

Palavras-chave: Artroplastia total do quadril. Vitamina D. Capacidade funcional. Análise de marcha. 



\begin{abstract}
Objectives: To investigate the association between baseline serum levels of 25hydroxyvitamin D (25OHD) and changes in functional capacity and gait parameters in patients undergoing total hip arthroplasty (THA) and ascertain whether this variables change between the preoperative and postoperative periods. Methods: Prospective study, including patients with hip osteoarthritis undergoing primary THA between January 2012 and December 2013. Blood samples were collected on the day of hospital admission. Analyses with Western Ontario and MacMaster University Osteoarthritis Index (WOMAC) and gait analyses were performed before surgery and 3 months postoperatively. Results: There was a significant improvement in the pain, stiffness and physical function domains 3 months after surgery ( $p<0.001$ in all analyses). No correlation was found between 25OHD levels and changes in WOMAC total or domain scores. Also, no significant difference was found in the mean change in WOMAC total and domain scores between baseline 25OHD groups. No significant association was detected after the exclusion of patients aged $<60$ years and on sensitivity analyses. Improvements were observed in single-limb support time, stride length, gait speed (all $\mathrm{p}<0.001)$, peak extension $(\mathrm{p}<0.001)$, peak flexion $(\mathrm{p}=0.01)$, peak abduction $(p<0,001)$, peak extensor moment $(p=0.002)$, peak power generation $(p<0.001)$, and peak power absorption $(\mathrm{p}=0.001)$. $25 \mathrm{OHD}$ levels correlated with change in peak extension $(\mathrm{R}=$ $0.25, \mathrm{p}=0.017)$ and peak power generation $(\mathrm{R}=0.25, \mathrm{p}=0.04)$. Multiple linear regression analysis was performed. In model 1, 25OHD and gait speed variation explained variability of peak extension $\left(\mathrm{R}^{2}=0.1, \mathrm{p}=0.004\right)$. In model 2 , only $25 \mathrm{OHD}$ explained variability of peak power generation $\left(\mathrm{R}^{2}=0.05, \mathrm{p}=0.044\right)$. Conclusions: No association was observed between baseline 25OHD levels and change in WOMAC scores. There was an improvement in WOMAC total and domain scores in patients undergoing THA, with greater improvement than previously reported in other studies. 25OHD levels were correlated with peak extension and peak power generation. The effect of $25 \mathrm{OHD}$ on change in gait variables after THA was quite modest. Significant improvement of spatiotemporal, kinematic, and kinetic gait data was observed after 3 months of THA.
\end{abstract}

Keywords: Total hip arthroplasty. Vitamin D. Functional capacity. Gait analysis. 


\section{ÍNDICE DE FIGURAS}

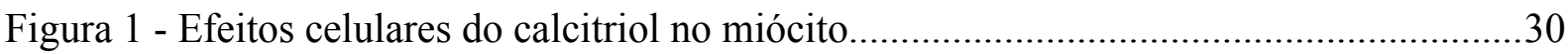

Figura 2 - Laboratório de movimento do hospital SARAH-Brasília......................................42

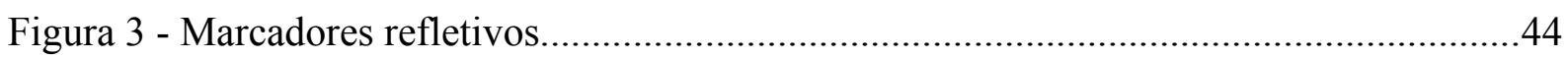

Figura 4: Câmera emissora de luz infravermelha Vicon MCAM M2, pertencente ao

Laboratório de Movimento do Hospital SARAH-Brasília.

Figura 5: Plataformas de força do Laboratório de Movimento do Hospital SARAH-Brasília. 45 Figura 6: Exemplo de análise cinemática (a) e cinética (b) de paciente em pré-operatório de ATQ realizada no Laboratório de Movimento do hospital SARAH-Brasília...........................48

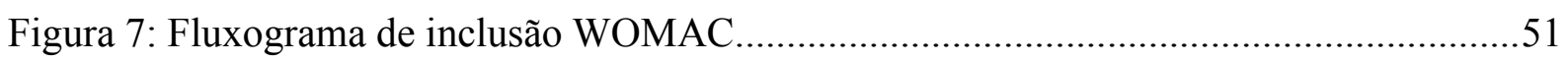

Figura 8 - Fluxograma de inclusão análise de marcha...........................................................57

Figura 9 - Gráfico de dispersão do teste de correlação de Pearson entre 25-hidroxivitamina D

basal (eixo horizontal) e variação da extensão máxima (eixo vertical)...................................59

Figura 10 - Gráfico de dispersão do teste de correlação de Pearson entre 25-hidroxivitamina D basal (eixo horizontal) e variação da potência máxima de geração de energia dos flexores do

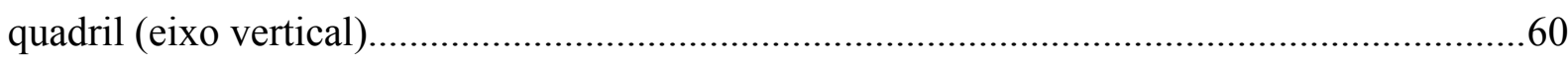




\section{ÍNDICE DE TABELAS}

Tabela 1 - Etiologias da osteoartrite de quadril.

Tabela 2 - Análise de marcha: valores normais do Laboratório de Movimento do Hospital

SARAH- Brasília. .46

Tabela 3 - Características basais: variáveis numéricas. .52

Tabela 4 - Características basais: variáveis categóricas. .54

Tabela 5 - WOMAC no pré-operatório e após 3 meses de pós-operatório. .55

Tabela 6 - Testes de correlação entre 25-hidroxivitamina D e a a variação do WOMAC .55

Tabela 7 - Comparação das médias de WOMAC entre os grupos de 25-hidroxivitamina D (25OHD) .55

Tabela 8 - Comparação de médias da variação do WOMAC entre os quartis de 25hidroxivitamina D (25OHD). .55

Tabela 9 - Testes de correlação entre 25-hidroxivitamina D e a variação do WOMAC no subgrupo de pacientes com idade $\geq 60$ anos .56

Tabela 10 - Comparação das médias da variação do WOMAC entre os grupos de 25hidroxivitamina D (25OHD) de acordo com a mediana no subgrupo de pacientes com idade $\geq$ 60 anos

Tabela 11 - Análise de marcha pré e pós-operatória. .58

Tabela 12 - Correlação entre 25-hidroxivitamina D basal e a variação dos dados de marcha.58 Tabela 13 - Correlação entre 25-hidroxivitamina D basal e os dados de marcha no subgrupo de pacientes idosos.

Tabela 14 - Comparação de dados de marcha entre os grupos de 25-hidroxivitamina D (25OHD).

Tabela 15 Comparação de dados de marcha entre os quartis de 25-hidroxivitamina D (25OHD).

Tabela 16 - Comparação de médias no subgrupo de pacientes idosos 



\section{LISTA DE ABREVIATURAS}

25OHD

ADM

ATQ

$\mathrm{OA}$

PTH

VDR

WOMAC 25-hidroxivitamina D

amplitude de movimento

artroplastia total do quadril

osteoartrite

paratormônio

receptor de vitamina $\mathrm{D}$

Western Ontario and MacMaster University Osteoarthritis

Index 


\section{SUMÁRIO}

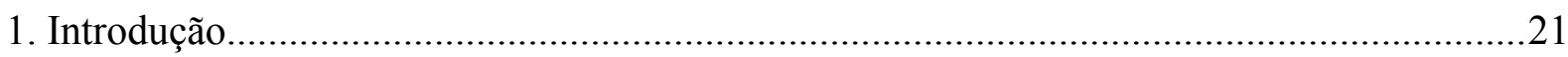

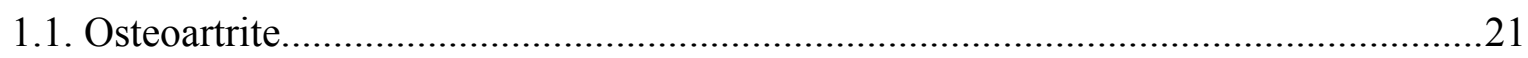

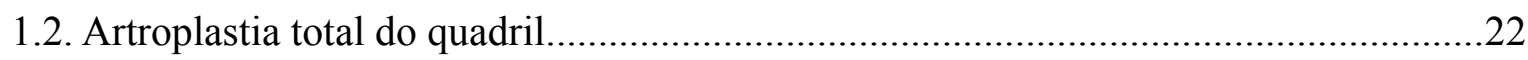

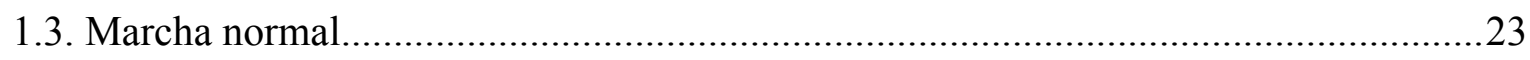

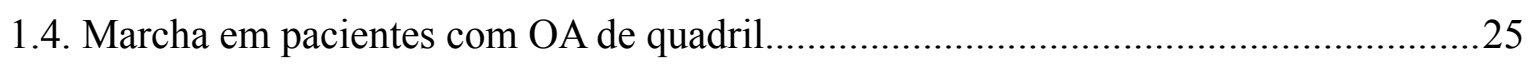

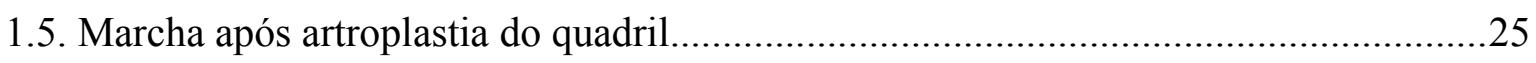

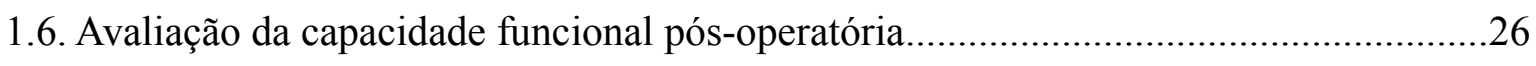

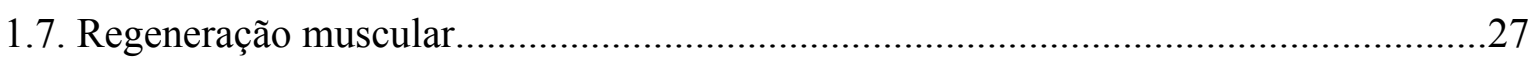

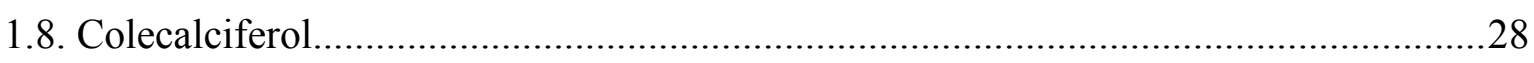

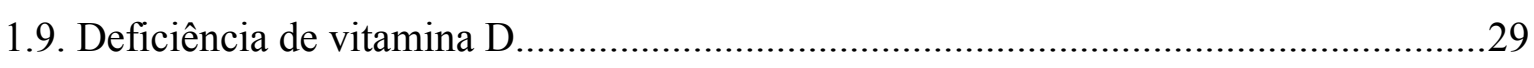

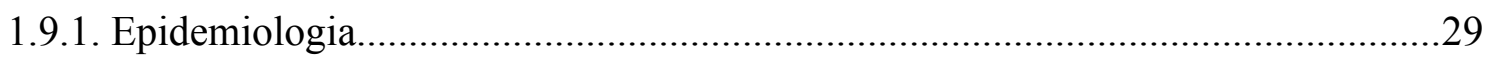

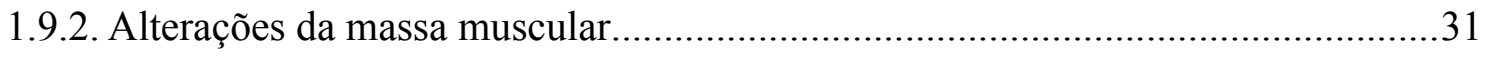

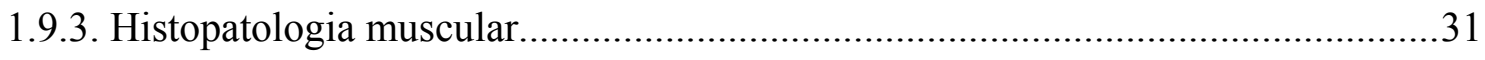

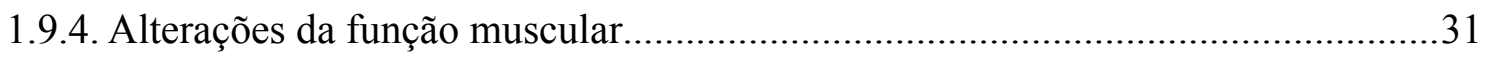

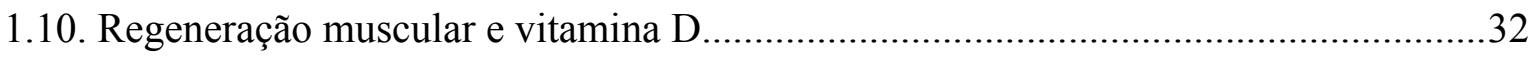

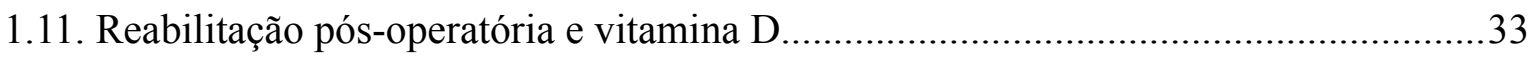

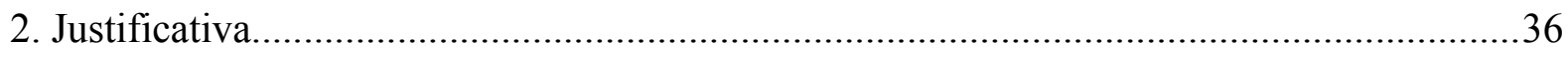

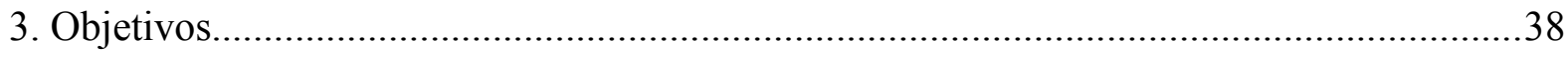

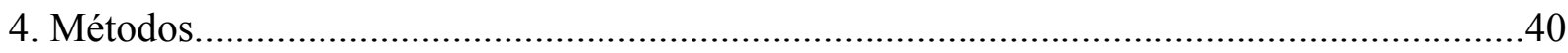

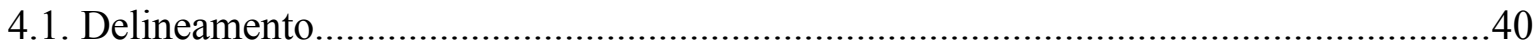

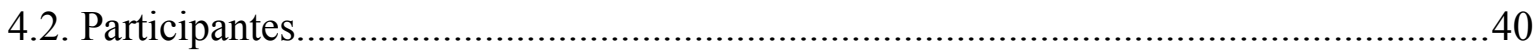

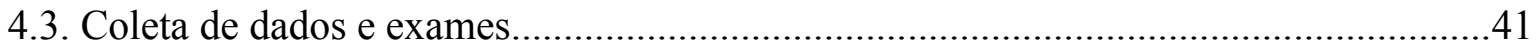

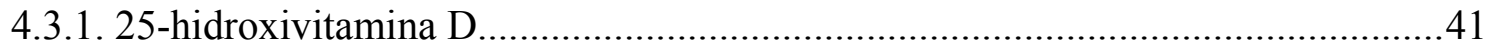

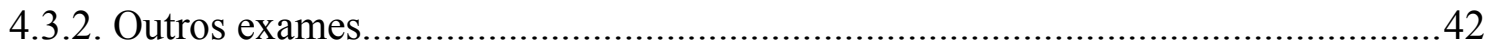

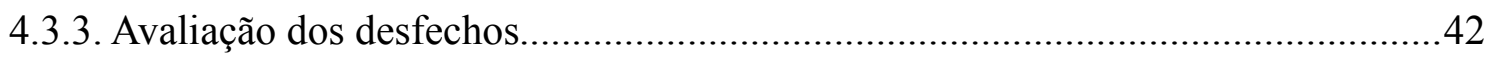

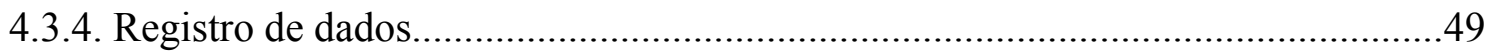

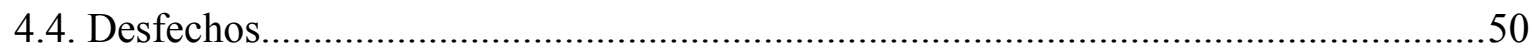

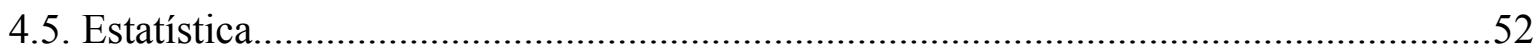

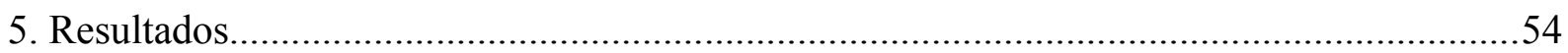

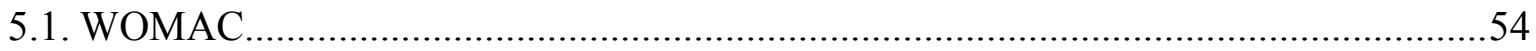

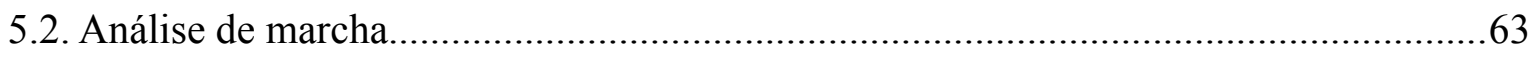

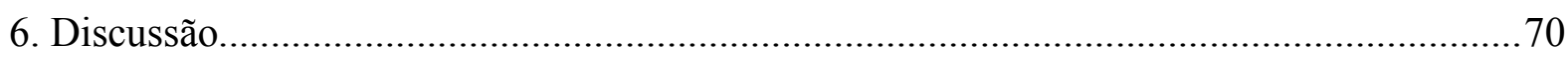


6.1. WOMAC

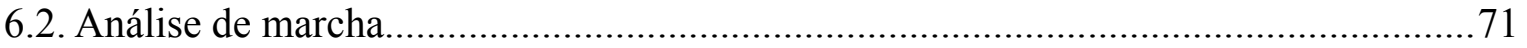

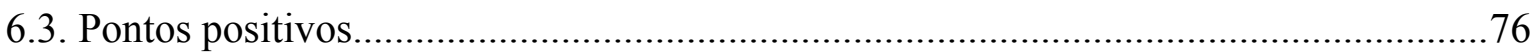

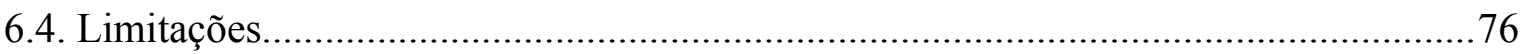

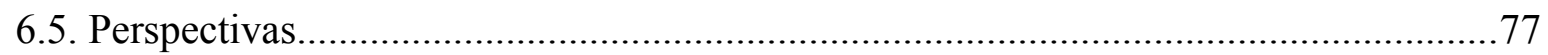

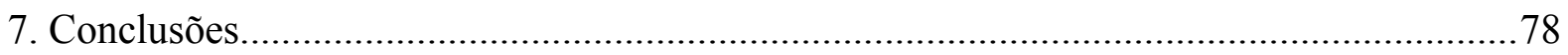

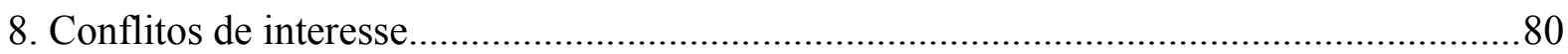

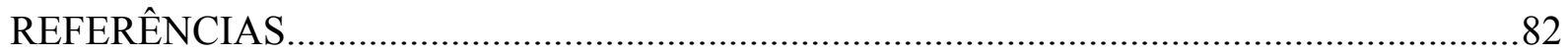

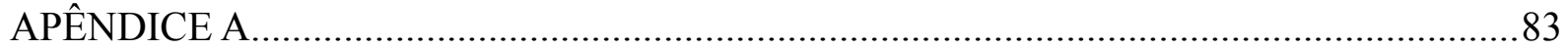

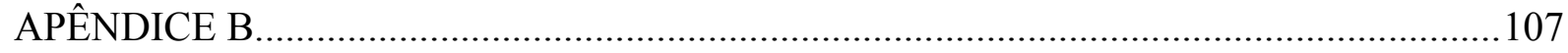

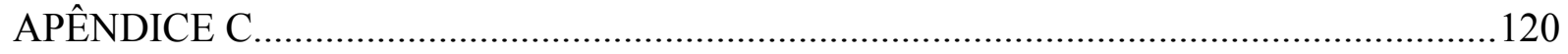

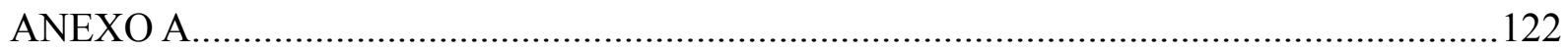

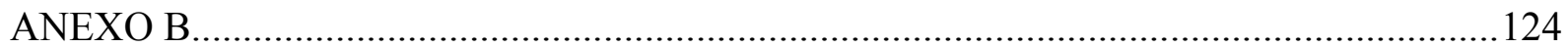




\section{Introdução}

\subsection{Osteoartrite}

A osteoartrite (OA) é a doença articular mais prevalente entre indivíduos com mais de 65 anos (1). A doença se origina da disfunção da cartilagem articular secundária a uma interação complexa de fatores genéticos, metabólicos, bioquímicos e biomecânicos com inflamação secundária, que evolui com degradação e reparação do osso, cartilagem e sinóvia (2). Seu mecanismo etiopatogênico ainda não foi esclarecido, mas alguns fatores de risco são conhecidos: idade, gênero, localização da articulação, predisposição genética, obesidade, fraqueza muscular, alterações da propriocepção, fatores ocupacionais, alguns tipos de esportes e desalinhamento articular (3). As etiologias mais frequentes da OA de quadril estão resumidas na tabela 1.

Alterações morfológicas têm sido descritas. Na OA precoce, ocorrem irregularidade das superfícies articulares, fendas superficiais e distribuição alterada de proteoglicanos. $\mathrm{Na}$ OA tardia, há um aprofundamento das fendas na cartilagem, aumento da irregularidade da superfície articular, evoluindo com ulceração da cartilagem, com exposição do osso subjacente; com isso, há a formação de agrupamentos de condrócitos, na tentativa de reparo e osteófitos se formam, por reação óssea (2).

Clinicamente, a doença se manifesta por dor articular, de características mecânicas, de evolução insidiosa e seu curso tem períodos de exacerbação e remissão, mas com agravamento progressivo. Frequentemente, pode ser notado discreto aumento de volume na articulação afetada, que tem como causa inflamação de baixo grau, típica da OA. Em estágio avançado, a OA do quadril evolui com dor articular intensa, refratária, que causa limitação da marcha, às vezes incapacitante. Na radiografia simples, as alterações cardinais da OA são a presença de redução do espaço articular, esclerose e geodos subcondrais e osteófitos. Métodos avançados de imagem, como a ressonância magnética, podem ser utilizados também para investigação diagnóstica.

Não está disponível, até o momento, nenhum tratamento clínico que interrompa a evolução da doença, por isso o objetivo do tratamento é o alívio sintomático. Nos casos avançados, o tratamento cirúrgico com artroplastia pode ser indicado. 
Tabela 1 - Etiologias da osteoartrite de quadril.

\begin{tabular}{l}
\hline \multicolumn{1}{c}{ Etiologia } \\
\hline Mecânica \\
idiopática \\
displasias \\
trauma \\
necrose óssea avascular \\
epifisiólise \\
impacto fêmoro-acetabular \\
doença de Postel \\
Inflamatória \\
artrite reumatoide \\
espondiloartrites \\
infecção \\
Neurogênica \\
tabes dorsalis \\
siringomielia \\
Metabólica \\
doença por depósito de cristais de pirofosfato de cálcio \\
hemocromatose \\
doença de Wilson \\
alcaptonúria \\
acromegalia \\
Outras \\
hipermobilidade articular
\end{tabular}

\subsection{Artroplastia total do quadril}

O tratamento cirúrgico de OA do quadril é empregado quando há falência do tratamento conservador, em pacientes com degeneração articular grave, com dor incapacitante e que atrapalha de forma significativa as atividades diárias.

A artroplastia total do quadril (ATQ) é a cirurgia mais utilizada para tratamento da OA avançada, primária ou secundária. Em 2013, 457.195 artroplastias totais ou parciais de quadril foram realizadas nos Estados Unidos da América (4). Embora a cirurgia tenha bons resultados em todas as faixas etárias, normalmente ela é reservada para pacientes idosos, uma vez que os 
24

dispositivos utilizados na cirurgia apresentam vida útil média conhecida de 10 a 15 anos. Neste procedimento, são substituídas as superfícies articulares desgastadas por dispositivos protéticos, aliviando a dor e melhorando a cinemática da articulação, tendo como objetivo a melhora da capacidade funcional e da qualidade de vida.

Vários tipos de técnicas e materiais para ATQ têm sido descritos na literatura. No hospital Sarah-Brasília, um dos hospitais da Rede Sarah de Hospitais de Reabilitação, a técnica de escolha da equipe cirúrgica é a abordagem lateral (tipo Hardinge). Nessa abordagem, são realizadas as seguintes etapas: o terço anterior do glúteo médio é destacado e rebatido anteriormente; a metade anterior do glúteo mínimo é dividida em linha com o colo femoral e uma excisão na cápsula é realizada; os ligamentos ântero-inferiores são liberados para permitir o deslocamento anterior da extremidade proximal do fêmur; após colocação do implante, a cápsula e as camadas musculares são reparadas com fios de sutura nãoabsorvíveis.

De forma geral, estudos mostram resultados clínicos, funcionais e radiográficos bastante satisfatórios e alto índice de satisfação entre os pacientes (5). Entretanto, complicações estão descritas, como fratura da prótese, fratura periprotética, luxação, calcificação heterotópica, tromboembolismo venoso, infecção ou mesmo o óbito. A mortalidade em 30 dias associada a ATQ gira em torno de 0,4\% nos Estados Unidos (6).

No Brasil, há poucos dados publicados sobre mortalidade em ATQ. Em um estudo retrospectivo realizado em um hospital privado de grande porte, a mortalidade de ATQ em 90 dias foi de $1,16 \%$, mas em todos os casos a cirurgia foi indicada após fratura do colo do fêmur (7). No hospital SARAH-Brasília, a taxa de mortalidade da ATQ em 1 ano foi de 1,29\% entre 2009 e 2013 (dados não publicados).

\subsection{Marcha normal}

A marcha é uma forma de locomoção bípede, em que há ação alternada dos membros inferiores, com uma sequência de movimentos para mover o corpo à frente enquanto, simultaneamente, é mantida a postura estável. Durante a marcha, são realizados movimentos coordenados entre os membros inferiores, superiores e tronco. Para que esse processo aconteça de forma harmônica, há uma ação integrada do sistema nervoso, músculos e articulações (8). 
À medida que o corpo se desloca anteriormente, um membro funciona como fonte móvel de apoio enquanto o outro membro avança para uma nova posição de apoio, o que é denominado balanço. Uma sequência completa dessas funções por um membro é chamada de ciclo da marcha ou passada, que é essencialmente a unidade funcional da marcha. O apoio é o período durante o qual o pé está em contato com a superfície e o balanço é o momento em que o pé está fora do solo para promover o avanço do membro (8). As subdivisões da marcha são baseadas nos movimentos dos membros no plano sagital.

O apoio é subdividido em fases. O duplo apoio inicial marca o começo do ciclo da marcha, sendo subdividido em duas fases: contato inicial e resposta à carga. $\mathrm{O}$ contato inicial é o instante em que o pé toca o solo e tem como objetivo a desaceleração do impacto. A resposta à carga é o restante do movimento até a retirada do pé contralateral do solo, em que o membro gera uma potência de absorção de energia dos flexores do quadril, levando a estabilidade do membro. O apoio simples permite o deslocamento do corpo sobre o pé estacionário e se inicia com o apoio médio, em que há o início do balanço do membro contralateral e termina com o alinhamento de ambos os tornozelos no plano coronal. O apoio terminal se segue a esse movimento e termina no momento em que o membro contralateral toca o solo. O duplo apoio terminal ocorre no pré-balanço, que se inicia após o apoio terminal e termina quando o membro ipsilateral é elevado para o balanço. Nesse momento, o membro gera uma potência de geração de energia dos flexores do quadril, com o objetivo de acelerar a progressão do corpo $(8,9)$.

O balanço é subdividido em três fases. O balanço inicial é a fase de aceleração, que se inicia com a retirada do pé do solo e termina quando o joelho atinge o pico de flexão. $\mathrm{O}$ balanço médio se inicia quando o pé em balanço está em oposição ao pé em apoio e termina quando o membro em balanço está a frente e a tíbia está vertical. O balanço terminal é a fase de desaceleração e de preparo para o apoio, se seguindo ao balanço médio e terminando no contato inicial (9).

A distância linear no plano de progressão entre o contato inicial de ambos os pés é denominada passo.

Durante a marcha em velocidade de conforto, a fase de balanço ocupa cerca de $40 \%$ do ciclo da marcha e, a fase de apoio, $60 \%$. Durante a fase de apoio, dois terços do tempo é ocupado pelo apoio simples e um terço é ocupado pelos dois períodos de duplo apoio, sendo um sexto pelo apoio inicial e um sexto pelo apoio terminal e pré-balanço (8). 
A análise de marcha consiste em um método propedêutico em que são analisadas todas as fases da marcha de forma sistemática, por meio de mensurações dos parâmetros espaçotemporais, cinemáticos e cinéticos. Nesse método, são analisados os ângulos dos movimentos articulares, torques e potências nos planos sagital, frontal e transverso. A análise de marcha pode incluir sistemas de captura de movimento, plataformas de força e eletromiografia dinâmica, que geram dados numéricos a partir dos quais podem ser construídos gráficos que são representativos do ciclo da marcha.

\subsection{Marcha em pacientes com OA de quadril}

Uma metanálise recente incluiu 30 artigos que avaliaram parâmetros espaço-temporais e mostrou que pacientes com OA de quadril apresentaram menor velocidade de marcha, cadência e comprimento da passada, com assimetria dos passos, por menor comprimento do passo e menor tempo de apoio no membro operado, em comparação com controles saudáveis (10). Outros estudos avaliaram parâmetros cinemáticos e identificaram: menor arco de movimento do quadril $(11,12)$ e ângulo máximo de extensão (12); correlação entre o ângulo de extensão durante o apoio terminal e o espaço articular (12). Os estudos também identificaram alterações cinéticas: menor torque extensor no apoio médio (12), pico de torque extensor (12), pico de torque flexor (11) e menores potências de geração e absorção de energia durante o apoio (11). Não há uma correlação forte entre tais alterações da análise de marcha e a capacidade funcional medida pelo Western Ontario and McMaster University Questionnaire (WOMAC), mesmo quando comparados com o domínio "atividade física", sugerindo que podem ser utilizadas como avaliações complementares $(12,13)$.

\subsection{Marcha após artroplastia do quadril}

Apesar dos bons resultados relatados do tratamento da OA do quadril com artroplastia total, a marcha geralmente não retorna a valores de indivíduos com articulações saudáveis. Perron e cols. avaliaram mulheres entre 6 e 18 meses de pós-operatório e mostraram que elas apresentaram marcha mais lenta, com menor cadência e com passos menores. No plano sagital, o mesmo estudo identificou menor pico de torque extensor durante o apoio, potência de absorção dos flexores do quadril, pico de extensão durante o apoio e pico de potência de geração de energia dos flexores do quadril durante o balanço. No plano frontal, foi identificado menor pico de torque abdutor durante o apoio. No plano transverso, foi 
evidenciado menor pico de torque rotacional externo durante o apoio (14). Beaulieu e cols. avaliaram pacientes entre 6 e 15 meses de pós-operatório. No membro operado, os pacientes apresentaram menor arco de movimento, ângulo máximo de adução, abdução e rotação externa, pico de torque rotacional externo e potência de geração e absorção de energia (15). Horstmann e cols. avaliaram pacientes após 6 meses de cirurgia e confirmaram as diferenças no arco de movimento entre pacientes com quadris operados e indivíduos saudáveis (16). Em casos de indivíduos com OA de quadril unilateral, Rasch e cols. compararam os parâmetros da marcha em cada membro e verificaram que houve diferença significativa entre os ângulos máximos de flexão, extensão e abdução após seis meses da cirurgia, mas somente a abdução permanece desigual após dois anos; por outro lado, os parâmetros espaço-temporais apresentaram semelhança após seis meses (17). Guedes e cols. avaliaram pacientes com 12 meses de pós-operatório e identificaram menor comprimento do passo, tempo do passo, maior tempo de apoio total e tempo de apoio simples (8).

Por outro lado, há melhora de alguns parâmetros no pós-operatório, em relação aos dados pré-operatórios. Kyriazis e Rigas avaliaram mulheres após 1 ano de cirurgia e identificaram aumento do tempo de apoio simples no membro operado (18). Lindemann e cols. evidenciaram aumento da velocidade de marcha, aumento da passada e aumento do arco de movimento do quadril operado após 3 meses de cirurgia (13). Rasch e cols. identificaram melhora na maioria dos parâmetros cinemáticos e espaço-temporais no membro operado após 6 meses da cirurgia (17).

Tais dados sugerem que a análise de marcha pode ser utilizada para guiar a reabilitação dos pacientes de forma evolutiva, permitindo a verificação de demandas residuais específicas, mesmo em momentos mais tardios do pós-operatório.

\subsection{Avaliação da capacidade funcional pós-operatória}

O resultado da reabilitação após a ATQ tem sido avaliado por meio de instrumentos de capacidade funcional e qualidade de vida com enfoque na perspectiva do paciente, como WOMAC e o Short Form 36, além de técnicas mais objetivas como a análise da marcha (13).

O WOMAC é um índice composto de 24 pontos que cobrem três domínios: dor, rigidez e atividade física. Para cada pergunta, são possíveis as seguintes respostas: nenhuma, pouca, moderada, intensa e muito intensa. Para cada resposta, é atribuído grau $0,1,2,3$ ou 4 , respectivamente. Os graus de todas as respostas são somados, perfazendo um escore que vai 
de 0 (mínimo) a 96 (máximo) (19). O questionário originalmente foi validado para o uso em pacientes portadores de OA de joelho e quadril, pois se mostra sensível a mudanças ao longo do tempo, podendo ser utilizado para pesquisa ou para a prática clínica (20). A responsividade do WOMAC para avaliação dos resultados de artroplastia de quadril já foi confirmada (20).

A reabilitação pós-operatória é influenciada por diversos fatores, principalmente pela presença de comorbidades clínicas, gênero e capacidade funcional prévia, mas também em alguns estudos pelo índice de massa corporal, idade, força do quadríceps, ângulo máximo de flexão do quadril, via de acesso cirúrgica, qualidade de vida prévia e avaliação de autoeficácia (21-29).

\subsection{Regeneração muscular}

A musculatura esquelética tem grande capacidade de regeneração após o trauma. Poucas horas após o dano, é iniciada a digestão dos componentes celulares por enzimas proteolíticas liberadas por lisossomos das fibras musculares e por macrófagos, sendo estes últimos responsáveis por fagocitar restos celulares. Durante essa fase, há uma desorganização dos componentes celulares. Com isso, há uma proliferação de células-satélites, que se alinham ao longo da membrana basal e se transformam em mioblastos. Após alguns dias, os mioblastos se fundem, formando os miotubos, que se depositam nas fibras em regeneração. Os miotubos sintetizam proteínas miofibrilares e os núcleos se posicionam na periferia das células, formando a fibra muscular. Há paralelamente um estímulo para neovascularização e reinervação. O ciclo de regeneração leva em torno de seis meses para se completar $(30,31)$.

Após o reparo, a contratilidade muscular se recupera lentamente, em modelos animais, ao longo de aproximadamente oito meses. Inicialmente, a recuperação da potência muscular só atinge 50\% da normal, mas outras características, incluindo o tamanho e a área de fibras individuais, se recuperam completamente, apesar de com uma massa menor. Da mesma forma, a atividade metabólica atinge apenas $50 \%$ da normal, tornando o músculo mais fatigável (30). Por outro lado, músculos de indivíduos idosos não conseguem atingir o mesmo grau de regeneração de músculos de indivíduos mais novos (30).

Estudos sugerem que fatores externos ao músculo são os principais envolvidos na capacidade de regeneração. Embora o músculo regenerado não recupere físiologicamente as características iniciais, a resistência muscular apresenta grande plasticidade em resposta ao uso, com aumento da atividade de enzimas oxidativas e glicolíticas, hipertrofia de fibras e 
aumento da ativação neural. Por isso, exercícios físicos podem melhorar a atividade muscular e consequentemente o desempenho (32).

\subsection{Colecalciferol}

A vitamina D3 (colecalciferol) é um nutriente cuja principal fonte no ser humano é a síntese a partir do metabolismo do 7-deidrocolesterol na pele, após exposição à radiação ultravioleta. Ela é metabolizada no fígado, sendo transformada em 25-hidroxivitamina D3 ou calcidiol pela enzima 25-hidroxilase, que por sua vez é transformado em 1,25-hidroxivitamina D3, ou calcitriol, nos túbulos renais. Alguns alimentos contêm vitamina D2 ou ergocalciferol que, ao ser absorvido, é convertido pelo fígado em 25-hidroxivitamina D2 e segue o mesmo caminho enzimático, tendo menor meia-vida plasmática, devido a menor afinidade com a proteína ligadora de vitamina D. As enzimas tubulares renais 1-alfa-hidroxilase, responsável pela síntese renal de calcitriol e 24-alfa-hidroxilase, responsável pela síntese de 24,25hidroxivitamina D (um metabólito inativo), são reguladas pela concentração sérica do próprio calcitriol, do paratormônio (PTH), cálcio, fosfato, fator de crescimento de fibroblastos $23 \mathrm{e}$ pela estimulação da ação da 24-hidroxilase, uma enzima que hidroxila o calcitriol, tornando-o inativo. O fígado e o tecido adiposo estocam a 25-hidroxivitamina D (25OHD) em excesso (33).

A síntese de colecalciferol varia de acordo com a cor da pele, hora do dia, estação e latitude. Mulheres obesas caucasianas têm menores níveis séricos de 25OHD, possivelmente devido a uma menor passagem do colecalciferol sintetizado na pele para a circulação, por acúmulo no tecido adiposo. Seus mecanismos de regulação da produção incluem a fotoconversão de previtamina D3 e vitamina D3 em metabólitos inativos e a produção de melanina, que reduz a absorção de radiação ultravioleta (33).

A ação do calcitriol acontece por meio de ligação aos receptores de vitamina D (VDR), que estão presentes na membrana e núcleo das células-alvo. Os VDR são amplamente distribuídos nos tecidos humanos, o que sugere que o hormônio tem diversas ações. Tais receptores permitem um mecanismo de regulação periférica da ação da 1,25-hidroxivitamina D, por meio de downregulation nas membranas celulares (33).

Ratos com bloqueio completo (knockout) da expressão de VDR apresentam anormalidades no desenvolvimento muscular como consequência da persistência de células musculares e proteínas imaturas. Polimorfismos do VDR foram descritos em estudos 
30

retrospectivos como relacionados à força muscular do quadríceps e dos músculos do jarrete, a área seccional do jarrete e com a massa magra (34). Dois estudos, realizados em pacientes submetidos a artroplastias de quadril e cirurgias de coluna, sugeriram uma correlação negativa entre a idade e o número de VDR nas células musculares, o que pode ser um fator contribuinte para o declínio da função muscular em idosos (35).

O calcitriol e o PTH são os principais hormônios envolvidos na homeostase óssea e no metabolismo do cálcio e fósforo. As principais ações do calcitriol são o aumento da absorção intestinal de cálcio, inibição da síntese de PTH, permissividade ao efeito do PTH nos osteoclastos e redução da excreção renal de cálcio e fosfato (33).

Há evidências da participação da vitamina D no metabolismo muscular. Desde a década de 1970, estudos têm demonstrado que o calcitriol facilita o fluxo de cálcio do retículo sarcoplasmático para o citosol e aumenta o influxo de cálcio do meio extracelular (36), além de aumentar a concentração de fósforo intracelular, possivelmente por meio de um mecanismo dependente de sódio (36,37), a concentração de ATP intracelular e a síntese proteica (36,38-41) (figura 1). Há também evidências de que a vitamina $\mathrm{D}$ tem participação na manutenção do complexo actomiosina-troponina (40). Peng e cols. demonstraram recentemente que a ação do calcitriol aumenta a expressão de proteína ligadora 3 de fator de crescimento semelhante à insulina (IGFBP-3), reduzindo a taxa de depuração de fator de crescimento semelhante à insulina tipo 1 (IGF-1). Tal ação pode estar relacionada a regulação do trofismo muscular e da relação entre massa magra e gorda (42). Por outro lado, Sakai e cols. mostraram recentemente que o tratamento com um análogo do calcitriol aumentou a secreção de IGF-1 pelas células de Schwann em nervos ciáticos de cobaias. O mesmo estudo identificou que ratos knockout para VDR apresentaram heterogeneidade dos diâmetros dos axônios do nervo ciático e tiveram má resposta em aumentar a capacidade locomotora após exercício físico (43). Portanto, a vitamina D parece melhorar a ação de nervos periféricos na musculatura esquelética. Há também evidências de que o calcitriol estimula a ativação de vias de sinalização ativadas por mitogênio e vias da fosfolipase $C$, o que pode estimular a proliferação e crescimento de células musculares $(39,44)$ (figura 1).

\subsection{Deficiência de vitamina $D$}

\subsubsection{Epidemiologia}


A deficiência de vitamina D é um distúrbio prevalente no Brasil. Os idosos estão mais expostos ao distúrbio por múltiplos fatores: redução da capacidade de síntese de vitamina $\mathrm{D}$ na pele, menor exposição solar, diminuição na absorção intestinal e redução da síntese renal de 1,25-hidroxivitamina D (33). Um estudo brasileiro identificou uma prevalência de deficiência de vitamina D de 43,8\% em idosos ambulatoriais e 71,2\% em idosos institucionalizados em São Paulo (45). No ambiente de reabilitação, é encontrada uma alta prevalência do distúrbio. Um estudo norte-americano mostrou que a prevalência de deficiência de vitamina $\mathrm{D}$ pode chegar a $83 \%$ dos pacientes internados, em todas as faixas etárias (46).

O estudo prospectivo Third National Health and Nutrition Examination (47) avaliou mulheres afroamericanas e caucasianas. Nas mulheres afroamericanas, os níveis plasmáticos de $25 \mathrm{OHD}$ foram mais baixos $(4,2 \%)$ do que os identificados nas mulheres caucasianas $(42,4 \%)$, principalmente nas mais magras ou que estavam em uso de contraceptivos orais. No grupo de mulheres caucasianas, houve associação entre os níveis baixos de 25OHD e obesidade.

Figura 1 - Efeitos celulares do calcitriol no miócito.

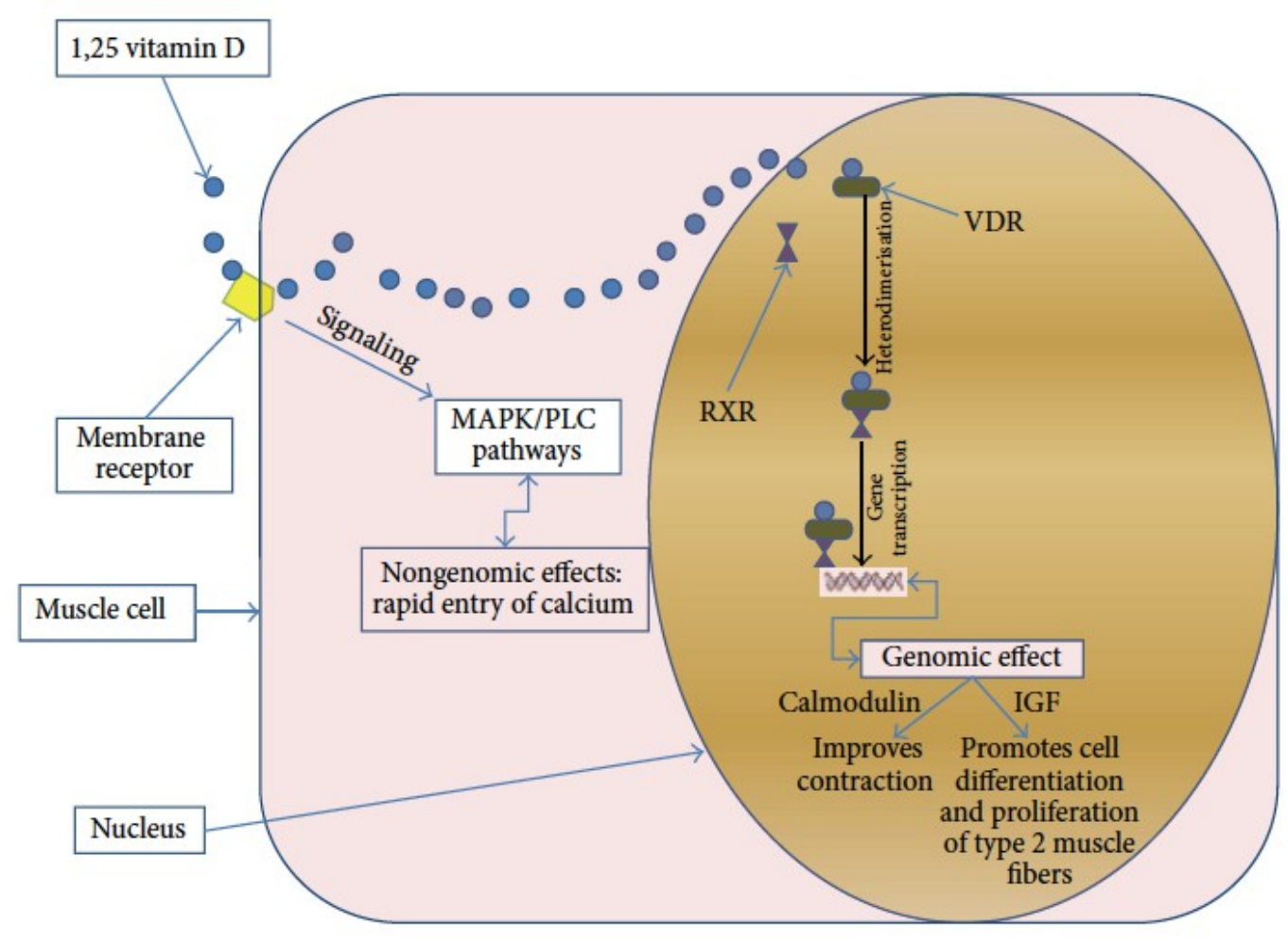




\subsubsection{Alterações da massa muscular}

Tagliafico e cols. identificaram, por meio de ressonância magnética, que níveis baixos de 25OHD se correlacionaram inversamente com o grau de infiltração gordurosa muscular em idosos (48). Gilsanz e cols. encontraram resultados semelhantes em mulheres jovens utilizando a tomografia computadorizada (49).

\subsubsection{Histopatologia muscular}

Biópsias musculares de pacientes com osteomalácia mostram atrofia de fibras musculares tipo 2, com espaços interfibrilares aumentados, infiltração de tecido adiposo e fibrose (50). Um estudo correlacionou baixos níveis de 25OHD e degeneração gordurosa dos músculos do manguito rotador (51).

\subsubsection{Alterações da função muscular}

A miopatia associada à osteomalácia produz fraqueza muscular proximal com hipotrofia, hipotonia e mialgia durante a deambulação, que melhora após reposição de vitamina D (50).

O nosso grupo realizou uma metanálise de coortes que não identificou associação consistente entre 25OHD, massa, força e desempenho muscular (artigo submetido, em revisão: APÊNDICE A).

O efeito da suplementação de vitamina D no risco de quedas foi avaliado em duas revisões sistemáticas recentes. A U.S. Preventive Services Task Force publicou em 2010 uma metanálise de nove estudos, que concluiu que a suplementação de vitamina D reduziu o risco de quedas em 17\% (52). Em 2012, a colaboração Cochrane publicou outra metanálise que não confirmou os achados da primeira. No entanto, essa metanálise incluiu 2 estudos com grande tamanho amostral, que haviam sido excluídos da metanálise de 2010 por baixa qualidade; além disso, incluiu um estudo que empregou tratamento com colecalciferol $500.000 \mathrm{U}$ em 
dose única, que mostrou aumento do risco de quedas (53). Após a publicação dessas revisões, Uusi-Rasi e cols. publicaram um ensaio clínico randomizado que incluiu idosas com alto risco de quedas e concluíram que a suplementação de vitamina D não reduziu tal risco (54). No entanto, a média de $25 \mathrm{OHD}$ basal das idosas incluídas foi de $26 \mathrm{ng} / \mathrm{mL}$, um nível sérico relativamente elevado, o que sugere que os níveis séricos basais de 25OHD podem influenciar na efetividade da suplementação.

Dhesi e cols. avaliaram o efeito da aplicação de uma dose única de 600.000 UI de colecalciferol intramuscular em um ensaio clínico de idosos com histórico de quedas, demonstrando melhora em testes neuromusculares e da estabilidade postural, mas não da força do quadríceps e no número de quedas (55).

O estudo de coorte Women's Health Initiative avaliou o efeito de reposição de cálcio e colecalciferol por cinco anos e não identificou benefício na maioria dos desfechos avaliados, exceto no tempo de marcha e na capacidade de execução de exercícios intensos; no entanto, os pacientes receberam doses baixas de colecalciferol (400 UI/dia), sem dosagem de 25OHD basal o que, conforme já foi exposto acima, pode ter reduzido o efeito da intervenção (56).

Em 2010, o estudo multicêntrico de Lips e cols. avaliou como desfecho principal o balanço médio-lateral com olhos abertos e não encontrou, na análise conforme o protocolo, benefício na reposição de colecalciferol (57).

Zhu e cols. identificaram melhora da força dos extensores e adutores do quadril e no TUG no grupo intervenção, em pacientes australianos no primeiro tercil de $25 \mathrm{OHD}$ basal (58).

Em 2014, Beaudart e cols. publicaram uma metanálise de 30 estudos, que concluiu com moderada qualidade de evidência que a suplementação de vitamina D aumentou discretamente a força muscular dos membros inferiores em indivíduos com idade $>65$ anos, embora os estudos tenham sido heterogêneos em relação à dose, via de administração e duração do tratamento (59). Além disso, foi encontrada correlação entre o aumento dos níveis séricos de $25 \mathrm{OHD}$ e o ganho de força muscular. Não foi identificado efeito da vitamina $\mathrm{D}$ na massa ou na potência muscular, mas houve baixa qualidade de evidência para esses desfechos. A metanálise incluiu indivíduos comunitários e institucionalizados e identificou que os últimos tiveram maior benefício da suplementação. Os autores recomendaram novos estudos para avaliação da massa e potência muscular.

\subsection{Regeneração muscular e vitamina $D$}


Srikuea e cols. identificaram que mioblastos e miotubos de cobaias, em regeneração, apresentaram aumento da expressão de VDR e CYP27B1 (o gene que codifica a enzima 1alfa-hidroxilase) em comparação a músculos controles, sugerindo uma ação parácrina do calcitriol. Além disso, a presença de 25OHD acarretou uma suprarregulação da expressão de VDR e inibiu a proliferação de mioblastos, o que pode representar um mecanismo de regulação das células-satélite (60).

Stratos e cols. induziram lesão muscular por esmagamento em cobaias que receberam suplementação de vitamina D. Os músculos das cobaias apresentaram maior proliferação celular, menor índice de apoptose, maior síntese de prolil-4-hidroxilase beta (que demonstra aumento da síntese de colágeno) e maior potência de contração muscular tetânica por área de tecido muscular, independentemente do número de células-satélites ou do grau de inflamação (61).

Garcia e cols. incubaram mioblastos com calcitriol, o que resultou em aumento da produção dos fatores pró-angiogênicos e redução da expressão de fatores anti-angiogênicos. Isso sugere uma possível ação pró-miogênica por aumento da vascularização local (62).

Estudos experimentais têm sugerido que a vitamina $\mathrm{D}$ participa no mecanismos de reparo do tecido muscular (60). Os mecanismos envolvidos podem ser: aumento da produção dos fatores pró-angiogênicos de crescimento endotelial vascular alfa e de crescimento de fibroblastos 1 (FGF-1) e redução da expressão de fatores anti-angiogênicos como o FGF-2 e inibidor de metaloproteinase 3, o que pode acarretar ação pró-miogênica por aumento da vascularização local. Recentemente, Owens e cols. mostraram que os mioblastos de voluntários hígidos, submetidos a reposição de colecalciferol, apresentaram maior regeneração muscular e facilitação à hipertrofia muscular após exercícios físicos repetidos (63).

\subsection{Reabilitação pós-operatória e vitamina D}

O estudo piloto de Nawabi e cols. avaliou candidatos a ATQ e identificou correlação entre o nível de $25 \mathrm{OHD}$ e a capacidade funcional pré-operatória medida pelo Harris Hip Score (64). Esse estudo avaliou a capacidade funcional pré e pós-operatória separadamente, sem considerar a mudança intra-individual. Unnanuntana e cols. avaliaram a variação intra- 
individual no WOMAC, de acordo com os níveis basais de 25OHD e não encontraram diferenças entre os grupos (65). 


\section{Justificativa}

Apesar de a associação entre 25OHD basal e a variação do WOMAC já ter sido estudada anteriormente, o seguimento foi de curta duração. É importante determinar se níveis basais de 25OHD estão relacionados com a evolução da capacidade funcional no pósoperatório de ATQ em um momento mais tardio, em que pode haver uma maior recuperação pós-operatória e, portanto, as diferenças podem estar mais evidentes.

Por outro lado, no nosso conhecimento, não há estudos que tenham avaliado a relação entre 25OHD e análise de marcha, até o momento. A análise de marcha é uma forma sensível de se avaliar o desempenho funcional na marcha.

Se alguma dessas associações fosse identificada, a correção dos níveis de 25OHD poderia favorecer o desfecho pós-operatório da ATQ. 


\section{Objetivos}

a) Verificar a hipótese de associação entre os níveis de 25OHD basais e a mudança da capacidade funcional e dados de análise de marcha entre o pré e pós-operatório de ATQ;

b) Identificar se a $25 \mathrm{OHD}$ basal explica a variabilidade da capacidade funcional e da análise de marcha;

c) Avaliar a diferença entre os dados pré e pós-operatórios e comparar com os resultados de outros estudos semelhantes, realizados em outras populações. 


\section{Métodos}

\subsection{Delineamento}

Coorte prospectiva de pacientes submetidos a ATQ, com análise em dois cortes transversais, no pré-operatório e com 3 meses de pós-operatório, delineada em conformidade com a declaração STROBE traduzida e validada para a língua portuguesa (66).

\subsection{Participantes}

Foram incluídos pacientes em acompanhamento pelo programa de Ortopedia Adulto do hospital SARAH-Brasília, portadores de OA do quadril, submetidos à primeira ATQ da articulação em questão entre janeiro de 2012 e dezembro de 2013, por duas equipes distintas de cirurgiões. A indicação de ATQ foi realizada pelos cirurgiões-assistentes, levando em consideração critérios clínicos e radiológicos, de acordo com o seu julgamento. Todas as ATQ realizadas foram cimentadas, conforme o protocolo do SARAH, com componente femoral Exeter Striker ${ }^{\circledR}$ e componente acetabular Exeter Comtemporare ${ }^{\circledR}$.

O diagnóstico de OA foi definido a partir dos critérios clínico-radiográficos da American College of Rheumatology (67).

Foram excluídos do estudo pacientes portadores das seguintes condições: doenças inflamatórias articulares, neoplasias malignas ativas, doenças genéticas sistêmicas, doença neurológica com alteração da marcha, que não realizaram avaliação pós-operatória após 3 meses com o ortopedista assistente e com a equipe de fisioterapia, submetidos a hemiartroplastia, artroplastia de revisão ou conversão de artrodese, doença renal crônica classe 4 ou 5 e suplementação de vitamina D com dose maior ou igual a $50.000 \mathrm{U} / \mathrm{semana}$. Os dados de portadores de artrite reumatoide, submetidos a ATQ e artroplastia total do joelho, foram incluídos em outro estudo (APENDICE B).

Todos os participantes receberam tratamento individualizado, que incluiu reabilitação com fisioterapia supervisionada uma vez por dia, do primeiro ou segundo dia de pós- 
42

operatório até o décimo-quarto dia de pós-operatório, em regime hospitalar. Primeiramente, os pacientes foram orientados a sentar e mover o joelho e tornozelo com o quadril estável. Após remoção do dreno de sucção, os pacientes foram instruídos a deambular com andador e quanto à realização de exercícios isométricos de abdução e extensão e exercícios de flexibilidade do quadril. Além disso, os pacientes recebem orientações nas atividades de vida diária e orientação sexual, quando necessário. Na alta, os pacientes receberam instrução para o uso de bengalas antebraquiais e orientações verbais e escritas para a prática de exercícios domiciliares. As primeiras consultas pós-operatórias foram realizadas pela equipe de fisioterapia em 1 mês. Nesse momento, foi considerada mudança do auxílio-locomoção para bengala em $\mathrm{T}$ contralateral ao membro operado e os pacientes foram encorajados a participar de um programa de exercícios resistidos progressivos por 2 meses. As segundas consultas de seguimento com a fisioterapia foram em 3 meses.

\subsection{Coleta de dados e exames}

\subsubsection{5-hidroxivitamina D}

Foi coletada, no dia da internação, amostra de sangue periférico para dosagem de $25 \mathrm{OHD} 2+25 \mathrm{OHD} 3$, por técnica de cromatografia líquida com detecção por espectrometria de massa, considerada uma técnica de medição direta.

O procedimento laboratorial consiste em injetar o soro em uma coluna de cromatografia líquida, que compreende um tubo de aço inoxidável estreito, preenchido por partículas de sílica. Os compostos são separados com base nas suas interações com o revestimento químico dessas partículas (fase estacionária) e pelo solvente para eluição da coluna (fase móvel) e são então introduzidos no espectrômetro de massa via uma interface de ionização por eletrospray. Nessa técnica, a amostra é introduzida na agulha de eletrospray, que tem um alto potencial de ação. Isso força a pulverização de gotículas carregadas com carga superficial da mesma polaridade da agulha, que são repelidas em direção ao cone de amostragem. À medida que as gotículas se dirigem ao cone, ocorre evaporação do solvente, o que reduz o diâmetro da gotícula a ponto de que a tensão superficial não suportar a carga e explodir. A explosão dá origem a gotículas menores que entram no mesmo processo e também a moléculas de analito carregadas. A partir desse procedimento, o espectrômetro pode calcular 
a razão entre a massa e a carga da molécula, o que possibilita sua identificação mais precisa (68).

A dosagem de 25OHD2 + 25OHD3 foi realizada com método inhouse pelo laboratório de Bioquímica do hospital SARAH-Brasília e foi calibrada com controle da Chromsystems®.

\subsubsection{Outros exames}

Foi realizada dosagem sérica de PTH, cálcio, fósforo e índice cálcio/creatinina urinário. Além disso, foi aproveitado o resultado da creatinina realizada na avaliação préoperatória e calculada a depuração de creatinina de acordo com a fórmula do grupo Modification in Diet in Renal Disease.

O médico responsável pela análise dos dados (BMC) e os fisioterapeutas que realizaram as avaliações funcionais, não tiveram acesso aos resultados dos exames por 3 meses de pós-operatório. Para isso, os dados foram inseridos no sistema de forma que só estivessem disponíveis para o chefe do laboratório, que não teve participação no estudo.

\subsubsection{Avaliação dos desfechos}

No pré-operatório, foi aplicada avaliação de capacidade funcional, com a utilização do WOMAC traduzido e validado para a língua portuguesa (ANEXO A) (19). O instrumento foi auto-aplicado ou aplicado por um fisioterapeuta ou pelo autor do estudo.

Foi realizada análise de marcha no Laboratório de Movimento do hospital SARAHBrasília (figura 2), por meio de dois sistemas combinados:

a) Análise cinemática: documenta a magnitude e tempo do movimento articular, utilizando marcadores refletivos (figura 3) e doze câmeras emissoras de luz infravermelha Vicon MCAM M2 (figura 4). Os marcadores foram fixados de acordo com o protocolo de Helen Hayes, nos seguintes pontos de referência do paciente: espinhas ilíacas ânterosuperiores, centro do sacro, ponto localizado em um quarto da distância entre o joelho e o quadril, côndilos laterais dos fêmures, pontos médios das patelas, pontos médios das faces anteriores das pernas, pontos médios da face lateral das tíbias distais, protuberâncias dos maléolos laterais, faces posteriores dos calcanhares e dorsos dos pés. As câmeras emitem pulsos de luz infravermelha e captam os reflexos dos marcadores, que passam por filtros de onda. A frequência de captura é de 60 imagens por segundo (protocolo do SARAH). As 
44

coordenadas bidimensionais de cada ponto, registrado por cada uma das câmeras, são enviados para uma unidade de processamento onde são calculadas as coordenadas tridimensionais de cada ponto de interesse, possibilitando assim a análise cinemática de cada articulação. Juntamente com as informações de força de reação do solo e parâmetros inerciais, são calculados os momentos articulares e a potência articular por meio do princípio da dinâmica inversa.

Figura 2 - Laboratório de movimento do hospital SARAH-Brasília.

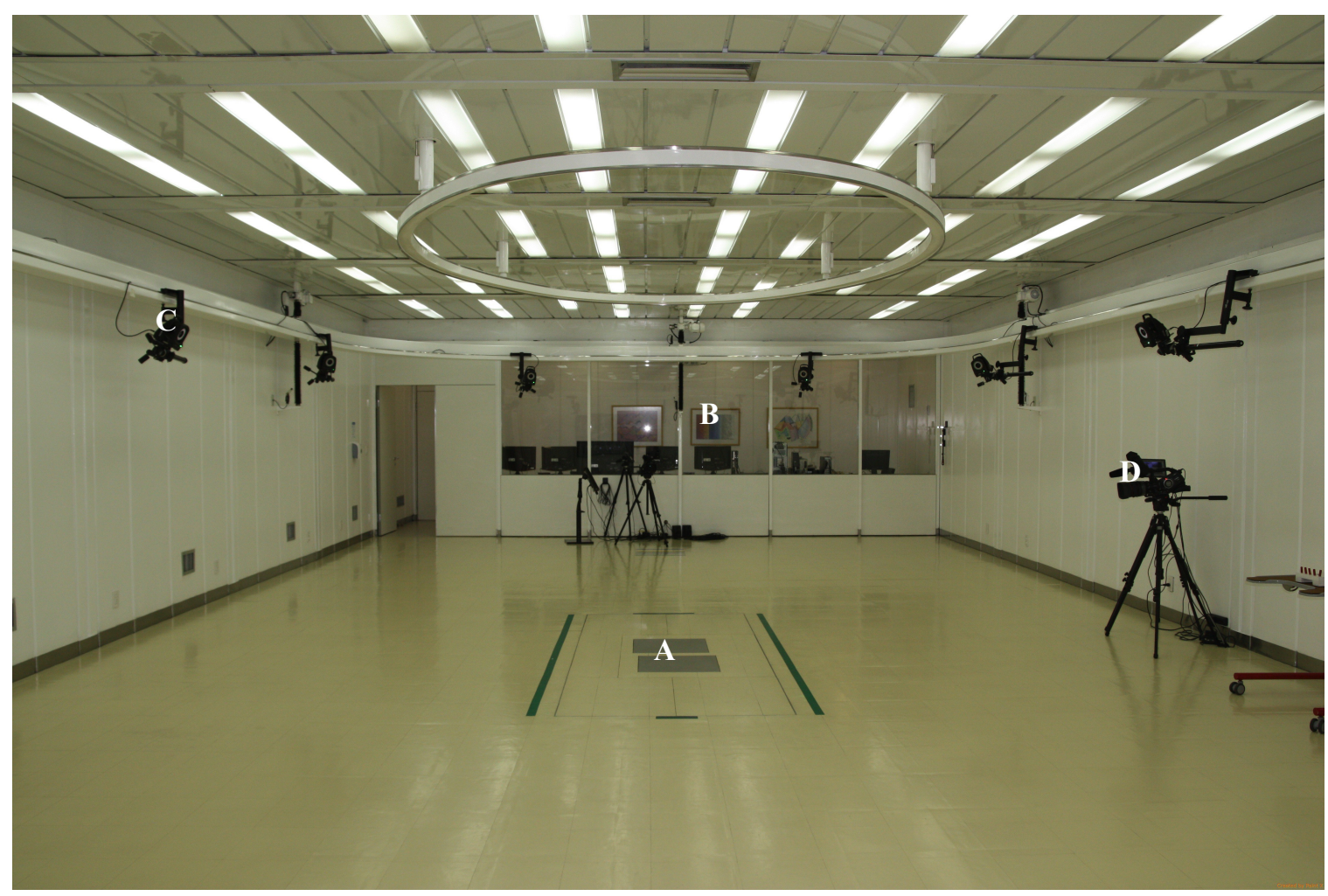

Vista geral: A) Plataformas de força. B) Central de controle. C) Câmera emissora de infravermelho. D) Câmera de vídeo

A posição neutra da articulação foi definida como $0^{\circ}$, a flexão, adução e rotação interna do quadril foram representados com valores positivos e extensão, abdução e rotação externa do quadril foram representados com valores negativos. Foram realizadas medidas da distância intermaleolar e intercondilar com tacômetro para estimativa dos centros articulares e do comprimento dos membros com fita métrica, sendo considerada a distância da espinha ilíaca ântero-superior até o maléolo medial. Os parâmetros espaço-temporais foram obtidos por meio da marcação entre fase de apoio e de balanço no momento do processamento do exame. Os marcadores dos pés mostram o momento do contato inicial e da retirada do pé do solo. No hospital SARAH, são realizadas capturas com e sem o uso do auxílio-locomoção, 
quando possível. Para efeito deste estudo, foram utilizados os dados gerados sem o uso do auxílio-locomoção, quando disponíveis, ou com o auxílio-locomoção, desde que a avaliação pré e pós-operatória fosse realizada com o mesmo auxílio. Nos casos de uso de andador ou em uso de auxílios-locomoção diferentes no pré-operatório e no pós-operatório, os dados cinéticos foram excluídos.

b) Plataforma de força (figura 5): consistem em duas placas rígidas AMTI ${ }^{\circledR}$ OS 5, medindo 40 por $60 \mathrm{~cm}$, suspensas em transdutores piezoelétricos, com frequência de captura de $1080 \mathrm{~Hz}$. Cada suporte da plataforma possui três sensores posicionados ortogonalmente aos outros, que captam dados tridimensionais dos vetores verticais e horizontais de força, documentando as demandas funcionais do membro durante o apoio. Isso permite medir as forças totais geradas pelos músculos, pelo princípio da dinâmica inversa. São utilizadas duas placas, uma para cada pé. Os pacientes foram orientados a passar pela plataforma de modo natural, de modo a reproduzir com maior exatidão uma pisada normal. Para uma captação adequada, um pé deve estar todo na plataforma, enquanto o outro deve estar todo fora. No procedimento, é utilizada mais de uma plataforma para facilitar uma captação adequada. Neste estudo, foram realizadas no mínimo seis capturas dinâmicas e uma estática, mas novas capturas foram realizadas quando necessário, sendo realizada a média de pelo menos três capturas adequadas. A partir da combinação desses dados com os dados ópticos, foram calculados o torque e a potência que atuam em cada articulação. 
Figura 3 - Marcadores refletivos.

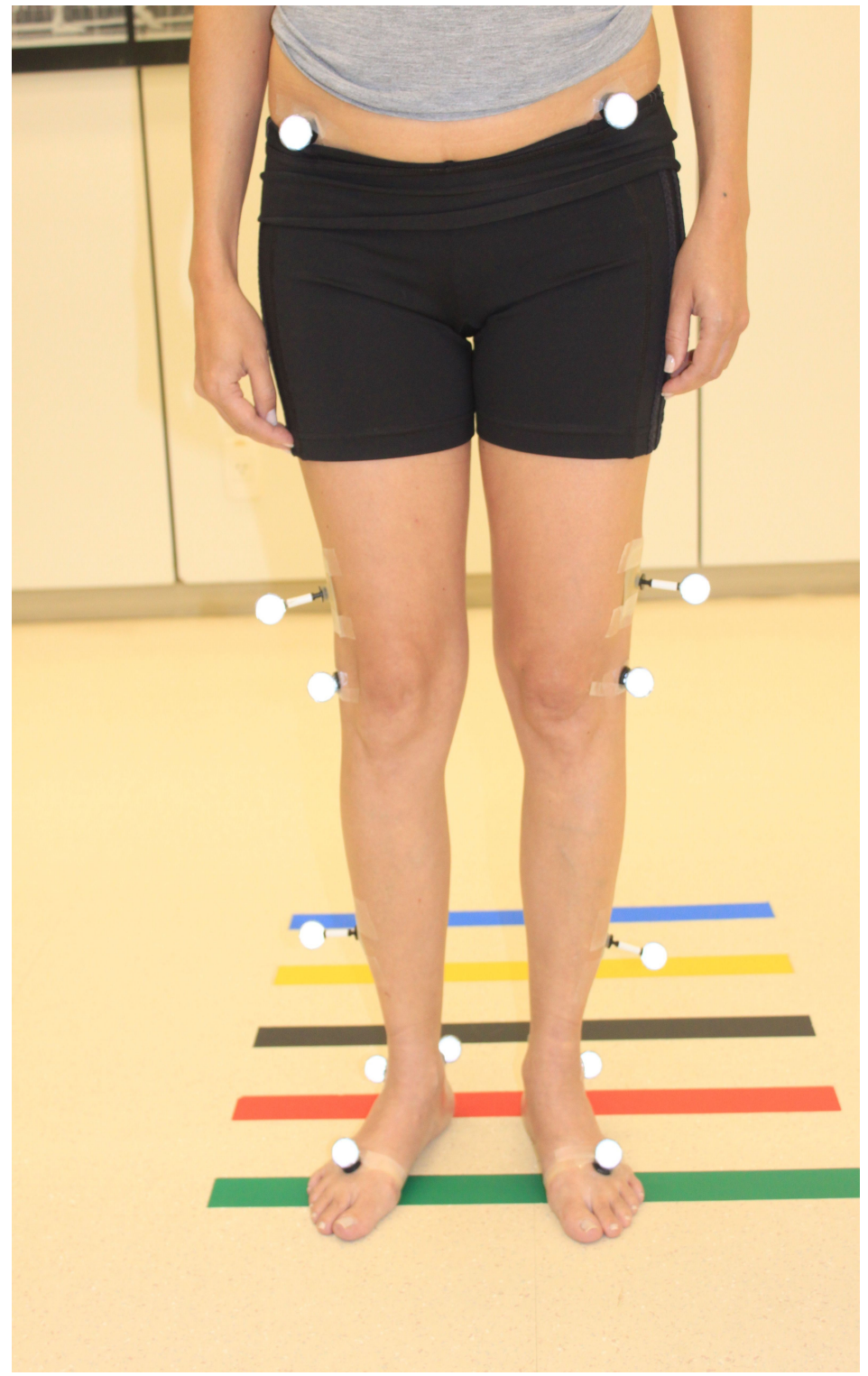


Figura 4: Câmera emissora de luz infravermelha Vicon MCAM M2, pertencente ao Laboratório de Movimento do Hospital SARAH-Brasília.

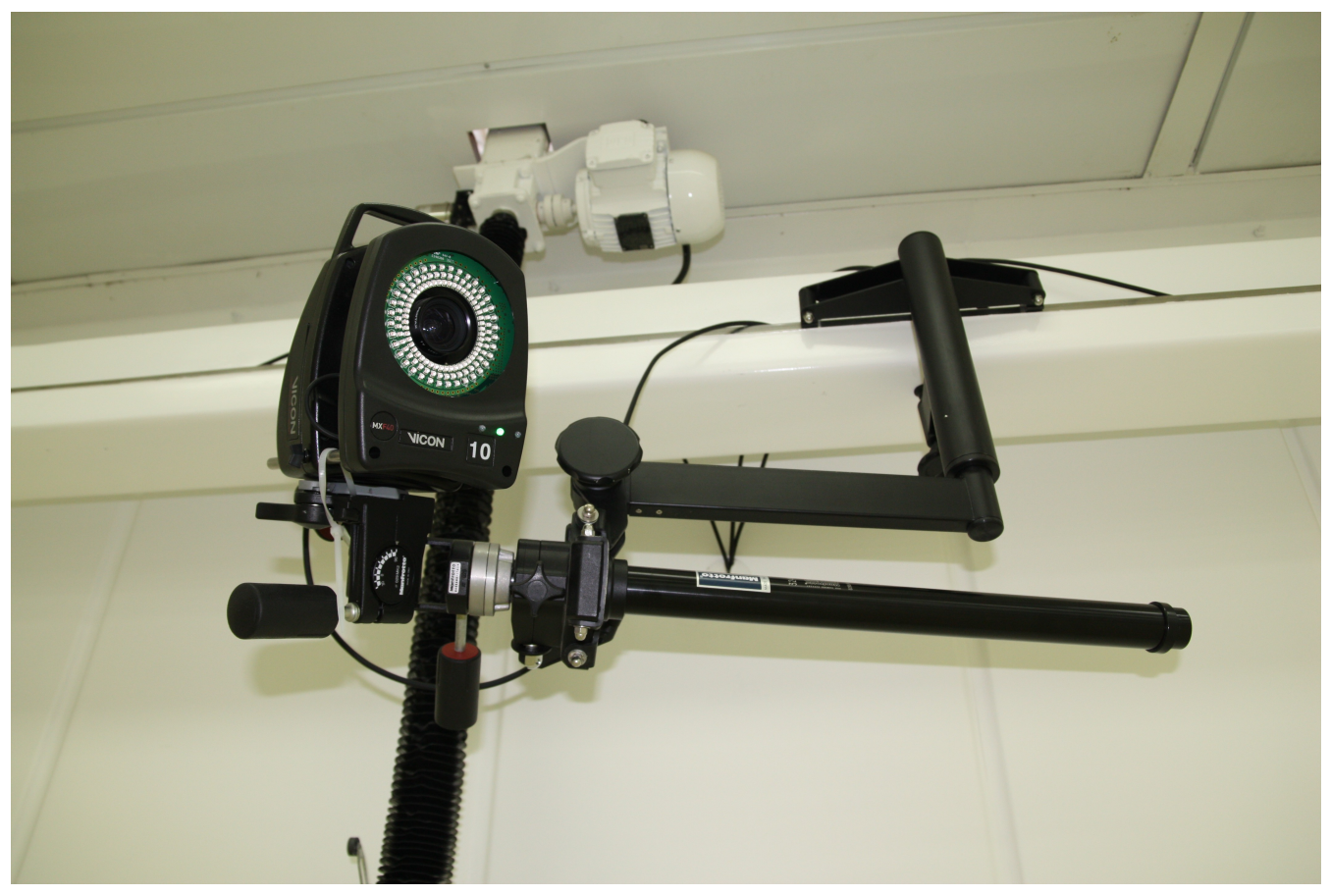

Figura 5: Plataformas de força do Laboratório de Movimento do Hospital SARAH-Brasília. 


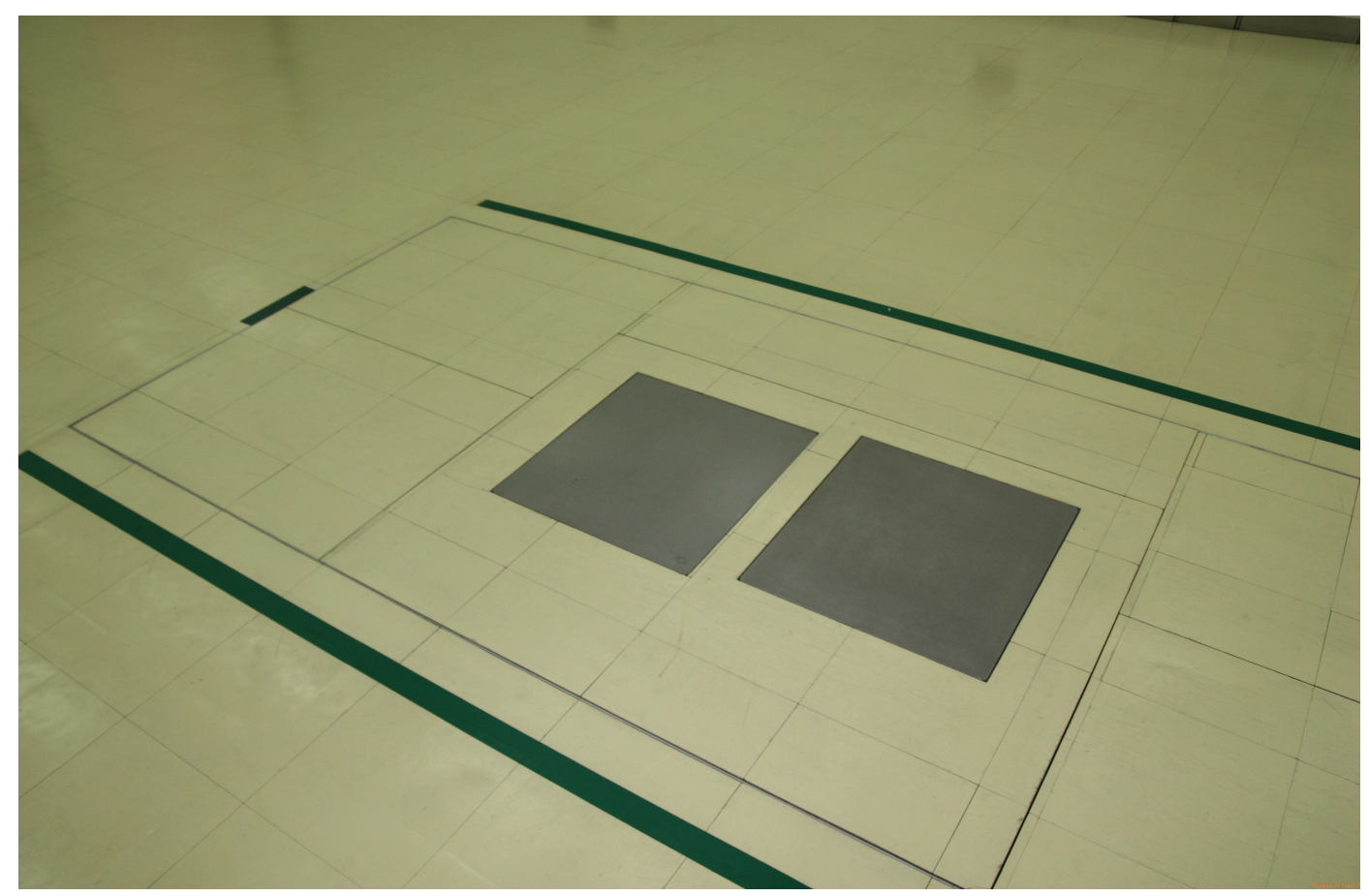

O momento é definido pelo deslocamento angular gerado por uma força, correspondendo ao produto vetorial da força pelo tamanho do "braço de alavanca", ou seja, a distância entre o ponto onde é aplicada a força e centro articular estimado, medida em Newton.metros (N.m). Durante o arco de movimento, o momento que age sobre uma articulação pode geralmente ser atribuído exclusivamente aos músculos, mas próximo ao fim da amplitude de movimento, outras forças podem atuar, como o estiramento de ligamentos e resistência proveniente da geometria óssea (69).

Potência significa a velocidade com que uma força é gerada, ou seja, corresponde ao produto entre o momento e a velocidade angular do membro, medida em Watts (W). Valores positivos indicam geração de energia, geralmente associada a contrações musculares concêntricas, enquanto valores negativos indicam absorção de energia, geralmente associada com contrações excêntricas (70). Os valores foram normalizados pela massa do paciente em quilogramas.

O sistema empregado no hospital SARAH-Brasília para análise de marcha é o Vicon Nexus ${ }^{\circledR}$ (Vicon Motion Systems Ltd., Oxford, UK) e o software utilizado é o Vicon ${ }^{\circledR} 612$. Foi utilizado um filtro Butterworth de $6 \mathrm{~Hz}$ para os dados cinemáticos e cinéticos. Um exemplo de gráficos gerados por este sistema está na figura 6. Os valores de referência de parâmetros 
espaço-temporais para a população normal, utilizados pelos Laboratórios de Movimento da Rede SARAH estão na tabela 2.

Tabela 2 - Análise de marcha: valores normais do Laboratório de Movimento do Hospital SARAHBrasília.

\begin{tabular}{lc}
\hline Apoio simples $(\%)$ & 38 \\
Velocidade de marcha (m/s) & 1,23 \\
Comprimento do passo (m) & 0,66 \\
Comprimento da passada (m) & 1,32 \\
Momento abdutor máximo (N.m/kg) & 0,771 \\
Momento extensor máximo (N.m/kg) & 0,537 \\
Momento flexor máximo (N.m/kg) & $-1,201$ \\
Adução máxima (graus) & 5,771 \\
Abdução máxima (graus) & $-7,317$ \\
Extensão máxima (graus) & $-8,419$ \\
Flexão máxima (graus) & 34,212 \\
Potência máxima de absorção de energia $(\mathrm{W} / \mathrm{kg})$ & $-0,796$ \\
Potência máxima de geração de energia $(\mathrm{W} / \mathrm{kg})$ & 1,359 \\
\hline
\end{tabular}

Tais avaliações foram repetidas após três meses de pós-operatório, por ocasião do primeiro retorno ambulatorial com o ortopedista assistente. Nesse momento, foram revelados os resultados dos exames para a equipe assistente e para os pacientes envolvidos. Foi oferecido tratamento para os pacientes que porventura tenham apresentado deficiência de vitamina $\mathrm{D}$ e acompanhamento até compensação do quadro no Ambulatório de Osteometabolismo do hospital SARAH-Brasília.

\subsubsection{Registro de dados}

Durante a internação hospitalar, foram registrados em planilha os seguintes dados:

a) Características gerais dos pacientes: nome, idade, sexo, peso, estatura, índice de massa corporal (IMC), escolaridade e registro no prontuário eletrônico;

b) Dados cirúrgicos: articulação operada, data da cirurgia, tempo cirúrgico, via de acesso, história de artroplastia em outros sítios; complicações diretamente relacionadas à cirurgia, como subluxação da prótese, fratura periprotética ou infecções, estas últimas classificadas conforme os critérios da Agência Nacional de Vigilância Sanitária . 
c) Dados clínicos: escore de comorbidades definido pelo Índice de Comorbidade de Charlson; classificação de estado físico da American Society of Anestesiology; envolvimento de outras articulações pela $\mathrm{OA}$; etiologia da $\mathrm{OA}$; complicações clínicas durante a internação; uso de auxílio-locomoção; tratamento com colecalciferol ou ergocalciferol, especificando a dose; ângulo máximo de flexão, abdução, extensão, rotação interna e externa do quadril operado, no pré-operatório.

Todos os pacientes preencheram Termo de Consentimento Livre e Esclarecido (ANEXO B) antes de participarem do estudo, sendo resolvidas pelo autor do estudo as dúvidas pertinentes. O estudo foi aprovado pelo Comitê de Ética em Pesquisa da Rede SARAH de Hospitais de Reabilitação e está registrado na Plataforma Brasil com o CAE 06262312.6.0000.0022.

\subsection{Desfechos}

Primário: diferença entre os valores de WOMAC total e seus domínios no préoperatório e no $3^{\circ}$ mês de pós-operatório.

Secundário: diferença entre os parâmetros de análise da marcha no pré-operatório e no $3^{\circ}$ mês de pós-operatório. As variáveis dependentes avaliadas incluíram:

Figura 6: Exemplo de análise cinemática (a) e cinética (b) de paciente em pré-operatório de ATQ realizada no Laboratório de Movimento do hospital SARAH-Brasília. 


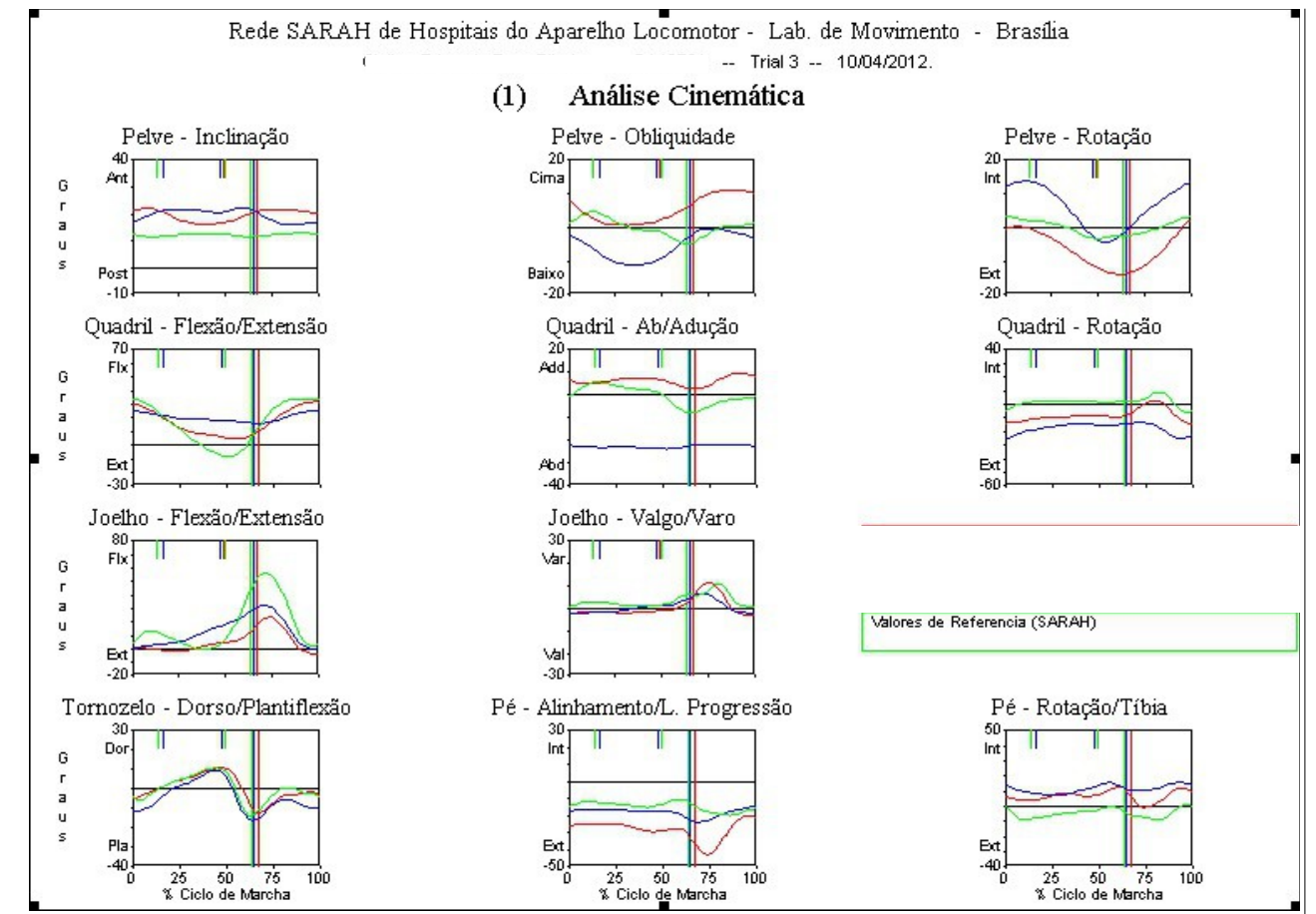

(a) 


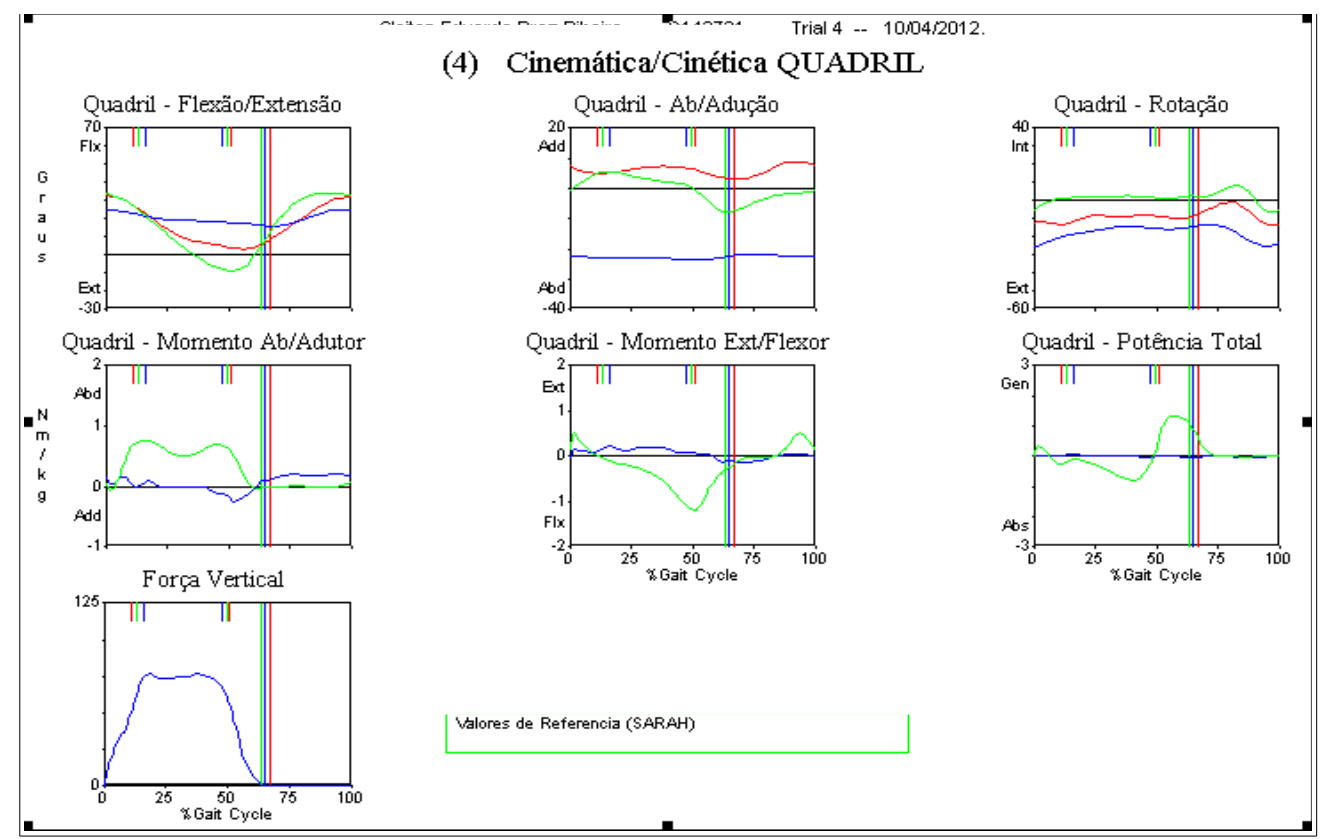

(b)

a) parâmetros espaço-temporais: velocidade, comprimento dos passos, comprimento da passada, tempo de apoio simples do membro operado em percentual;

b) cinemática do quadril: grau de flexão, extensão, adução e abdução máximos;

c) cinética do quadril: potência máxima de geração de energia dos flexores do quadril no pré-balanço, potência máxima de absorção de energia dos flexores do quadril no apoio, momento extensor máximo e momento abdutor máximo durante a resposta à carga, momento flexor máximo no apoio terminal.

\subsection{Estatística}

Para o cálculo de tamanho amostral, foi considerado um desvio-padrão igual a 19 pontos nos resultados dessa escala, estimado a partir de dados retrospectivos de pacientes operados no hospital SARAH-Brasília (dados não publicados). Foi assumida uma diferença de médias entre os grupos (presença/ausência de deficiência de vitamina D) de 10 pontos na pontuação normalizada do WOMAC (para uma escala de 0 a 100 pontos), baseado na diferença de 10\% no Harris Hip Score entre os grupos, encontrada no estudo de Nawabi e cols. (64). O nível de significância e o poder estatístico foram definidos em 5\% e 80\%, respectivamente. Assumiu-se uma prevalência de deficiência de vitamina D $(25 \mathrm{OHD}<20$ 
$\mathrm{ng} / \mathrm{ml}$ ) aproximadamente igual a $60 \%$ na população estudada, que corresponde a um valor intermediário entre pacientes de estudos comunitários e em ambiente hospitalar $(45,46)$. Com isso, foi calculado um tamanho amostral de 102 pacientes para um teste unicaudal, sendo 68 pacientes no grupo portador de deficiência de vitamina D e 34 pacientes no grupo com dosagem sérica de 25OHD mais próxima da "normal". Para descartar a possibilidade de redução da amostra final com perdas de seguimento, foi planejada a inclusão de 110 pacientes.

Para avaliação do objetivo primário, a amostra foi classificada em grupos de acordo com os níveis de 25OHD, seguindo dois critérios:

a) níveis de $25 \mathrm{OHD}$ abaixo ou acima de $20 \mathrm{ng} / \mathrm{ml}$;

b) quartis dos níveis de $25 \mathrm{OHD}$ encontrados na amostra.

A avaliação de normalidade da distribuição das variáveis dependentes foi realizada com os testes de Kolmogorov-Smirnov e Shapiro-Wilk e com a análise visual dos gráficos.

Para comparação entre os valores pré e pós-operatórios, foi utilizado teste t para amostras emparelhadas no caso de variáveis com distribuição paramétrica e o teste de Postos com Sinais de Wilcoxon no caso de variáveis com distribuição não-paramétrica.

Para comparação de médias entre os grupos de 250HD, foi utilizado ANOVA no caso de variáveis dependentes com distribuição paramétrica e o teste de Kruskal-Wallis no caso de variáveis dependentes de distribuição não-paramétrica. Foi utilizado teste de correlação de Pearson entre os níveis de 250HD e as variáveis dependentes paramétricas e Spearman no caso de variáveis dependentes não-paramétricas.

Para a comparação de proporções entre os grupos de $25 \mathrm{OHD}$, foi utilizado o teste quiquadrado ou teste exato de Fisher, dependendo do número de observações em cada categoria.

No caso da identificação de variáveis dependentes estatisticamente significativas, foi construído modelo de regressão linear múltipla.

Como análises de sensibilidade, foi decidido a priori repetir as análises com as seguintes modificações:

a) Exclusão dos oito pacientes operados pelo cirurgião que menos frequentemente realizou ATQ na amostra;

b) Exclusão dos pacientes em reposição de vitamina D. 
Como análise de subgrupos, foi decidido a priori repetir as análises com exclusão dos pacientes com idade $<60$ anos, mas com divisão dos grupos de 25OHD somente pela mediana.

Foi realizada análise interina ao chegar à metade aproximada da casuística. Para essa análise, foram utilizados os mesmos instrumentos estatísticos descritos acima, mas considerando apenas o desfecho primário, ou seja, a variação do WOMAC total e seus domínios e dividindo a amostra apenas em duas metades, utilizando como ponto de corte a mediana. Naquele momento, não foram realizadas análises de sensibilidade ou de subgrupos.

\subsection{Orçamento}

Os exames necessários foram realizados na instituição, não acarretando nenhum custo para os pacientes ou familiares. As avaliações dos desfechos são realizadas de rotina pela equipe de reabilitação, não acarretando em custos adicionais de transporte pra os pacientes.

\section{Resultados}

\subsection{WOMAC}

Foram triados ao todo 158 pacientes, sendo incluídos 110 pacientes consecutivos. Destes, 104 completaram as avaliações. Nenhum paciente teve perda do seguimento clínico, mas houve seis pacientes em que não foi aplicado o questionário WOMAC no terceiro mês de pós-operatório por motivos não relacionados a comorbidades ou complicações da cirurgia. Uma paciente teve seus resultados revelados antes da avaliação de 3 meses. Oito pacientes foram operados pela equipe do Dr. Claudio Sollaci (equipe A) e 102 pela equipe do Dr. Eugênio Paixão (equipe B). O fluxograma de inclusão está descrito na figura 7. 


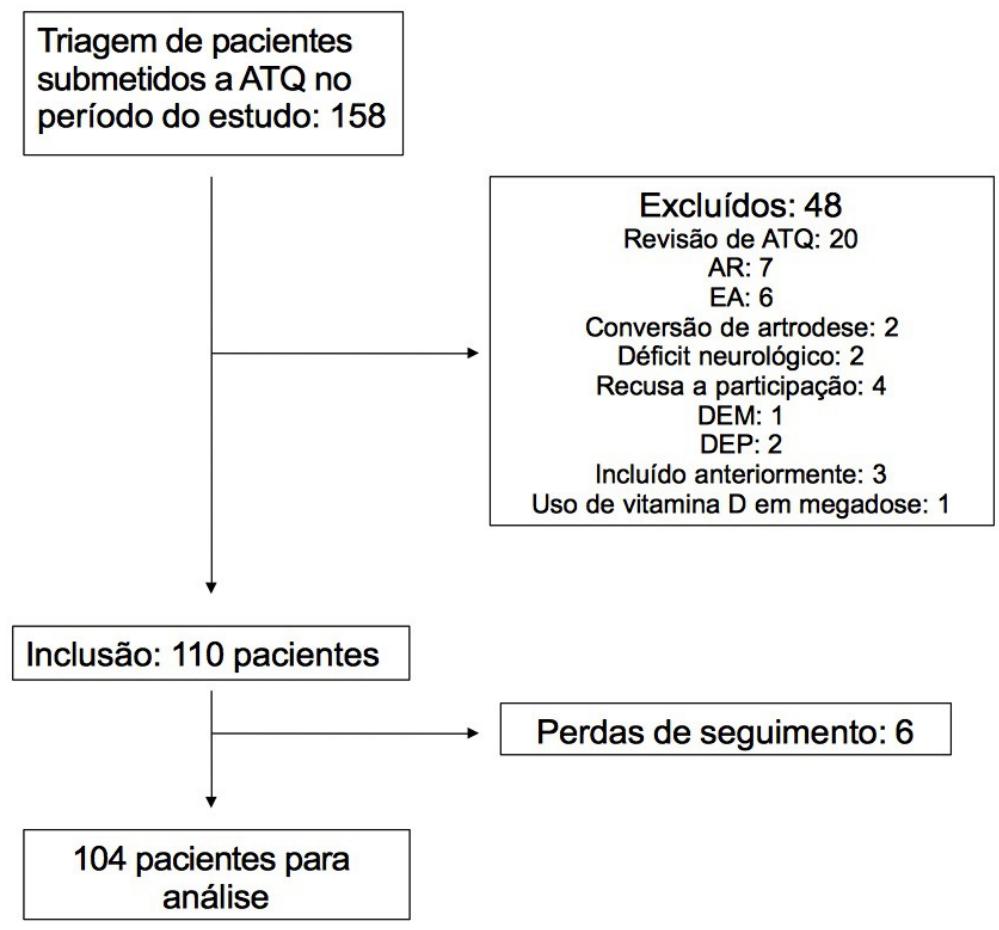

ATQ: artroplastia total do quadril. AR: artrite reumatoide. EA: Espondilite anquilosante. DEM: displasia epifisária múltipla. DEP: displasia espondiloepifisária. Megadose: $\geq 50.000 \mathrm{UI} / \mathrm{semana}$.

Apenas cinco pacientes estavam em suplementação de colecalciferol no momento da internação, com média de 1.331 U/dia (200-3.000). A 25OHD basal média (DP) foi de 14,4 $(7,6) \mathrm{ng} / \mathrm{mL}$. A $25 \mathrm{OHD}$ foi $>20 \mathrm{ng} / \mathrm{mL}$ em $18 \%$ dos pacientes.

Houve poucas complicações em ambos os grupos: dois casos de infecções não-graves e um caso de disfunção asséptica (luxação) no grupo com $25 \mathrm{OHD} \leq 20 \mathrm{ng} / \mathrm{mL}$ e quatro casos de infecções não-graves e um caso de fratura periprotética no grupo com $25 \mathrm{OHD}>20 \mathrm{ng} / \mathrm{mL}$. Não houve infecções cirúrgicas precoces ou tromboembolismo venoso sintomático em ambos os grupos.

As características basais da amostra estão descritas nas tabelas 5 e 6. Desconsiderando a 25OHD, a única variável basal que teve diferença entre os grupos foi a dosagem sérica de cálcio corrigido, que esteve $0,4 \mathrm{mg} / \mathrm{dL}$ maior no grupo $>20 \mathrm{ng} / \mathrm{mL}$. 


\begin{tabular}{lccc}
\hline & \multicolumn{2}{c}{ Grupos de 25OHD $(\mathbf{n g} / \mathbf{m L})$} & \\
\cline { 2 - 3 } \multicolumn{1}{c}{ variáveis } & $\leq \mathbf{2 0}(\mathbf{n}=\mathbf{8 5})$ & $\mathbf{2} \mathbf{2 0}(\mathbf{n}=\mathbf{1 9})$ & $\mathbf{p}$ \\
\cline { 2 - 3 } & média $(\mathrm{DP})$ & média $(\mathrm{DP})$ & \\
\hline Idade $($ anos) & $59(10,8)$ & $62,8(12,5)$ & 0,172 \\
Estatura (m) & $1,60(0,1)$ & $1,60(0,1)$ & 0,532 \\
peso $(\mathrm{kg})$ & $77,4(15,5)$ & $74,2(13,1)$ & 0,408 \\
IMC $\left(\mathrm{kg} / \mathrm{m}^{2}\right)$ & $28,4(4,4)$ & $28(5,1)$ & 0,711 \\
Tempo cirúrgico $(\mathrm{min})$ & $131(25,6)$ & $134,7(24,2)$ & 0,567 \\
25OHD $(\mathrm{ng} / \mathrm{mL})$ & $11,6(4,6)$ & $26,8(6)$ & $<\mathbf{0 , 0 0 1}$ \\
Creatinina $(\mathrm{mg} / \mathrm{dL})$ & $1,1(0,2)$ & $1,2(0,2)$ & 0,246 \\
Cálcio $(\mathrm{c})(\mathrm{mg} / \mathrm{dL})$ & $9,1(0,5)$ & $9,5(0,6)$ & $\mathbf{0 , 0 0 6}$ \\
ICC & $91,1(69,2)$ & $95,2(70,4)$ & 0,821 \\
Fósforo $(\mathrm{mg} / \mathrm{dL})$ & $3,6(0,6)$ & $3,5(0,7)$ & 0,472 \\
PTH $(\mathrm{pg} / \mathrm{mL})$ & $50,3(18,5)$ & $45,4(14,5)$ & 0,278 \\
\hline
\end{tabular}

IMC: índice de massa corporal; 25OHD: 25-hidroxivitamina D; ICC: índice cálcio/creatinina. PTH: paratormônio.

Houve melhora significativa dos domínios dor, rigidez e atividade física após 3 meses de pós-operatório (tabela 7).

Não foi encontrada correlação significativa entre 25OHD e a variação do WOMAC total e seus domínios (tabela 8).

Não foi encontrada diferença significativa nas médias da variação do WOMAC total e seus domínios entre os grupos de 25OHD (tabelas 9 e 10).

As análises foram repetidas excluindo os pacientes com idade $<60$ anos e os testes permaneceram sem demonstrar associação significativa. Os resultados estão descritos em detalhes nas tabelas 11 e 12.

Os resultados não apresentaram modificação após exclusão dos pacientes operados pela equipe do cirurgião A e após exclusão dos pacientes em suplementação com vitamina D.

O poder estatístico post-hoc foi de 0,46 . 
Tabela 4 - Características basais: variáveis categóricas.

\begin{tabular}{|c|c|c|c|}
\hline \multirow{3}{*}{ variáveis } & \multicolumn{2}{|c|}{ Grupos de 25OHD (ng/mL) } & \multirow{3}{*}{$\mathbf{p}$} \\
\hline & $\leq 20(n=85)$ & $>20(n=19)$ & \\
\hline & $\mathrm{n}$ & $\mathrm{n}$ & \\
\hline Sexo masculino & 45 & 12 & 0,419 \\
\hline \multicolumn{4}{|l|}{ Escolaridade } \\
\hline baixa & 33 & 13 & \\
\hline média & 24 & 5 & $\mathbf{0 , 0 1 8}$ \\
\hline alta & 28 & 1 & \\
\hline \multicolumn{4}{|l|}{ ASA } \\
\hline 1 & 31 & 3 & \\
\hline 2 & 46 & 15 & 0,155 \\
\hline 3 & 8 & 1 & \\
\hline
\end{tabular}

Charlson

0

1

2

3

ATQ lado direito

ATQ prévia contralateral

suplementação de vitamina D

OA em outros sítios

Etiologia OA

primária

Legg-Perthes-Calvé

NOA

displasia

epifisiólise

hipermobilidade articular

impacto femoroacetabular

luxação congênita

trauma

Auxílio-locomoção

Bengala em T

bengalas antebraquiais

bengalas axilares

andador

cadeira de rodas
$65 \quad 16$

162

21

20

47

12

0,532

14

10

$<0,001$

3

2

0,225

50

11

0,941

0,696

$0 \quad 0,897$

35

20

20

$1 \quad 0$ 
Tabela 5 - WOMAC no pré-operatório e após 3 meses de pós-operatório.

\begin{tabular}{lccc}
\hline \multirow{2}{*}{ WOMAC } & Pré-operatório & 3 meses & \multirow{2}{*}{$\mathbf{p}$} \\
\cline { 2 - 3 } & média (DP) & média (DP) & \\
\hline Total & $64,5(17,1)$ & $19,7(15,1)$ & $<0,001$ \\
Dor & $12,6(4,5)$ & $2,6(3,1)$ & $<0,001$ \\
Rigidez & $5,1(2,3)$ & $1,6(1,8)$ & $<0,001$ \\
Atividade física & $46,8(12,6)$ & $15,5(11,6)$ & $<0,001$ \\
\hline
\end{tabular}

O domínio "rigidez" foi analisado com o teste de Mann-Whitney e os outros domínios foram analisados com o ANOVA.

Tabela 6 - Testes de correlação entre 25-hidroxivitamina D e a a variação do WOMAC.

\begin{tabular}{lccc}
\hline \multicolumn{1}{c}{$\Delta$ WOMAC } & $\mathbf{R}$ & IC $\mathbf{9 5 \%}$ & $\mathbf{p}$ \\
\hline Total & $-0,1$ & $-0,29 ; 0,09$ & 0,313 \\
Dor & $-0,01$ & $-0,2 ; 0,18$ & 0,902 \\
Rigidez & $-0,01$ & $-0,2 ; 0,18$ & 0,983 \\
Atividade física & $-0,12$ & $-0,31 ; 0,07$ & 0,207 \\
\hline
\end{tabular}

O domínio "rigidez" foi analisado com o teste de correlação de Spearman e os outros domínios foram analisados com o teste de correlação de Pearson. $\Delta$ : variação entre a avaliação pré-operatória e a de 3 meses de pós-operatório.

Tabela 7 - Comparação das médias de WOMAC entre os grupos de 25-hidroxivitamina D (25OHD).

\begin{tabular}{lccc}
\hline \multirow{2}{*}{$\boldsymbol{\Delta}$ WOMAC } & \multicolumn{2}{c}{ Grupos de $250 H D(\mathbf{n g} / \mathbf{m L})$} & \\
\cline { 2 - 3 } & $\leq \mathbf{2 0}(\mathbf{n}=\mathbf{8 5})$ & $\mathbf{> 2 0}(\mathbf{n}=\mathbf{1 9})$ & $\mathbf{p}$ \\
\cline { 2 - 3 } & média $(\mathrm{DP})$ & média $(\mathrm{DP})$ & \\
\hline Total & $46,2(19,6)$ & $38,4(19,9)$ & 0,177 \\
Dor & $10,2(4,7)$ & $9,4(6,5)$ & 0,495 \\
Rigidez & $3,6(2,7)$ & $2,9(3)$ & 0,219 \\
Atividade física & $32,5(15)$ & $26,1(14,8)$ & 0,131 \\
\hline
\end{tabular}

O domínio "rigidez" foi analisado com o teste de Mann-Whitney e os outros domínios foram analisados com o ANOVA. $\Delta$ : variação entre a avaliação pré-operatória e a de 3 meses de pós-operatório.

Tabela 8 - Comparação de médias da variação do WOMAC entre os quartis de 25-hidroxivitamina D (25OHD).

\begin{tabular}{lccccc}
\hline \multirow{2}{*}{$\Delta$ WOMAC } & \multicolumn{5}{c}{ Quartis 25OHD (ng/mL) } \\
\cline { 2 - 5 } & $\mathbf{<}, \mathbf{8 2}$ & $\mathbf{8 , 0 2 - 1 2 , 9 0}$ & $\mathbf{1 2 , 9 1 - 1 8 , 8 4}$ & $\mathbf{2 1 8 , 8 5}$ & \multirow{2}{*}{$\mathbf{p}$} \\
\cline { 2 - 5 } & média (DP) & média (DP) & média (DP) & média (DP) & \\
\hline Total & $41,3(20,9)$ & $51,6(20,9)$ & $46,5(15,6)$ & $39,9(20,2)$ & 0,133 \\
Dor & $9,3(5,4)$ & $10,8(4,8)$ & $10,5(3,7)$ & $9,4(6,1)$ & 0,634 \\
Rigidez & $3,2(2,9)$ & $3,9(2,6)$ & $3,5(2,6)$ & $3,4(2,9)$ & 0,868 \\
Atividade física & $28,8(15,5)$ & $36,8(15,8)$ & $32,5(12,4)$ & $27,1(15,4)$ & 0,092 \\
\hline
\end{tabular}


62

O domínio "rigidez" foi analisado com o teste de Kruskal-Wallis e os outros domínios foram analisados com ANOVA. $\Delta$ : variação entre a avaliação pré-operatória e a de 3 meses de pós-operatório.

Tabela 9 - Testes de correlação entre 25-hidroxivitamina D e a variação do WOMAC no subgrupo de pacientes com idade $\geq 60$ anos.

\begin{tabular}{lccc}
\hline \multicolumn{1}{c}{$\Delta$ WOMAC } & $\mathbf{R}$ & IC 95\% & $\mathbf{p}$ \\
\hline Total & $-0,19$ & $-0,38 ; 0,16$ & 0,176 \\
Dor & $-0,06$ & $-0,33 ; 0,22$ & 0,669 \\
Rigidez & 0,05 & $-0,32 ; 0,23$ & 0,605 \\
Atividade física & $-0,24$ & $-0,48 ; 0,04$ & 0,091 \\
\hline
\end{tabular}

O domínio "rigidez" foi analisado com o teste de correlação de Spearman e os outros domínios foram analisados com o teste de correlação de Pearson. $\Delta$ : variação entre a avaliação pré-operatória e a de 3 meses de pós-operatório.

Tabela 10 - Comparação das médias da variação do WOMAC entre os grupos de 25-hidroxivitamina D (25OHD) de acordo com a mediana no subgrupo de pacientes com idade $\geq 60$ anos.

\begin{tabular}{lccc}
\hline \multirow{2}{*}{$\Delta$ WOMAC } & \multicolumn{2}{c}{ Grupos de 25OHD $(\mathbf{n g} / \mathbf{m L})$} & \\
\cline { 2 - 3 } & $\leq \mathbf{1 4 , 3 8}$ & $>\mathbf{1 4 , 3 8}$ & $\mathbf{p}$ \\
\cline { 2 - 3 } & média (DP) & média (DP) & \\
\hline Total & $49,3(19,4)$ & $43,5(19,6)$ & 0,289 \\
Dor & $11,1(4,6)$ & $9,9(6)$ & 0,436 \\
Rigidez & $3,6(3,1)$ & $3,8(3,8)$ & 0,8 \\
Atividade física & $34,6(15)$ & $29,7(14,8)$ & 0,247 \\
\hline
\end{tabular}

O domínio "rigidez" foi analisado com o teste de Mann-Whitney e os outros domínios foram analisados com o ANOVA. $\Delta$ : variação entre a avaliação pré-operatória e a de 3 meses de pós-operatório.

\subsection{Análise de marcha}

O fluxograma de inclusão está na figura 8. No caso das perdas de seguimento, a maioria dos pacientes não realizaram a avaliação de 3 meses por motivos não relacionados a comorbidades ou complicações da cirurgia, exceto dois casos de fratura periprotética. Não houve ruptura precoce de sigilo em nenhum caso. Seis pacientes foram operados pela equipe A e 87 pela equipe B. A mediana dos valores de $25 \mathrm{OHD}$ basais foi 12,59 ng/ml. Foram encontrados valores $<20 \mathrm{ng} / \mathrm{ml}$ em $82,8 \%$ dos pacientes.

Na comparação entre as médias pré e pós-operatórias (tabela 13), foi identificada melhora significativa dos parâmetros pós-operatórios nas seguintes variáveis: tempo de apoio 
simples no membro operado, velocidade, comprimento do passo, passada, índice de claudicação, extensão máxima, flexão maxima, abdução máxima, momento extensor máximo, momento flexor máximo, potência máxima de geração de energia e potência máxima de absorção de energia.

Figura 8 - Fluxograma de inclusão análise de marcha.

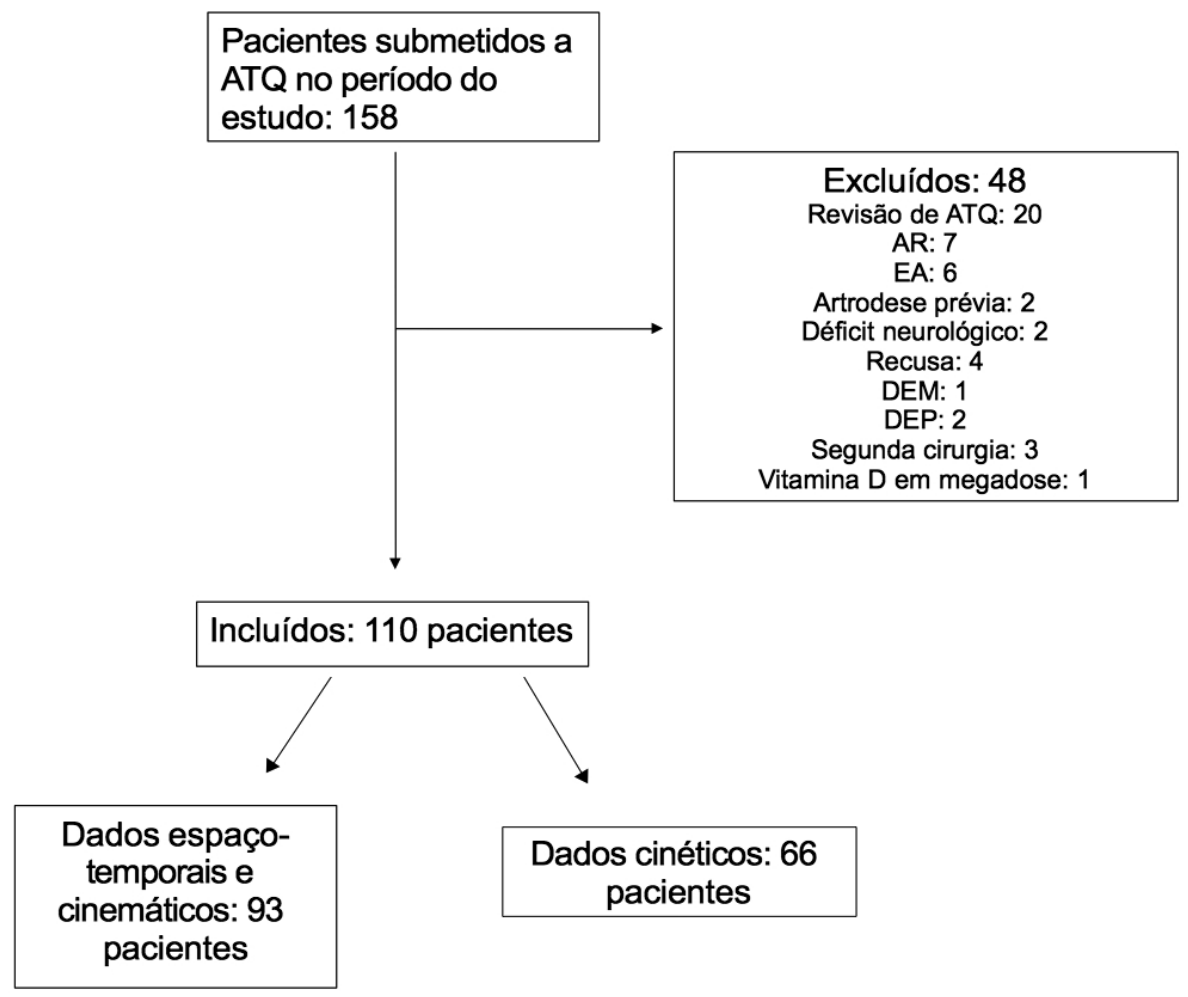

ATQ: artroplastia total do quadril. AR: artrite reumatoide. EA: Espondilite anquilosante. DEM: displasia epifisária múltipla. DEP: displasia espondiloepifisária. Megadose: $\geq 50.000 \mathrm{UI} / \mathrm{semana}$.

Foi identificada correlação significativa entre 25OHD basal e as seguintes variáveis: variação do pico de extensão e variação da potência máxima de geração de energia dos flexores no pré-balanço (tabela 14 e figuras 9 e 10).

Após exclusão dos pacientes operados pela equipe A, a correlação com a variação do pico de extensão persistiu significativa $(\mathrm{R}=0,24, \mathrm{p}=0,026)$, mas a correlação com a potência máxima de geração de energia não foi significativa $(\mathrm{R}=0,23, \mathrm{p}=0,074)$. Após exclusão dos pacientes em uso de vitamina $\mathrm{D}$, ambas as correlações permaneceram significativas (variação 
64

do pico de extensão: $\mathrm{R}=0,30, \mathrm{p}=0,004$; variação da potência máxima de geração de energia: $\mathrm{R}=0,25, \mathrm{p}=0,049)$. No subgrupo de pacientes idosos, não foi encontrada nenhuma correlação significativa (tabela 15).

A comparação de médias não mostrou diferenças entre os grupos de 25OHD (tabelas

\section{6 e 17).}

Tabela 11 - Análise de marcha pré e pós-operatória.

\begin{tabular}{lccc}
\hline \multirow{2}{*}{\multicolumn{1}{c}{ análise de marcha }} & Pré-operatório & $\mathbf{3}$ meses & \multirow{2}{*}{$\mathbf{p}$} \\
\cline { 2 - 3 } & média (DP) & média (DP) & \\
\hline Apoio simples (\%) & $30,9(5,5)$ & $32,8(4,2)$ & $<\mathbf{0 , 0 0 1}$ \\
Velocidade de marcha (m/s) & $0,7(26,1)$ & $0,8(24,6)$ & $<\mathbf{0 , 0 0 1}$ \\
Comprimento do passo (m) & $0,46(13,3)$ & $0,51(10,8)$ & $<\mathbf{0 , 0 0 1}$ \\
Comprimento da passada (m) & $0,9(24,5)$ & $1(20,4)$ & $<\mathbf{0 , 0 0 1}$ \\
Momento abdutor máximo (N.m/kg) & $0,6(0,3)$ & $0,6(0,2)$ & 0,425 \\
Momento extensor máximo (N.m/kg) & $0,4(0,2)$ & $0,5(0,2)$ & $\mathbf{0 , 0 0 2}$ \\
Momento flexor máximo (N.m/kg) & $-0,4(0,2)$ & $-0,4(0,2)$ & 0,168 \\
Adução máxima (graus) & $6,9(6,1)$ & $6,8(5,1)$ & 0,795 \\
Abdução máxima (graus) & $2,3(6,6)$ & $-0,3(5,4)$ & $<\mathbf{0 , 0 0 1}$ \\
Extensão máxima (graus) & $12,8(9,6)$ & $5,29(7,8)$ & $<\mathbf{0 , 0 0 1}$ \\
Flexão máxima (graus) & $31,4(9,3)$ & $33,6(7,9)$ & $\mathbf{0 , 0 1}$ \\
Potência máxima de absorção de energia $(\mathrm{W} / \mathrm{kg})$ & $-0,2(0,2)$ & $-0,4(0,3)$ & $\mathbf{0 , 0 0 1}$ \\
Potência máxima de geração de energia $(\mathrm{W} / \mathrm{kg})$ & $0,3(0,1)$ & $0,5(1,6)$ & $<\mathbf{0 , 0 0 1}$ \\
\hline
\end{tabular}

Todos os dados se referem ao membro operado. A potência máxima de absorção de energia foi analisada com o teste de postos e sinais de Wilcoxon e os outros dados foram analisados com o teste t-pareado.

Tabela 12 - Correlação entre 25-hidroxivitamina D basal e a variação dos dados de marcha.

\begin{tabular}{lccc}
\hline \multicolumn{1}{c}{$\Delta$ análise de marcha } & R & IC 95\% & p \\
\hline Apoio simples (\%) & $-0,01$ & $-0,213 ; 0,194$ & 0,961 \\
Velocidade de marcha (m/s) & $-0,01$ & $-0,213 ; 0,194$ & 0,942 \\
Comprimento do passo (m) & $-0,03$ & $-0,232 ; 0,175$ & 0,763 \\
Comprimento da passada (m) & 0,04 & $-0,165 ; 0,242$ & 0,697 \\
Momento abdutor máximo (N.m/kg) & 0,00 & $-0,204 ; 0,204$ & 0,993 \\
Momento extensor máximo (N.m/kg) & 0,08 & $-0,126 ; 0,279$ & 0,508 \\
Momento flexor máximo (N.m/kg) & $-0,10$ & $-0,298 ; 0,106$ & 0,421 \\
Abdução máxima (graus) & $-0,11$ & $-0,307 ; 0,96$ & 0,307 \\
Extensão máxima (graus) & $\mathbf{- 0 , 2 5}$ & $\mathbf{- 0 , 4 3 2 ; - 0 , 0 4 9}$ & $\mathbf{0 , 0 1 7}$ \\
Adução máxima (graus) & $-0,01$ & $-0,213 ; 0,194$ & 0,956 \\
Flexão máxima (graus) & 0,12 & $-0,086 ; 0,316$ & 0,243 \\
Potência máxima de geração de energia (W/kg) & $\mathbf{0 , 2 5}$ & $\mathbf{0 , 0 4 9 ; 0 , 4 3 2}$ & $\mathbf{0 , 0 4}$ \\
Potência máxima de absorção de energia (W/kg) & $-0,11$ & $-0,307 ; 0,96$ & 0,307 \\
\hline
\end{tabular}

Todos os dados se referem ao membro operado. Os dados foram analisados com o teste de correlação de

Pearson. $\Delta$ : variação entre a avaliação pré-operatória e a de 3 meses de pós-operatório. 
Figura 9 - Gráfico de dispersão do teste de correlação de Pearson entre 25-hidroxivitamina D basal (eixo horizontal) e variação da extensão máxima (eixo vertical).

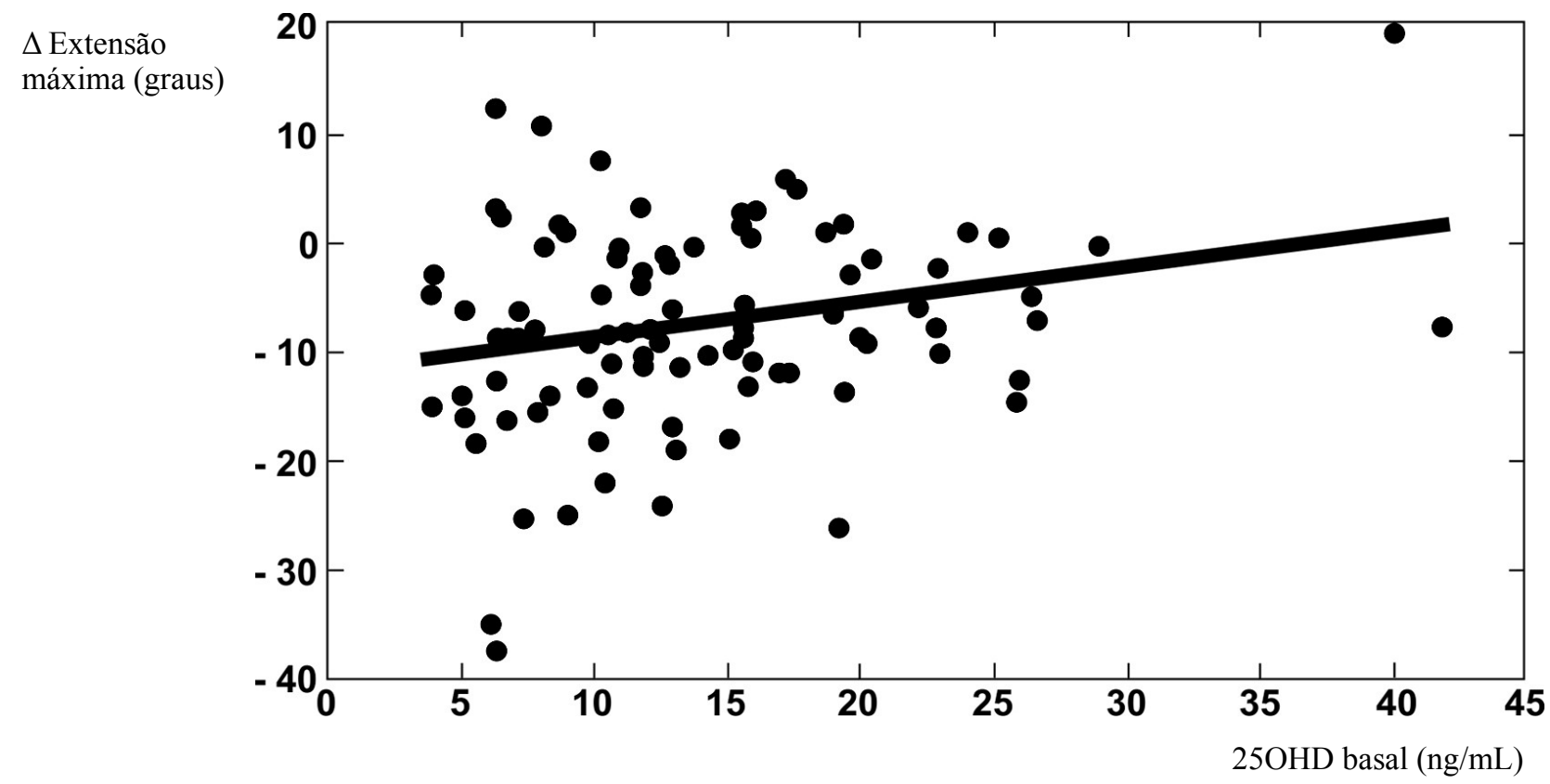

Os dados se referem ao membro operado. Figura importada do software Statistics Open For All (SOFA) versão 1.4.3 e modificada pela equipe de Comunicação Visual do SARAH. $\Delta$ : variação entre a avaliação préoperatória e a de 3 meses de pós-operatório.

No subgrupo de pacientes idosos, também não foi encontrada nenhuma comparação significativa (tabela 18).

Foi realizada regressão linear múltipla pelo método backward stepwise, para avaliação de duas variáveis dependentes: variação do pico de extensão (modelo 1) e da potência máxima de geração de energia (modelo 2). Em ambos os modelos, as covariáveis analisadas foram 25OHD, WOMAC pré-operatório, sexo, idade (71) e variação da velocidade de marcha (72). No modelo 1, 25OHD e variação da velocidade de marcha tiveram efeito na variabilidade da variável dependente, embora de forma modesta ( $R 2$ ajustado $=0,1, \mathrm{p}=0,004)$. 
66

No modelo 2, apenas 25OHD explicou a variabilidade, também de forma modesta (R2 ajustado $=0,05, \mathrm{p}=0,044)$.

Figura 10 - Gráfico de dispersão do teste de correlação de Pearson entre 25-hidroxivitamina D basal (eixo horizontal) e variação da potência máxima de geração de energia dos flexores do quadril (eixo vertical).

$\Delta$ potência máxima de geração de energia $(\mathrm{W} / \mathrm{kg})$

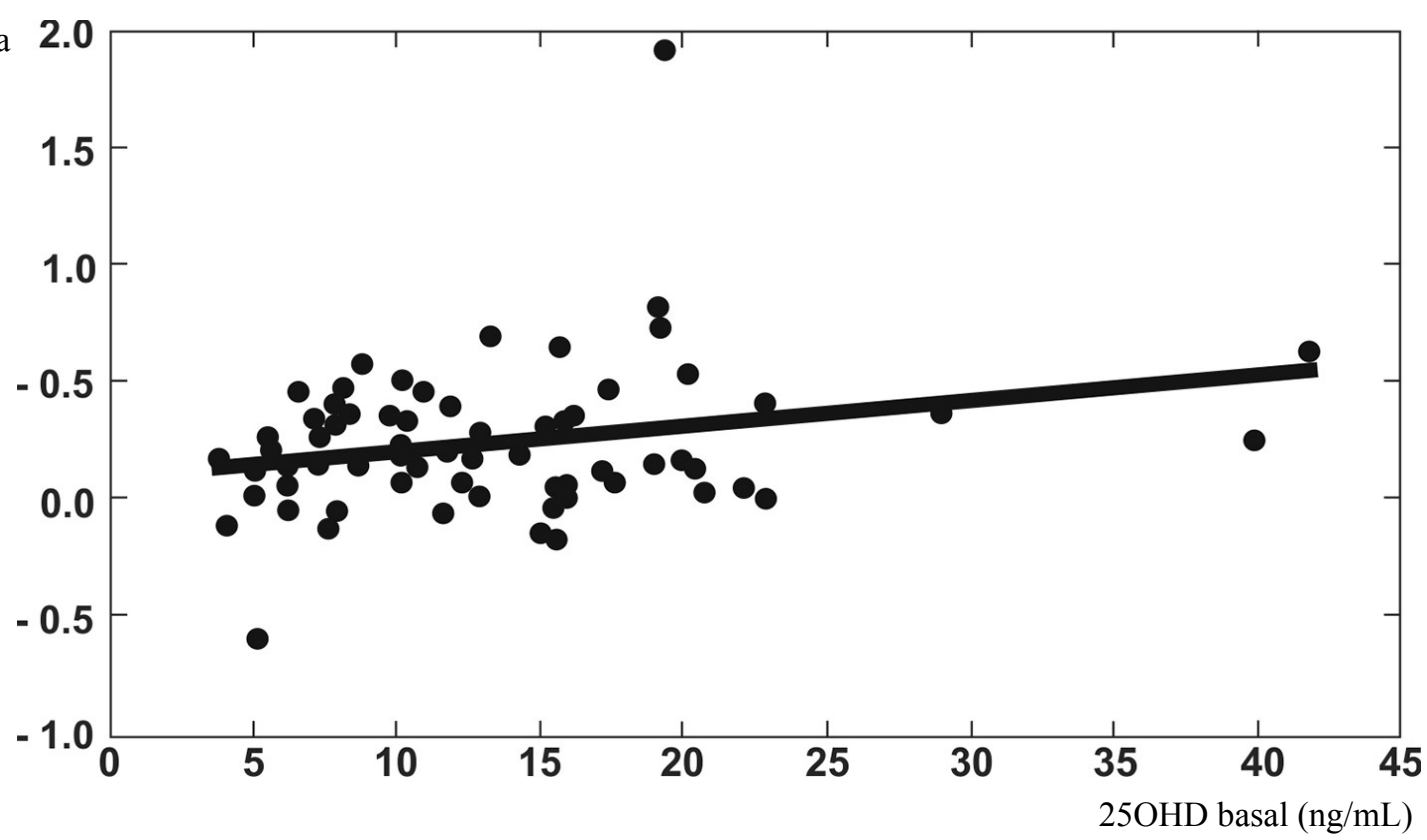

Os dados se referem ao membro operado. Figura importada do software Statistics Open For All (SOFA) versão 1.4.3 e modificada pela equipe de Comunicação Visual do SARAH. $\Delta$ : variação entre a avaliação préoperatória e a de 3 meses de pós-operatório. 
Tabela 13 - Correlação entre 25-hidroxivitamina D basal e os dados de marcha no subgrupo de pacientes idosos.

\begin{tabular}{lccc}
\hline \multicolumn{1}{c}{$\Delta$ análise de marcha } & R & IC 95\% & p \\
\hline Apoio simples (\%) & $-0,04$ & $-0,327 ; 0,253$ & 0,773 \\
Comprimento do passo (m) & $-0,05$ & $-0,335 ; 0,244$ & 0,743 \\
Comprimento da Passada (m) & $-0,09$ & $-0,371 ; 0,206$ & 0,575 \\
Velocidade de marcha (m/s) & 0,06 & $-0,234 ; 0,344$ & 0,705 \\
Momento abdutor máximo (N.m/kg) & 0,12 & $-0,176 ; 0,396$ & 0,573 \\
Momento extensor máximo (N.m/kg) & 0,27 & $-0,022 ; 0,520$ & 0,201 \\
Momento flexor máximo (N.m/kg) & 0,22 & $-0,075,0,480$ & 0,286 \\
Abdução máxima (graus) & $-0,04$ & $-0,327 ; 0,253$ & 0,771 \\
Extensão máxima (graus) & 0,17 & $-0,127 ; 0,439$ & 0,274 \\
Adução máxima (graus) & $-0,03$ & $-0,318 ; 0,263$ & 0,857 \\
Flexão máxima (graus) & 0,08 & $-0,215 ; 0,362$ & 0,621 \\
Potência máxima de absorção de energia $(\mathrm{W} / \mathrm{kg})$ & 0,01 & $-0,281 ; 0,299$ & 0,968 \\
Potência máxima de geração de energia $(\mathrm{W} / \mathrm{kg})$ & 0,23 & $-0,065 ; 0,488$ & 0,251 \\
\hline
\end{tabular}

Todos os dados se referem ao membro operado. Os dados foram analisados com o teste de correlação de Pearson. $\Delta$ : variação entre a avaliação pré-operatória e a de 3 meses de pós-operatório.

Tabela 14 - Comparação de dados de marcha entre os grupos de 25-hidroxivitamina D (25OHD).

\begin{tabular}{|c|c|c|c|}
\hline \multirow{3}{*}{$\Delta$ Análise de marcha } & \multicolumn{2}{|c|}{ Grupos de 25OHD (ng/mL) } & \multirow{3}{*}{$\mathbf{p}$} \\
\hline & $<20(\mathrm{n}=77)$ & $\geq 20(n=16)$ & \\
\hline & mediana (IQR) & mediana (IQR) & \\
\hline Apoio simples (\%) & $2,0(4,5)$ & $0(4,5)$ & 0,249 \\
\hline Velocidade de marcha $(\mathrm{m} / \mathrm{s})$ & $0,1(27,5)$ & $0,1(18)$ & 0,551 \\
\hline Comprimento do passo (m) & $0,1(11,5)$ & $0,04(7,5)$ & 0,791 \\
\hline Comprimento da passada (m) & $0,1(22,5)$ & $0,07(12,5)$ & 0,819 \\
\hline Momento abdutor máximo (N.m/kg) & $0,0(0,4)$ & $0,0(0,2)$ & 0,964 \\
\hline Momento extensor máximo (N.m/kg) & $0,1(0,3)$ & $0,1(0,4)$ & 0,802 \\
\hline Momento flexor máximo (N.m/kg) & $0,0(0,3)$ & $-0,1(0,3)$ & 0,352 \\
\hline Abdução máxima (graus) & $5,5(5,5)$ & $-3,3(6,3)$ & 0,283 \\
\hline Extensão máxima (graus) & $-8,8(13,4)$ & $-5,4(7,6)$ & 0,198 \\
\hline Adução máxima (graus) & $0,0(5,1)$ & $1,1(4,6)$ & 0,684 \\
\hline Flexão máxima (graus) & $2,2(9,9)$ & $3,5(7,0)$ & 0,733 \\
\hline Potência máxima de geração de energia (W/kg) & $0,2(0,3)$ & $0,3(0,4)$ & 0,633 \\
\hline Potência máxima de absorção de energia (W/kg) & $-0,1(0,3)$ & $-0,1(0,1)$ & 0,526 \\
\hline
\end{tabular}

Todos os dados se referem ao membro operado. Os dados foram analisados com o teste de Mann-Whitney. $\Delta$ : variação entre a avaliação pré-operatória e a de 3 meses de pós-operatório. 
Tabela 15 Comparação de dados de marcha entre os quartis de 25-hidroxivitamina D (25OHD).

\begin{tabular}{|c|c|c|c|c|c|c|c|c|c|}
\hline \multirow{3}{*}{$\Delta$ análise de marcha } & \multicolumn{8}{|c|}{ Quartis de 25OHD (ng/mL) } & \multirow{3}{*}{$\mathbf{p}$} \\
\hline & \multicolumn{2}{|c|}{$\leq 7,94$} & \multicolumn{2}{|c|}{$<7,94-12,59$} & \multicolumn{2}{|c|}{$>12,59-18,14$} & \multicolumn{2}{|c|}{$>18,14$} & \\
\hline & mediana & IQR & mediana & IQR & mediana & IQR & mediana & IQR & \\
\hline Apoio Simples (\%) & 1,0 & 5,0 & 3,0 & 5,0 & 1,0 & 4,5 & 1,5 & 5,0 & 0,332 \\
\hline Comprimento Passo (m) & 0,0 & 0,0 & 0,1 & 0,0 & 0,0 & 0,1 & 0,0 & 0,1 & 0,627 \\
\hline Passada (m) & 0,1 & 0,2 & 0,1 & 0,3 & 0,1 & 0,2 & 0,1 & 0,2 & 0,643 \\
\hline Velocidade de marcha $(\mathrm{m} / \mathrm{s})$ & 0,1 & 0,2 & 0,1 & 0,3 & 0,1 & 0,2 & 0,1 & 0,2 & 0,71 \\
\hline Momento abdutor máximo (N.m/kg) & 0,0 & 0,3 & $-0,1$ & 0,6 & 0,0 & 0,4 & 0,0 & 0,5 & 0,961 \\
\hline Momento extensor máximo (N.m/kg) & $-0,1$ & 0,5 & 0,0 & 0,4 & 0,1 & 0,4 & 0,2 & 0,3 & 0,335 \\
\hline Momento flexor máximo (N.m/kg) & $-0,1$ & 0,5 & $-0,1$ & 0,2 & 0,1 & 0,3 & $-0,1$ & 0,4 & 0,225 \\
\hline Abdução máxima (graus) & $-1,4$ & 5,6 & $-2,9$ & 4,4 & $-0,8$ & 5,3 & $-3,3$ & 4,8 & 0,201 \\
\hline Extensão máxima (graus) & $-9,0$ & 10,4 & $-7,5$ & 13,5 & $-7,8$ & 13,6 & $-6,1$ & 7,6 & 0,323 \\
\hline Adução máxima (graus) & $-0,3$ & 5,2 & $-0,1$ & 5,0 & 0,5 & 7,1 & 1,1 & 3,7 & 0,762 \\
\hline Flexão máxima (graus) & $-0,3$ & 12,9 & 2,4 & 10,2 & 4,0 & 8,8 & 3,4 & 7,5 & 0,451 \\
\hline Potência máxima de absorção de energia (W/kg) & $-0,1$ & 0,3 & $-0,1$ & 0,3 & 0,0 & 0,1 & $-0,1$ & 0,3 & 0,654 \\
\hline Potência máxima de geração de energia (W/kg) & 0,1 & 0,3 & 0,2 & 0,3 & 0,1 & 0,3 & 0,3 & 0,5 & 0,050 \\
\hline
\end{tabular}

Todos os dados se referem ao membro operado. Os dados foram analisados com o teste de Kruskal-Wallis. $\Delta$ : variação entre a avaliação pré-operatória e a de 3 meses de pós-operatório.

Tabela 16 - Comparação de médias no subgrupo de pacientes idosos.

\begin{tabular}{lccc}
\hline \multirow{1}{*}{\multicolumn{1}{c}{$\Delta$ análise de marcha }} & \multicolumn{2}{c}{ Grupos de 25OHD (ng/mL) } & \\
\cline { 2 - 3 } & $\mathbf{\leq 1 2 , 9 1}$ & $\mathbf{> 1 2 , 9 1}$ & p \\
\cline { 2 - 3 } & mediana (IQR) & mediana (IQR) & \\
\hline Apoio simples (\%) & $3,5(5)$ & $2(4,5)$ & 0,366 \\
Comprimento do passo (cm) & $5,5(16,5)$ & $4(13,5)$ & 0,706 \\
Comprimento da passada (cm) & $11(23)$ & $13(21)$ & 0,689 \\
Velocidade de marcha (cm/s) & $15(15,5)$ & $12(23,5)$ & 0,639 \\
Momento abdutor máximo (N.m/kg) & $-0,1(0,2)$ & $-0,1(0,4)$ & 0,907 \\
Momento extensor máximo (N.m/kg) & $-0,2(0,1)$ & $-0,1(0,1)$ & 0,159 \\
Momento flexor máximo (N.m/kg) & $-0,2(0,6)$ & $0,1(0,4)$ & 0,208 \\
Abdução máxima (graus) & $-2,1(7,7)$ & $-1,9(6,0)$ & 0,689 \\
Extensão máxima (graus) & $-1,1(6,1)$ & $1,6(5,2)$ & 0,417 \\
Adução máxima (graus) & $-913,8)$ & $-5,8(11)$ & 0,209 \\
Flexão máxima (graus) & $2,2(14,6)$ & $2(8,1)$ & 0,656 \\
Potência máxima de geração de energia $(\mathrm{W} / \mathrm{kg})$ & $0,2(0,3)$ & $0,2(0,6)$ & 0,742 \\
Potência máxima de absorção de energia $(\mathrm{W} / \mathrm{kg})$ & $-0,0(0,2)$ & $-0,0(0,3)$ & 0,935 \\
\hline
\end{tabular}

A amostra está dividida pela mediana de 25-hidroxivitamina D (25OHD). Todas os dados se referem ao membro operado. Os dados foram analisados com o teste de Mann-Whitney. $\Delta$ : variação entre a avaliação pré-operatória e a de 3 meses de pósoperatório. 


\section{Discussão}

\subsection{WOMAC}

Nosso estudo identificou melhora precoce do WOMAC total e seus domínios em pacientes submetidos a ATQ. A cirurgia permitiu melhora da dor, rigidez articular e atividade física na população estudada, com poucas complicações cirúrgicas. No nosso conhecimento, este é o primeiro estudo da América Latina a quantificar o resultado da ATQ utilizando o WOMAC.

Vários estudos relataram resultados da ATQ com diferentes técnicas cirúrgicas e tempo de avaliação pós-operatória variando entre 6 semanas e 3,6 anos $(13,21,24,27,73,74)$. Apesar das diferenças significativas no tempo de seguimento, os resultados desses estudos são semelhantes, o que sugere que a avaliação em 3 meses é válida e que o WOMAC parece ser um instrumento responsivo para avaliação precoce.

A maioria dos estudos citados acima incluiu pacientes com níveis menores de dor e incapacidade funcional no pré-operatório do que o nosso $(21,24,27,74)$, mas o resultado final não difere dos nossos achados. Portanto, no nosso estudo os pacientes parecem ter apresentado maior variação intra-individual. Dois estudos $(13,27)$ empregaram critérios de inclusão que podem ter selecionado pacientes com melhor função física, enquanto um estudo (75) teve um grande número de perdas de seguimento não-aleatórias. Fortin e cols. mostraram que os pacientes com maior disfunção melhoraram mais (27), o que pode explicar as diferenças entre o nosso estudo e os estudos prévios. Além disso, na maioria dos estudos, não estão claros os detalhes sobre os protocolos de reabilitação.

Outros fatores podem justificar um efeito intra-individual mais acentuado no nosso estudo são os seguintes: as cirurgias foram realizadas por equipe de ortopedistas com larga experiência; os pacientes operados no hospital SARAH-Brasília participaram sistematicamente de programa de reabilitação pós-operatória com fisioterapeutas, que se iniciou no primeiro dia de pós-operatório; os pacientes foram acompanhados por equipe de clínicos gerais desde o pré-operatório, em regime ambulatorial, até o pós-operatório. Tais características não se restringem ao ambiente de pesquisa, pois fazem parte da rotina da instituição.

Os resultados deste estudo se opõem aos de Nawabi e cols. (64). Algumas hipóteses podem explicar tal diferença. Primeiro, Nawabi e cols. avaliaram os pacientes com o Harris 
70

Hip Score, que avalia questões diferentes do WOMAC, como o uso de auxílio-locomoção, deformidades e mobilidade articular ao exame físico. Segundo, os valores pós-operatórios do instrumento utilizado dependem dos valores pré-operatórios, pois o grau de incapacidade funcional é variável entre os pacientes, como foi possível comprovar neste estudo. Para contornar o problema, decidimos avaliar a diferença entre os valores pré e pós-operatórios em cada paciente em vez de analisar os valores brutos. Terceiro, o domínio de dor do Harris Hip Score embute ao instrumento reprodutibilidade insatisfatória (75), o que pode levar a falsas conclusões sobre comparação entre duas avaliações distintas. O WOMAC apresenta boa consistência interna (73), o que o torna um instrumento mais robusto para avaliações seriadas.

Nossos resultados confirmaram os do estudo norte-americano de Unnanuntana e cols. (65). Esse estudo teve uma amostra mais numerosa, teve um delineamento muito semelhante ao do nosso estudo e a instituição onde ocorreu o estudo parece ter rotinas de reabilitação similares. Em contrapartida, nosso estudo teve um seguimento mais longo ( 3 meses vs. 6 semanas) e teve mais pacientes com níveis séricos de 25OHD baixos. No entanto, como o poder estatístico post hoc foi menor do que o esperado, não podemos excluir a possibilidade de erro beta.

\subsection{Análise de marcha}

Nosso estudo identificou melhora de grande parte dos parâmetros espaço-temporais, cinemáticos e cinéticos em pacientes submetidos a ATQ, em 3 meses de pós-operatório. Em outros estudos, ocorreram resultados semelhantes, embora nem sempre em avaliações tão precoces $(18,76,77)$. Dessa forma, ratificamos que a ATQ permite não só melhora da dor articular, como também da amplitude de movimento (ADM) coxofemoral, além de uma ação muscular mais intensa e com maior velocidade.

Apesar da melhora evolutiva do pico de extensão, este não adquiriu valores negativos como em pessoas normais ( $-20^{\circ}$ em média) (78), ou seja, houve persistência da flexão durante o pré-balanço. A alteração da extensão pode ser secundária a recuperação incompleta do encurtamento da musculatura flexora do quadril. O mesmo ocorreu no estudo de Queen et cols. (76) e em outros estudos (79), embora no primeiro os valores basais tenham sido menos positivos do que em nosso estudo, o que sugere que incluíram pacientes com contratura em flexão menos grave. 
Também não houve melhora completa do pico de abdução. Em média, o pico de abdução pós-operatório evoluiu para o ângulo neutro. Os gráficos pré-operatórios e pósoperatórios de todos os pacientes foram avaliados visualmente e foram notadas as seguintes alterações: a) alguns pacientes apresentavam o quadril em adução em todo o ciclo da marcha e melhoraram acentuadamente tal alteração no pós-operatório, ainda que para o ângulo neutro; b) em outros casos, houve piora, ou seja, acentuação do ângulo de adução no pós-operatório. No primeiro caso, a adução do quadril pré-operatória pode ter sido acarretada por deslocamento lateral do eixo de rotação do quadril, devido à deformidade da cabeça do fêmur e subluxação, como ocorre em alguns casos de OA (80). No segundo caso, pode ter ocorrido contratura da musculatura adutora no pós-operatório ou uma horizontalização do componente acetabular.

No pré-operatório, os pacientes apresentaram ângulo máximo de flexão passiva médio de 67 graus. Embora isso represente uma redução importante, não implicou em alteração do ângulo máximo de flexão dinâmico no pré-operatório que, em pessoas saudáveis, é muito menor do que esse valor (78). Com isso concluímos que a melhora de 2 graus encontrada não pode ser atribuída diretamente à articulação protética. O ângulo máximo de flexão no balanço depende da geração de energia no pré-balanço (78). De fato, testes de correlação post hoc mostraram correlação significativa entre a variação do ângulo máximo de flexão e a variação da potência máxima de geração de energia dos flexores do quadril $(\mathrm{R}=0,24, \mathrm{p}=0,046)$. Em contrapartida, o estudo de Queen et al. não conseguiu demonstrar diferença significativa da flexão máxima (76).

Os pacientes aumentaram a velocidade de marcha em torno de $11 \mathrm{~cm} / \mathrm{s}$ em média, valor menor do que a mínima diferença clinicamente significativa calculada recentemente por Foucher (81), que foi de $32 \mathrm{~cm} / \mathrm{s}$, em seguimento médio de 1 ano. No nosso estudo, apenas $9,7 \%$ dos pacientes conseguiu atingir essa meta, em comparação a $21,6 \%$ dos pacientes da casuística de Foucher (81), o que sugere que há mais espaço para melhora em avaliações subsequentes. Por outro lado, o aumento da ADM no plano sagital foi de 9,68 em média, semelhante ao estudo de Foucher e Freels (82), valor menor que a mínima diferença clinicamente significativa calculada por Foucher (81), que foi de 13,3 $3^{\circ}$. No nosso estudo, 33\% dos pacientes atingiram essa meta, em comparação com 16,6\% na casuística de Foucher. Esses dados sugerem que o ganho de ADM sagital não parece ter relação com a velocidade de marcha, o que confirma achados de outros estudos (79). 
Observamos que a rotação externa esteve aumentada no pré-operatório em relação a pessoas normais, o que é comum em pacientes portadores de OA de quadril. Com a rotação externa, diminuem as forças compressivas na articulação do quadril, o que leva a redução da dor (80). No entanto, testes de correlação post hoc mostraram que não houve correlação linear entre o ângulo máximo de rotação interna e externa medidos pelos fisioterapeutas e o ângulo máximo de rotação interna e externa medidos na análise de marcha. Para uma mesma rotação máxima aferida pelos fisioterapeutas, observou-se uma extensa amplitude de ângulos dinâmicos entre os indivíduos, o que sugere que os dados aferidos na análise de marcha, nesse caso, apresentaram grande variabilidade. A análise qualitativa de alguns exames que apresentavam maior discrepância mostrou que, em todos eles, as curvas do plano transverso estavam com forma semelhante às de referência, porém com um "shift" para rotação externa ou interna. Tal dificuldade já foi descrita previamente por Baker (83) e parece estar relacionada ao movimento das partes moles sobre os ossos na massa muscular da coxa e à definição precária da posição ideal do marcador refletivo nesse local. Além disso, os marcadores refletivos são ligados ao adesivo que se fixa na pele por meio de um mecanismo articulado de "bola-e-soquete", que permite o deslocamento no sentido ântero-posterior. De acordo com Schache e cols., o ponto de colocação do marcador refletivo com menor variabilidade seria na face lateral da coxa, entre o terço médio e o terço distal, conforme foi feito neste estudo. Ainda assim, tal configuração permite estimativa de somente $60 \%$ da rotação do quadril (84). Na atualidade, fatores de correção para esse artefato ainda estão em desenvolvimento. Devido a esses problemas, os dados de rotação não foram reportados.

A melhora do momento extensor máximo sugere que a ATQ leva a maior estabilidade do quadril, no plano sagital, durante a resposta à carga. Foucher e Freels encontraram achado semelhante (82).

O momento flexor máximo não apresentou melhora, diferentemente do estudo de Foucher e Freels (82), apesar de a recuperação da amplitude de movimento ter sido semelhante. Tal momento tem como sua principal fonte o ligamento iliofemoral (78), cuja função não está relacionada à recuperação da função muscular.

O momento abdutor máximo ocorre durante o apoio simples, por contração muscular abdutora, em reação à instabilidade contralateral da pelve. Este não apresentou melhora, provavelmente porque o glúteo médio, um dos músculos abdutores do quadril, sofre lesão durante o acesso cirúrgico lateral. 
A média da potência máxima de geração de energia dos flexores do quadril esteve muito reduzida no pré-operatório em relação a valores normais (78), mas quase dobrou após 3 meses de pós-operatório, o que sugere que a ATQ permite maior velocidade de contração dos flexores do quadril. No entanto, esse parâmetro não atingiu valores normais, o que também ocorreu em outros estudos (79), possivelmente devido ao fato de que o deslocamento angular durante o pré-balanço não teve recuperação total, devido à persistência do déficit de extensão. Embora testes post-hoc tenham mostrado correlação entre a potência máxima de geração de energia no pré-balanço e o ângulo máximo de flexão no balanço conforme descrito acima, o coeficiente de correlação de 0,24 sugere que o aumento da potência não pode ser explicado somente pelo aumento da amplitude de movimento articular. Por isso, concluímos que pode ter havido melhora da ação muscular. Tal efeito pode ter contribuído para a melhora dos parâmetros espaço-temporais, uma vez que o avanço do membro ocorre de forma passiva durante o balanço, como consequência da contração muscular flexora no pré-balanço (78). De fato, em testes post-hoc houve estreita correlação entre a variação da potência de geração de energia dos flexores do quadril e a variação da velocidade de marcha $(R=0,57, p<0,001)$.

A 25OHD basal se correlacionou com o pico de extensão. Tsukagoshi e cols. identificaram que o pico de extensão após ATQ se correlacionou com o momento abdutor máximo, dor e ADM passiva de extensão (85). Neste estudo, não houve correlação entre a 25OHD e essas variáveis. As variáveis cinemáticas do plano sagital são as que tem maior amplitude, portanto são as que há maior probabilidade de se identificar diferenças. A amplitude de movimento no plano sagital é a mais importante para a marcha, uma vez que a sua direção é igual ao sentido do deslocamento. Embora o pico de extensão ocorra de forma passiva conforme o tronco avança sobre o quadril, os músculos isquiotibiais contribuem para a extensão durante o apoio médio, em resposta à extensão do joelho (78). Por outro lado, o músculo tensor da fáscia lata e o adutor longo são responsáveis por contrabalançar a extensão do quadril durante o apoio terminal (78). É possível que a correlação entre a 25OHD e o pico de extensão esteja relacionada com diferentes distribuições de VDR nos grupamentos musculares dos membros inferiores, permitindo uma melhor coordenação entre eles. A ação da vitamina $\mathrm{D}$ ativa nesses músculos pode estar relacionada com o padrão de tempo de contração. De fato, Rodman e Baker demonstraram que cobaias com dieta deficiente de vitamina $\mathrm{D}$ apresentaram maior tempo de relaxamento do pico de tensão muscular sem redução da amplitude (86). 
A geração de energia dos flexores do quadril durante o pré-balanço tem como responsáveis principais os músculos íleo-psoas, adutor longo, grácil e sartório (78). A velocidade de contração da musculatura flexora do quadril é fundamental para a passagem do membro para a fase de balanço e para o movimento em toda essa fase, uma vez que a flexão do quadril durante o balanço ocorre de forma passiva (78). Os resultados deste estudo sugerem que a vitamina $\mathrm{D}$ permite maior velocidade de contração dos flexores do quadril, mas que não se traduziu em aumento da velocidade de marcha. Conforme já exposto anteriormente, ensaios clínicos encontraram aumento do equilíbrio estático em pacientes que receberam suplementação de vitamina $\mathrm{D}$ (58), o que também pode estar relacionado com o aumento da potência muscular. Neste estudo, pacientes com maiores níveis de 25OHD podem ter tido uma maior regeneração muscular, o que pode ter permitido uma maior recuperação da função muscular no pós-operatório de ATQ.

O subgrupo de pacientes com idade $\geq 60$ anos não apresentou qualquer associação significativa entre dados da análise de marcha e 25OHD basal. Isso pode ter acontecido pela ocorrência de erro beta, em consequência da redução do tamanho de amostra (46 indivíduos), considerando que testes post hoc não mostraram diferenças significativas na variação dos dados de marcha entre pacientes com idade acima ou abaixo de 60 anos, exceto na variação do momento extensor máximo durante a resposta à carga, em que os pacientes com idade $>60$ anos tiveram uma variação maior $(0,204$ vs. $0,047, \mathrm{p}=0,041)$.

Os resultados da regressão linear mostraram que a 25OHD basal explica de forma discreta a variabilidade da variação do pico de extensão e da potência máxima de geração de energia dos flexores do quadril. Outras covariáveis não acrescentaram nada ao modelo. A recuperação da extensão pode estar mais associada a outras variáveis não avaliadas, como características biomecânicas da articulação acometida pela OA.

\subsection{Pontos positivos}

No nosso conhecimento, este foi o primeiro estudo que: avaliou a relação entre níveis de 25OHD e análise de marcha em pacientes submetidos a ATQ; estudou parâmetros cinemáticos e cinéticos de marcha em nessa população na América Latina; avaliou potência no pré e pós-operatório de ATQ. Em relação à análise de marcha em ATQ, no nosso conhecimento, este estudo apresenta a maior casuística estudada prospectivamente até agora.

Foi possível atingir o tamanho amostral planejado para o desfecho primário e houve 
poucas perdas de seguimento. Houve homogeneidade em relação à técnica cirúrgica, como já exposto antes.

\subsection{Limitações}

Os domínios do WOMAC incluem avaliação de dor e rigidez, que podem estar mais relacionadas com aspectos articulares do que musculares. Entretanto, mesmo o domínio "atividade física", que está mais relacionado com a capacidade funcional per se e as atividades de vida diária, também não apresentou diferença entre os grupos.

A média de idade dos pacientes foi baixa, por isso o grau de lesão muscular associada à $\mathrm{OA}$ pode não ter sido tão acentuada, o que pode ter tornado menos importante o efeito da 25OHD. No entanto, o subgrupo de pacientes com idade maior do que 60 anos também não apresentou associação significativa entre 25OHD e WOMAC.

Foram incluídos pacientes com etiologias diversas para a OA de quadril. Se por um lado isso aumentou a heterogeneidade da população estudada, por outro correspondeu a um cenário da "vida real".

Os pacientes que não conseguiram realizar as avaliações sem uso de auxíliolocomoção ou que utilizaram andador não puderam ser avaliados quanto aos dados cinéticos; isso reduziu o tamanho amostral para avaliação dessas variáveis e excluiu os pacientes supostamente mais graves.

Os dados não foram normalizados quanto ao comprimento do membro ou quanto à velocidade de marcha, porém foi utilizada a variação intra-individual para as análises, o que corrigiu esse viés. Por outro lado, a velocidade de marcha foi incluída nos modelos de regressão linear.

Os dados de rotação interna e externa não puderam ser aproveitados porque não se conseguiu uma boa reprodutibilidade, devido a problemas com o posicionamento do marcador refletivo na massa muscular da coxa, porém não acreditamos que tal dado isoladamente traria informações conclusivas.

A avaliação dos picos não representa necessariamente o ciclo da marcha como um todo, no entanto todos os estudos utilizam essa mesma forma de avaliação e nos parece a melhor forma de avaliar os momentos mais importantes do ciclo da marcha. 
Não foi realizada eletromiografia dinâmica, não sendo possível individualizar a ação de grupos musculares e correlacioná-los aos achados cinemáticos e cinéticos, o que poderia ter confirmado algumas inferências descritas acima.

Os dados deste estudo não podem ser extrapolados para pacientes com doenças articulares inflamatórias, que foram excluídos.

Não foi avaliado o efeito dos níveis de 25OHD ao longo do acompanhamento, pois foi dosada somente a 25OHD basal, no entanto o período de acompanhamento foi curto, o que torna menos provável a influência desse fator nos resultados.

O efeito da vitamina D no desempenho de pacientes no pós-operatório de ATQ poderia ser percebido de forma mais acentuada em tarefas mais demandantes do que a marcha em velocidade confortável.

\subsection{Perspectivas}

A normalização dos níveis séricos de 25OHD, por meio de suplementação, poderia ser uma intervenção simples e barata para a melhora da capacidade funcional pós-operatória de pacientes submetidos a ATQ. Tal intervenção poderia ser testada em estudos subsequentes.

A avaliação de dados eletromiográficos e de densidade de VDR em diversos sítios musculares em seres humanos poderiam esclarecer alguns achados de nosso estudo.

Populações mais específicas de pacientes submetidas a ATQ, como por exemplo grupos com etiologias específicas, com alterações da marcha distintas das apresentadas pelo grupo de pacientes estudado, poderiam ser estudadas em separado. 


\section{Conclusões}

Não foi observada relação entre níveis basais de 25OHD e a evolução do WOMAC até o terceiro mês de pós-operatório.

Houve melhora acentuada no WOMAC e seus domínios em pacientes submetidos a ATQ, com variação intra-individual maior do que outros estudos.

Houve correlação entre níveis de 25OHD basais e o pico de extensão e a potência máxima de geração de energia dos flexores do quadril. $\mathrm{O}$ efeito da $25 \mathrm{OHD}$ na mudança dessas variáveis é modesto.

Houve melhora significativa de parâmetros espaço-temporais, cinemáticos e cinéticos no terceiro mês de pós-operatório de ATQ.

As alterações da marcha possivelmente secundárias a níveis mais baixos de 25OHD são discretas e não são perceptíveis pelo paciente no pós-operatório de ATQ. 


\section{Conflitos de interesse}

Os autores não declaram conflitos de interesse de qualquer espécie. 


\section{REFERÊNCIAS}

1. Coimbra IB Greve JMD, Puccinelli MLC, Fuller R, Cavalcanti FS PEH. Osteoartrite (Artrose): Tratamento [Internet]. Projeto Diretrizes. Conselho Federal de Medicina; 2003 [cited 2016 Mar 3]. Available from: projetodiretrizes.org.br

2. Kalunian KC. Pathogenesis of osteoarthritis [Internet]. Basow D, editor. UpToDate. Waltham, MA: UpToDate; 2016 [cited 2016 Mar 3]. Available from: www.uptodate.com

3. Kalunian KC. Risk factors for and possible causes of osteoarthritis. Basow DS, editor. UptoDate. Waltham, MA: UptoDate; 2016.

4. National and regional estimates on hospital use for all patients from the HCUP National Inpatient Sample [Internet]. 2013 [cited 2016 Mar 2]. Available from: http://hcupnet.ahrq.gov

5. Erens GA, Thronhill TS. Total hip arthroplasty [Internet]. Basow D, editor. Waltham, MA: UpToDate; 2016 [cited 2016 Mar 3]. Available from: www.uptodate.com

6. Cram P, Lu X, Kaboli PJ, Vaughan-Sarrazin MS, Cai X, Wolf BR, et al. Clinical characteristics and outcomes of Medicare patients undergoing total hip arthroplasty, 1991-2008. JAMA. 2011/04/21 ed. 2011;305(15):1560-7.

7. Lenza M, Ferraz S de B, Viola DCM, Garcia Filho RJ, Cendoroglo Neto M, Ferretti M. Epidemiology of total hip and knee replacement: a cross-sectional study. Einstein (São Paulo). Instituto Israelita de Ensino e Pesquisa Albert Einstein; 2013 Jun;11(2):197202.

8. Guedes RC. Parâmetros têmporo-espaciais da marcha de idosos com osteoartrite, após artroplastia total do quadril. Mestrado em Ciências da Reabilitação. [Belo Horizonte]: Universidade Federal de Minas Gerais; 2009.

9. Uustal H, Baerga E, Jaclyn J. Gait Analysis. In: Cuccurullo SJ, editor. Physical Medicine and Rehabilitation Board Review. 3rd ed. New York: Demos Mecial Publishing; 2004. p. 471-7.

10. Constantinou M, Barrett R, Brown M, Mills P. Spatial-temporal gait characteristics In individuals With hip osteoarthritis: a systematic literature review and meta-analysis. J Orthop Sport Phys Ther. 2014/01/24 ed. 2014;

11. Watelain E, Dujardin F, Babier F, Dubois D, Allard P. Pelvic and lower limb compensatory actions of subjects in an early stage of hip osteoarthritis. Arch Phys Med Rehabil. 2001/12/26 ed. 2001;82(12):1705-11.

12. Eitzen I, Fernandes L, Nordsletten L, Risberg MA. Sagittal plane gait characteristics in hip osteoarthritis patients with mild to moderate symptoms compared to healthy 
controls: a cross-sectional study. BMC Musculoskelet Disord. 2012/12/22 ed. 2012;13:258.

13. Lindemann U, Becker C, Unnewehr I, Muche R, Aminin K, Dejnabadi H, et al. Gait analysis and WOMAC are complementary in assessing functional outcome in total hip replacement. Clin Rehabil. 2006;20(5):413-20.

14. Perron M, Malouin F, Moffet H, McFadyen BJ. Three-dimensional gait analysis in women with a total hip arthroplasty. Clin Biomech (Bristol, Avon). 2000/06/01 ed. 2000;15(7):504-15.

15. Beaulieu ML, Lamontagne M, Beaule PE. Lower limb biomechanics during gait do not return to normal following total hip arthroplasty. Gait Posture. 2010/06/15 ed. 2010;32(2):269-73.

16. Horstmann T, Listringhaus R, Haase GB, Grau S, Mundermann A. Changes in gait patterns and muscle activity following total hip arthroplasty: a six-month follow-up. Clin Biomech (Bristol, Avon). 2013/08/03 ed. 2013;28(7):762-9.

17. Rasch A, Dalen N, Berg HE. Muscle strength, gait, and balance in 20 patients with hip osteoarthritis followed for 2 years after THA. Acta Orthop. 2010/04/07 ed. 2010;81(2):183-8.

18. Kyriazis V, Rigas C. Temporal gait analysis of hip osteoarthritic patients operated with cementless hip replacement. Clin Biomech (Bristol, Avon). 2002/05/30 ed. 2002;17(4):318-21.

19. Fernandes MI. Tradução e validação do questionário de qualidade de vida específico para osteoartrose WOMAC (Western Ontario McMaster Universities) para a língua portuguesa. Reumatologia. [São Paulo]: Universidade Federal de São Paulo - Escola Paulista de Medicina; 2003.

20. Angst F, Aeschlimann A, Steiner W, Stucki G. Responsiveness of the WOMAC osteoarthritis index as compared with the SF-36 in patients with osteoarthritis of the legs undergoing a comprehensive rehabilitation intervention. Ann Rheum Dis. 2001/08/15 ed. 2001;60(9):834-40.

21. Wang W, Morrison TA, Geller JA, Yoon RS, Macaulay W. Predicting short-term outcome of primary total hip arthroplasty:a prospective multivariate regression analysis of 12 independent factors. J Arthroplast. 2009/08/15 ed. 2010;25(6):858-64.

22. Roder C, Staub LP, Eggli S, Dietrich D, Busato A, Muller U. Influence of preoperative functional status on outcome after total hip arthroplasty. J Bone Jt Surg Am. 2007/01/04 ed. 2007;89(1):11-7. 
23. Nilsdotter A-K, Petersson IF, Roos EM, Lohmander LS. Predictors of patient relevant outcome after total hip replacement for osteoarthritis: a prospective study. Ann Rheum Dis. 2003/09/16 ed. 2003;62(10):923-30.

24. Jandric S, Manojlovic S. Quality of life of men and women with osteoarthritis of the hip and arthroplasty: assessment by WOMAC questionnaire. Am J Phys Med Rehabil. 2009/02/05 ed. 2009;88(4):328-35.

25. Kennedy DM, Hanna SE, Stratford PW, Wessel J, Gollish JD. Preoperative function and gender predict pattern of functional recovery after hip and knee arthroplasty. $\mathrm{J}$ Arthroplast. 2006/06/20 ed. 2006;21(4):559-66.

26. Holtzman J, Saleh K, Kane R. Gender differences in functional status and pain in a Medicare population undergoing elective total hip arthroplasty. Med Care. 2002/05/22 ed. 2002;40(6):461-70.

27. Fortin PR, Clarke AE, Joseph L, Liang MH, Tanzer M, Ferland D, et al. Outcomes of total hip and knee replacement: preoperative functional status predicts outcomes at six months after surgery. Arthritis Rheum. 1999/08/14 ed. 1999;42(8):1722-8.

28. Dohnke B, Knauper B, Muller-Fahrnow W. Perceived self-efficacy gained from, and health effects of, a rehabilitation program after hip joint replacement. Arthritis Rheum. 2005/08/06 ed. 2005;53(4):585-92.

29. Holtzman J, Saleh K, Kane R. Effect of baseline functional status and pain on outcomes of total hip arthroplasty. J Bone Joint Surg Am. 2002/11/14 ed. 2002;84A(11):1942-8.

30. Lieber RL. Skeletal muscle response to injury. In: Lieber RL, editor. Skeletal muscle structure, function and plasticity. 2nd ed. Baltimore, MD e Philadelphia, PA: Lippincott Williams and Wilkins; 2010. p. 229-69.

31. Ferrari RJ, Picchi LD, Botelho AP, Minamoto V. Processo de regeneração na lesão muscular: uma revisão. Fisioter em Mov. 2005;18(2):63-71.

32. Lieber RL. Skeletal muscle adaptation to increased use. In: Lieber RL, editor. Skeletal muscle structure, function and plasticity. 2nd ed. Baltimore, MD e Philadelphia, PA: Lippincott Williams and Wilkins; 2010. p. 141-82.

33. Agus ZS. Metabolism of vitamin D. DS B, editor. UpToDate. Waltham, MA: UpToDate; 2016.

34. Roth SM, Zmuda JM, Cauley JA, Shea PR, Ferrell RE. Vitamin D receptor genotype is associated with fat-free mass and sarcopenia in elderly men. J Gerontol A Biol Sci Med Sci. 2004/01/14 ed. 2004;59(1):10-5. 
35. Bischoff-Ferrari HA, Borchers M, Gudat F, Durmuller U, Stahelin HB, Dick W. Vitamin D receptor expression in human muscle tissue decreases with age. J Bone Min Res. 2004/02/19 ed. 2004;19(2):265-9.

36. Birge SJ, Haddad JG. 25-hydroxycholecalciferol stimulation of muscle metabolism. J Clin Invest. 1975/11/01 ed. 1975;56(5):1100-7.

37. Bellido T, Boland R. Phosphate accumulation by muscle in vitro and the influence of vitamin d3 metabolites. Zeitschrift fur Naturforsch - Sect C J Biosci. 1987;42(3):23744.

38. Curry OB, Basten JF, Francis MJ, Smith R. Calcium uptake by sarcoplasmic reticulum of muscle from vitamin D-deficient rabbits. Nature. 1974/05/03 ed. 1974;249(452):834.

39. Halfon M, Phan O, Teta D. Vitamin D: a review on its effects on muscle strength, the risk of fall, and frailty. Biomed Res Int. 2015;2015:953241.

40. Girgis CM, Clifton-Bligh RJ, Hamrick MW, Holick MF, Gunton JE. The roles of vitamin D in skeletal muscle: Form, function, and metabolism. Endocr Rev. 2013;34(1):33-83.

41. Ceglia L. Vitamin D and skeletal muscle tissue and function. Mol Asp Med. 2008/08/30 ed. 2008;29(6):407-14.

42. Peng L, Malloy PJ, Feldman D. Identification of a functional vitamin D response element in the human insulin-like growth factor binding protein-3 promoter. Mol Endocrinol. 2004/02/14 ed. 2004;18(5):1109-19.

43. Sakai S, Suzuki M, Tashiro Y, Tanaka K, Takeda S, Aizawa K, et al. Vitamin D receptor signaling enhances locomotive ability in mice. J Bone Miner Res. 2015 Jan;30(1):12836.

44. Ceglia L. Vitamin D and its role in skeletal muscle. Curr Opin Clin Nutr Metab Care. 2009/09/23 ed. 2009;12(6):628-33.

45. Saraiva GL, Cendoroglo MS, Ramos LR, Araújo LMQ, Vieira JGH, Maeda SS, et al. Prevalence of vitamin D deficiency, insufficiency and secondary hyperparathyroidism in the elderly inpatients and living in the community of the city of São Paulo, Brazil. Arq Bras Endocrinol Metabol. 2007/06/05 ed. 2007;51(3):437-42.

46. Shinchuk LM, Morse L, Huancahuari N, Arum S, Chen TC, Holick MF. Vitamin D deficiency and osteoporosis in rehabilitation inpatients. Arch Phys Med Rehabil. 2006/07/04 ed. 2006;87(7):904-8.

47. Kant AK, Graubard BI. Race-ethnic, family income, and education differentials in nutritional and lipid biomarkers in US children and adolescents: NHANES 2003-2006. Am J Clin Nutr. 2012/07/28 ed. 2012;96(3):601-12. 
48. Tagliafico AS, Ameri P, Bovio M, Puntoni M, Capaccio E, Murialdo G, et al. Relationship between fatty degeneration of thigh muscles and vitamin D status in the elderly: a preliminary MRI study. AJR Am J Roentgenol. 2010/02/23 ed. 2010;194(3):728-34.

49. Gilsanz V, Kremer A, Mo AO, Wren TA, Kremer R. Vitamin D status and its relation to muscle mass and muscle fat in young women. J Clin Endocrinol Metab. 2010/02/19 ed. 2010;95(4):1595-601.

50. Bhan A, Rao AD, Rao DS. Osteomalacia as a result of vitamin D deficiency. Rheum Dis Clin North Am. 2012;38(1):81-91, viii - ix.

51. Oh JH, Kim SH, Kim JH, Shin YH, Yoon JP, Oh CH. The level of vitamin D in the serum correlates with fatty degeneration of the muscles of the rotator cuff. J Bone Jt Surg Br. 2009/12/02 ed. 2009;91(12):1587-93.

52. Michael YL, Whitlock EP, Lin JS, Fu R, O'Connor EA, Gold R. Primary care-relevant interventions to prevent falling in older adults: a systematic evidence review for the U.S. Preventive Services Task Force. Ann Intern Med. 2010 Dec 21;153(12):815-25.

53. Gillespie LD, Robertson MC, Gillespie WJ, Sherrington C, Gates S, Clemson LM, et al. Interventions for preventing falls in older people living in the community. Cochrane database Syst Rev. 2012 Jan;9:CD007146.

54. Uusi-Rasi K, Patil R, Karinkanta S, Kannus P, Tokola K, Lamberg-Allardt C, et al. Exercise and vitamin $\mathrm{D}$ in fall prevention among older women: a randomized clinical trial. JAMA Intern Med. 2015 May;175(5):703-11.

55. Dhesi JK, Jackson SH, Bearne LM, Moniz C, Hurley M V, Swift CG, et al. Vitamin D supplementation improves neuromuscular function in older people who fall. Age Ageing. 2004/10/27 ed. 2004;33(6):589-95.

56. Brunner RL, Cochrane B, Jackson RD, Larson J, Lewis C, Limacher M, et al. Calcium, vitamin D supplementation, and physical function in the Women's Health Initiative. J Am Diet Assoc. 2008/08/30 ed. 2008;108(9):1472-9.

57. Lips P, Binkley N, Pfeifer M, Recker R, Samanta S, Cohn DA, et al. Once-weekly dose of 8400 IU vitamin $\mathrm{D}(3)$ compared with placebo: effects on neuromuscular function and tolerability in older adults with vitamin D insufficiency. Am J Clin Nutr. 2010/02/05 ed. 2010;91(4):985-91.

58. Zhu K, Austin N, Devine A, Bruce D, Prince RL. A randomized controlled trial of the effects of vitamin D on muscle strength and mobility in older women with vitamin D insufficiency. J Am Geriatr Soc. 2010/11/09 ed. 2010;58(11):2063-8.

59. Beaudart C, Buckinx F, Rabenda V, Gillain S, Cavalier E, Slomian J, et al. The effects of vitamin D on skeletal muscle strength, muscle mass, and muscle power: a systematic 
review and meta-analysis of randomized controlled trials. J Clin Endocrinol Metab. 2014 Nov;99(11):4336-45.

60. Srikuea R, Zhang X, Park-Sarge OK, Esser KA. VDR and CYP27B1 are expressed in $\mathrm{C} 2 \mathrm{C} 12$ cells and regenerating skeletal muscle: potential role in suppression of myoblast proliferation. Am J Physiol Cell Physiol. 2012/06/01 ed. 2012;303(4):C396-405.

61. Stratos I, Li Z, Herlyn P, Rotter R, Behrendt AK, Mittlmeier T, et al. Vitamin D increases cellular turnover and functionally restores the skeletal muscle after crush injury in rats. Am J Pathol. 2012/12/25 ed. 2013;182(3):895-904.

62. Garcia LA, Ferrini MG, Norris KC, Artaza JN. 1,25(OH)(2)vitamin D(3) enhances myogenic differentiation by modulating the expression of key angiogenic growth factors and angiogenic inhibitors in $\mathrm{C}(2) \mathrm{C}(12)$ skeletal muscle cells. J Steroid Biochem Mol Biol. 2012/09/18 ed. 2013;133:1-11.

63. Owens DJ, Sharples AP, Polydorou I, Alwan N, Donovan TF, Tang J, et al. A Systems Based Investigation into Vitamin D and Skeletal Muscle Repair, Regeneration and Hypertrophy. Am J Physiol - Endocrinol Metab. 2015 Oct 27;309(12):ajpendo.00375.2015.

64. Nawabi DH, Chin KF, Keen RW, Haddad FS. Vitamin D deficiency in patients with osteoarthritis undergoing total hip replacement: a cause for concern? J Bone Jt Surg Br. 2010/04/02 ed. 2010;92(4):496-9.

65. Unnanuntana A, Saleh A, Nguyen JT, Sculco TP, Cornell CN, Mancuso CA, et al. Low Vitamin D Status Does Not Adversely Affect Short-Term Functional Outcome After Total Hip Arthroplasty. J Arthroplasty. 2013 Feb;28(2):315-22.e2.

66. Malta M, Cardoso LO, Bastos FI, Magnanini MMF, da Silva CMFP. STROBE initiative: guidelines on reporting observational studies. Rev Saude Publica. 2010/06/16 ed. 2010;44(3):559-65.

67. Altman R, Alarcón G, Appelrouth D, Bloch D, Borenstein D, Brandt K, et al. The American College of Rheumatology criteria for the classification and reporting of osteoarthritis of the hip. Arthritis Rheum. 1991/05/01 ed. 1991;34(5):505-14.

68. High Performance Liquid Chromatography Mass Spectrometry (HPLC/MS) [Internet]. Bristol University; 2012. Available from: www.bris.ac.uk/nerclsmsf/techniques/hplcms.html.

69. Baker R. Basic Measurements. In: Hart HM, editor. Measuring walking A Handbook of Clinical Gait Analysis. First. Mac Keith Press; 2013. p. 8-28.

70. Perry J, Burnfield JM. Kinetics of gait: ground reaction forces, vectors, moments, power and pressure. Gait Analysis: normal and pathological function. second. Thorofare, NJ: Slack Incorporated; 2010. p. 457-70. 
71. McClelland JA, Webster KE, Feller JA. Gait analysis of patients following total knee replacement: A systematic review. Knee. 2014;14(4):253-63.

72. Moisio KC, Sumner DR, Shott S, Hurwitz DE. Normalization of joint moments during gait: a comparison of two techniques. J Biomech. 2003 Apr;36(4):599-603.

73. Zampelis V, Ornstein E, Franzen H, Atroshi I. A simple visual analog scale for pain is as responsive as the WOMAC, the SF-36, and the EQ-5D in measuring outcomes of revision hip arthroplasty. Acta Orthop. 2014/02/01 ed. 2014;85(2):128-32.

74. Holstege MS, Lindeboom R, Lucas C. Preoperative quadriceps strength as a predictor for short-term functional outcome after total hip replacement. Arch Phys Med Rehabil. Elsevier Inc.; 2011 Feb;92(2):236-41.

75. Reuling EM, Sierevelt IN, van den Bekerom MP, Hilverdink EF, Schnater JM, van Dijk $\mathrm{CN}$, et al. Predictors of functional outcome following femoral neck fractures treated with an arthroplasty: limitations of the Harris hip score. Arch Orthop Trauma Surg. 2011/11/25 ed. 2012;132(2):249-56.

76. Queen RM, Butler RJ, Watters TS, Kelley SS, Attarian DE, Bolognesi MP. The effect of total hip arthroplasty surgical approach on postoperative gait mechanics. J Arthroplast. 2011/06/28 ed. 2011;26(6 Suppl):66-71.

77. van den Akker-Scheek I, Stevens M, Bulstra SK, Groothoff JW, van Horn JR, Zijlstra W. Recovery of gait after short-stay total hip arthroplasty. Arch Phys Med Rehabil. 2007 Mar;88(3):361-7.

78. Perry J, Burnfield J. Hip. Gait Analysis: normal and pathological function. second. Thorofare, NJ: Slack Incorporated; 2010. p. 103-20.

79. Kolk S, Minten MJM, van Bon GE a, Rijnen WH, Geurts ACH, Verdonschot N, et al. Gait and gait-related activities of daily living after total hip arthroplasty: A systematic review. Clin Biomech (Bristol, Avon). Elsevier Ltd; 2014;29(6):705-18.

80. Perry J, Burnfield JM. Hip Gait Deviations. Gait Analysis: normal and pathological function. second. Thorofare, NJ: Slack Incorporated; 2010. p. 237-58.

81. Foucher KC. Identifying clinically meaningful benchmarks for gait improvement after total hip arthroplasty. J Orthop Res. 2015 Jul 27;34(1):88-96.

82. Foucher KC, Freels S. Preoperative factors associated with postoperative gait kinematics and kinetics after total hip arthroplasty. Osteoarthritis Cartilage. 2015 May 28;23(10):1685-94.

83. Baker R. Gait analysis methods in rehabilitation. J Neuroeng Rehabil. 2006;3:4.

84. Schache AG, Baker R, Lamoreux LW. Influence of thigh cluster configuration on the estimation of hip axial rotation. Gait Posture. 2008;27(1):60-9. 
85. Tsukagoshi R, Tateuchi H, Fukumoto Y, Akiyama H, So K, Kuroda Y, et al. Factors associated with restricted hip extension during gait in women after total hip arthroplasty. Hip Int. 2015 Nov 25;25(6):543-8.

86. Rodman JS, Baker T. Changes in the kinetics of muscle contraction in vitamin Ddepleted rats. Kidney Int. 1978 Mar;13(3):189-93. 


\title{
VITAMINA D E SARCOPENIA: UMA REVISÃO SISTEMÁTICA
}

\author{
Cunha BM, Sollaci LB, Oliveira SB, Santos-Neto LL
}

Submetido ao European Journal of Clinical Nutrition, em revisão.

\section{Resumo}

Introdução: sarcopenia é definida como a redução da massa muscular, associada a redução da força muscular e/ou do desempenho. A vitamina D tem participação na fisiologia muscular, mas ensaios clínicos randomizados são inconsistentes em demonstrar melhora da função muscular com a reposição de vitamina D. Objetivos: revisão sistemática de estudos observacionais que tenham avaliado, de forma prospectiva ou retrospectiva, a associação entre níveis de 25OHD e o desenvolvimento de sarcopenia em indivíduos comunitários. Métodos: revisão de coortes que avaliaram a massa muscular e/ou força muscular e/ou performance muscular de acordo com os níveis basais de 25OHD, em nmol/L, em indivíduos comunitários com idade $>50$ anos. A busca foi realizada nas bases de dados MEDLINE, EMBASE e LILACS. A avaliação de qualidade foi realizada por dois revisores de forma independente, utilizando a escala de avaliação de coortes de Newcastle-Ottawa. Foram agrupados os dados dos estudos quando apresentaram heterogeneidade clínica aceitável. Resultados: Oito estudos foram selecionados para análise metodológica. Cinco estudos incluíram homens e mulheres, dois somente mulheres e um estudo, somente homens. O tempo de seguimento médio entre os estudos foi de 3 anos, variando entre 2 a 6 anos. No geral, os estudos apresentaram baixo risco de vieses. O declínio da força de preensão palmar foi menor nos grupos com maiores níveis de $25 \mathrm{OHD}$ basal ( $\mathrm{p}=0,033$ ). Essa variável, os quartis de $25 \mathrm{OHD}$ e as covariáveis idade, IMC e estudo de origem foram incluídas em um modelo linear generalizado de efeitos mistos. Nessa análise, as variáveis associadas com o declínio da preensão palmar foram a idade e a interação entre o estudo de origem e os quartis de 25OHD (ambos com $\mathrm{p}<0,001$ ). Porém, quando excluído um estudo com alto risco de vieses, não foi encontrada associação entre o declínio da força de preensão palmar e os quartis de 25OHD. Conclusão: não foi identificada associação consistente entre os níveis basais de 25OHD e o desenvolvimento de sarcopenia em 
indivíduos comunitários. É necessária a realização de novos estudos prospectivos para avaliar a relação entre vitamina $\mathrm{D}$ e sarcopenia.

Palavras-chave: sarcopenia; vitamna D; força muscular; desempenho muscular; massa muscular

\section{Introdução}

Sarcopenia é definida como a redução da massa muscular, associada a redução da força muscular e do desempenho (1). Ela acomete uma grande parcela da população idosa e se desenvolve progressivamente com a senescência. Sua prevalência é de 3 e $30 \%$, variando de acordo com os diferentes métodos de avaliação e faixas etárias estudadas (2). Alguns estudos sugerem que a presença de sarcopenia é preditora de incapacidade funcional, quedas e aumento da mortalidade em idosos (2).

Os pacientes com sarcopenia apresentam redução da massa muscular, com redução do número de fibras musculares e da relação entre as fibras tipo II e as fibras tipo I, aumento de áreas não contráteis, redução de pontes cruzadas entre as fibras e redução da força e da velocidade intrínsecas das fibras. Com a redução da massa muscular, há substituição por tecido adiposo (2).

A etiologia da sarcopenia é multifatorial. Alguns fatores são consistentemente relacionados, como fatores genéticos, estado nutricional, atividade física, mudanças hormonais, resistência à insulina, aterosclerose e mudanças na concentração de citocinas próinflamatórias (2).

Os critérios classificatórios para sarcopenia são variados o que implica numa variabilidade na classificação dos pacientes em ensaios clínicos. O European Working Group on Sarcopenia in Older People (EWGSOP) elaborou em 2009 uma diretriz classificatória conceitual, na qual foi estabelecida a premissa da utilização de métodos de avaliação de massa, força e performance muscular (1).

A deficiência de vitamina $\mathrm{D}$ é um distúrbio prevalente, particularmente nos idosos que estão mais expostos ao distúrbio por redução à exposição solar e da capacidade de síntese de vitamina D na pele (3). Saraiva et al identificaram deficiência de vitamina D em 43,8\% em idosos ambulatoriais e 71,2\% em idosos institucionalizados brasileiros (4).

A vitamina D tem participação na fisiologia muscular. A osteomalácia pode cursar com miopatia $_{2}$ composta de fraqueza muscular proximal com hipotrofia, hipotonia e desconforto 
92

durante a deambulação, que melhora após reposição de vitamina D (5). Os receptores de vitamina D estão presentes nas células musculares, já tendo sido descrita a associação entre polimorfismos do receptor de vitamina D e massa magra (6) e com o número de quedas (7) em idosos. Foi identificada também associação entre os níveis de 25-hidroxivitamina D (25OHD) e degeneração gordurosa da musculatura da coxa (8).

A reposição de vitamina $\mathrm{D}$ apresenta resultados clínicos inconsistentes em relação à força muscular. Sato e cols. identificaram aumento do número e do diâmetro das fibras musculares tipo II em pacientes tratados com doses baixas de ergocalciferol (9), enquanto dois outros estudos demonstraram melhora da estabilidade postural após reposição de vitamina $\mathrm{D}(10,11)$. Uma revisão sistemática indicou que a reposição de vitamina $\mathrm{D}$ e cálcio reduz o risco de quedas em idosos (12).

O objetivo deste estudo é realizar uma revisão sistemática de estudos observacionais que tenham avaliado, de forma prospectiva ou retrospectiva, a associação entre níveis de 25OHD e o desenvolvimento de sarcopenia em indivíduos comunitários.

\section{Métodos}

O delineamento desta revisão está em conformidade com as recomendações do PRISMA Statement (13).

\subsection{Tipos de estudos}

Estudos de coorte que avaliaram a massa muscular e/ou força muscular e/ou performance muscular de acordo com os níveis basais de 25OHD, em nmol/L. Foram considerados todos os estudos disponíveis, independentemente do ano de publicação. Foram incluídos estudos em inglês, português e espanhol.

\subsection{Tipos de pacientes}

Indivíduos da comunidade com idade maior ou igual a 50 anos. Foram excluídos estudos incluindo pacientes institucionalizados ou em terapia de substituição renal.

\subsection{Desfechos}


Sarcopenia foi definida, em conformidade com os critérios da EWGSOP, como redução da massa muscular associada à redução da força ou performance muscular $(1,2)$. Para a massa muscular, foi considerada a avaliação por análise de bioimpedância e por métodos de imagem, como a absorciometria por emissão de raios-X (DXA), tomografia computadorizada ou ressonância magnética. A força muscular foi avaliada por dinamometria da preensão palmar ou dos membros inferiores. Em relação à performance muscular foi considerada a avaliação pelo Short Physical Performance Battery (SPPB), velocidade de marcha, teste de caminhada de 6 minutos, Timed Up And Go (TUG) ou Timed Chair Stands (TCS). Foram selecionados estudos com pontos de corte definidos por critérios objetivos, mas não foram exigidos critérios específicos, uma vez que não há consenso na literatura quanto a sua definição (1).

\subsection{Estratégia de busca}

A busca foi realizada por bibliotecária especializada (LS) nas bases de dados MEDLINE, EMBASE e LILACS em 8 de setembro de 2014.

Foi utilizada a seguinte estratégia no Pubmed, utilizando unitermos Mesh: ("Vitamin D Deficiency" OR "Vitamin D") AND ("Muscular Atrophy" OR "Muscle Weakness" OR "Muscle, Skeletal" OR "Muscle Strength"). Para excluir estudos em pacientes jovens, foi aplicado filtro para inclusão de pacientes com idade $>18$ anos, da seguinte forma: Filters: +19 years.

Na EMBASE, foi utilizada a seguinte estratégia: (“muscle atrophy”/exp OR "muscle weakness"/de OR "skeletal muscle"/de OR “muscle strength"/exp) AND ("vitamin d deficiency"/exp OR “vitamin d"/de). Foram aplicados os seguintes filtros: Adult: 18 to 64 years; Aged: $65+$ years.

No LILACS, foi utilizada a seguinte estratégia, utilizando unitermos DeCs: ("Vitamina D OR deficiência de Vitamina D") AND (Atrofia Muscular OR Debilidade Muscular OR Músculo Esquelético OR Força Muscular).

As referências dos artigos selecionados foram revisadas manualmente em busca de outros estudos não encontrados nas bases de dados.

\subsection{Coleta de dados}


Após os resultados da busca, as referências foram arquivadas no Endnote X6. Os estudos foram avaliados em etapas. Inicialmente, foi realizada checagem para verificar os artigos em duplicata em duas fases, primeiramente de forma automatizada e depois manualmente. Em seguida, foi realizada leitura dos títulos e, sequencialmente, dos resumos. Foram pré-selecionados os resumos e, então, foi realizada uma leitura geral do texto completo. Os artigos que preencheram os critérios de inclusão tiveram seus dados relevantes extraídos por um dos revisores (BMC), incluindo ano de publicação, local de origem da população, delineamento, método de amostragem, tamanho da amostra, tempo de acompanhamento, desfechos avaliados, instrumentos de avaliação e resultados.

Os dados brutos foram solicitados aos autores. Em alguns casos, foram realizados contatos via correio eletrônico aos autores dos estudos para solicitação de dados relevantes para a revisão. Para isso foi utilizado o seguinte protocolo: foi criada uma mensagem padrão que foi enviada por correio eletrônico para o primeiro autor de cada estudo. Nos casos em que não houve resposta em sete dias, a mensagem foi enviada para o último autor, aguardando-se novo período de sete dias

\subsection{Análise metodológica}

A análise metodológica foi realizada por dois revisores (BMC e LLS-N) de forma independente. Para tal, foi aplicada a escala de avaliação de coortes de Newcastle-Ottawa (14). Tais critérios dividem a análise em três domínios: seleção, comparabilidade e desfecho. Em cada um destes domínios, é realizado certo número de perguntas e, de acordo com a resposta, pode ser atribuída uma "estrela". Nos domínios "seleção" e "desfecho", a cada uma das perguntas pode ser atribuída apenas uma "estrela", enquanto que, na pergunta do domínio “comparabilidade", podem ser atribuídas até duas "estrelas". Para classificação de qualidade, foram empregados critérios já utilizados em outra revisão de nosso grupo (15). Foram considerados de baixo risco de vieses os estudos que apresentassem pelo menos uma "estrela" em cada um dos domínios e se a soma das "estrelas" fosse igual ou maior do que cinco. As discordâncias foram resolvidas por consenso.

\subsection{Metanálise}


Os dados dos estudos foram agrupados quando apresentaram heterogeneidade clínica aceitável. Os dados brutos foram solicitados aos autores para contornar dificuldades com as diferentes medidas de associação informadas nos artigos. Quando necessário, foi realizada busca de outros artigos dos mesmos grupos, com o objetivo de obter mais detalhes de características dos indivíduos incluídos nas coortes selecionadas.

Os dados foram planilhados separadamente por desfecho. Foi calculada a diferença entre os valores basais e de seguimento e os resultados foram divididos pelo número médio de anos de seguimento de cada estudo.

Foi utilizado ANOVA para comparação de médias do declínio de cada desfecho entre os quartis de $25 \mathrm{OHD}$ e foi empregado o teste post hoc de Tukey para avaliações múltiplas entre pares de quartis.

Modelos lineares generalizados de efeitos aleatórios foram elaborados, em que a dosagem de 25OHD foi considerada como variável independente e as avaliações de força, desempenho e massa muscular como variáveis dependentes. Como covariáveis, foram incluídas a origem do estudo, idade, sexo e IMC.

Foi decidido a priori, como análise de sensibilidade, repetir a análise após exclusão de estudos com alto risco de vieses, no caso de associação significativa. No caso de heterogeneidade substancial, exploramos os dados, de forma a realizar análises de sensibilidade e de subgrupos, que foram definidas post hoc.

A análise foi realizada com o SPSS versão 21.

\section{Resultados}

\subsection{Busca}

Os resultados da busca estão detalhados na figura. Foram selecionados oito estudos para análise metodológica. Alguns estudos avaliaram mais de um desfecho de interesse. Todos os estudos incluídos foram publicados em inglês.

\subsection{Avaliação de qualidade}

Os resultados da avaliação de qualidade de acordo com a escala de Newcastle-Ottawa estão na tabela 1. 
96

No domínio "seleção dos pacientes", quatro estudos (Sergi e cols., Dam e cols., Chan e cols. e Liu e cols.) apresentaram risco de vieses. Nos estudos de Sergi e cols. e Chan e cols., as amostras foram constituídas de voluntários, o que pode ter selecionado pacientes em melhores condições de saúde, sendo que o estudo de Chan e cols. estratificou a amostra de acordo com a idade. No estudo de Dam e cols., o método de amostragem não está claro, apesar de ter sido realizada em base populacional. Liu e cols. excluíram pacientes com demências, que podem apresentar níveis reduzidos de 25OHD (16) e maior declínio funcional (17).

Figura - Fluxograma de inclusão 


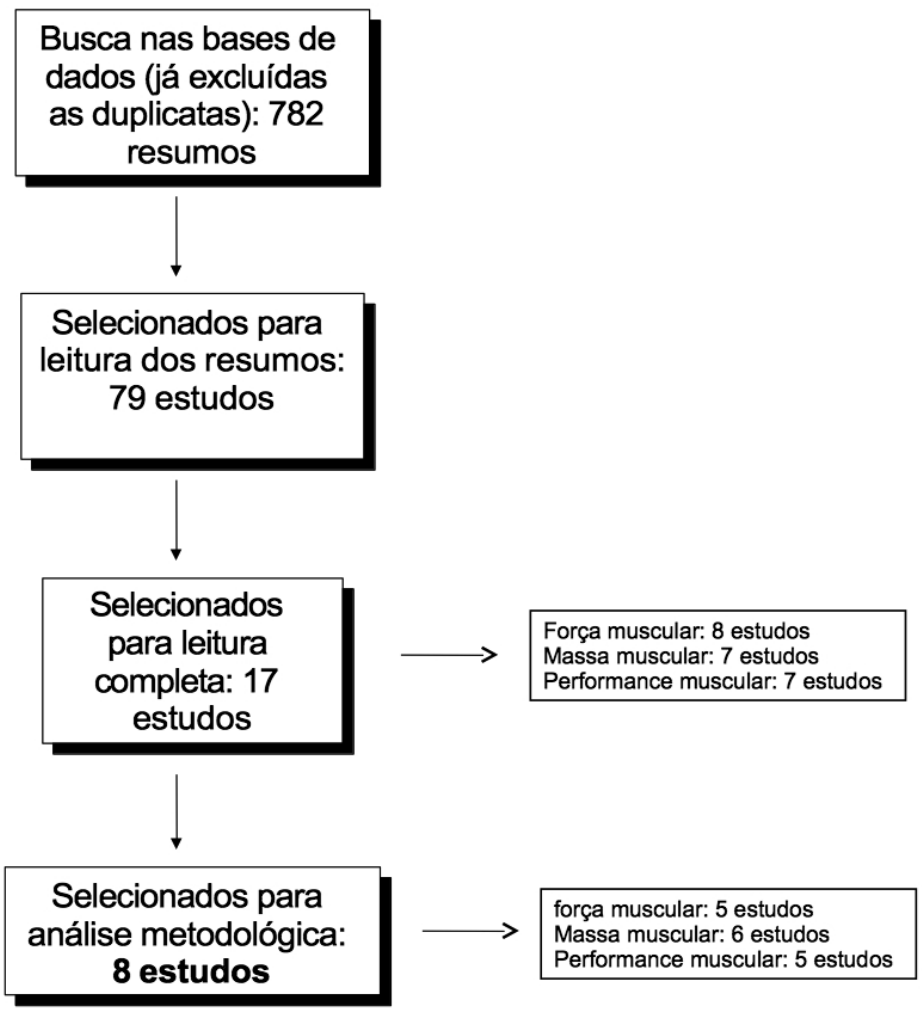


Tabela 1 - Resultados da avaliação de qualidade dos estudos incluídos, de acordo com a escala de Newcastle-Ottawa.

\begin{tabular}{|c|c|c|c|c|c|c|c|c|}
\hline Critérios & Sergi e cols. 2011 & Scott e cols. 2010 & Visser e cols. 2003 & Verreault e cols. & 2002 Faulkner e cols. 2006 & Dam e cols. 2008 & Chan e cols. 2012 & Liu e cols. 2014 \\
\hline \multicolumn{9}{|l|}{ Selection } \\
\hline Representativity of the exposed cohort & 0 & 1 & 1 & 1 & 1 & 0 & 1 & 1 \\
\hline Selection of the non exposed cohort & 1 & 1 & 1 & 1 & 1 & 1 & 1 & 1 \\
\hline Asceirtment of exposure & 1 & 1 & 1 & 1 & 1 & 1 & 1 & 1 \\
\hline Demonstration of absence of outcome at the start of study & 1 & 1 & 1 & 1 & 1 & 1 & 1 & 1 \\
\hline Comparability & 0 & 2 & 2 & 2 & 2 & 2 & 2 & 2 \\
\hline \multicolumn{9}{|l|}{ Outcome } \\
\hline Assessment of outcome & 0 & 0 & 0 & 0 & 0 & 0 & 0 & 0 \\
\hline Follow up long enough & 1 & 1 & 1 & 1 & 1 & 1 & 1 & 1 \\
\hline Adequacy of follow-up & 1 & 1 & 0 & 1 & 1 & 1 & 0 & 0 \\
\hline Total & 4 & 8 & 7 & 8 & 8 & 7 & 7 & 7 \\
\hline Risco de vieses & alto & baixo & baixo & baixo & baixo & baixo & baixo & baixo \\
\hline
\end{tabular}

A primeira coluna está em inglês porque a escala não tem tradução validada para o português. 
No domínio "comparabilidade", o estudo de Sergi e cols. apresenta risco de vieses, pois na análise dos dados não foi realizado controle dos fatores de confundimento.

No domínio "desfecho", foi identificado risco de vieses em todos os estudos, uma vez que não está claro se houve cegamento dos avaliadores em relação ao status de 25OHD dos indivíduos.

\subsection{Descrição dos estudos}

O delineamento dos estudos incluídos está resumido na tabela 2. As características basais da população incluída nos estudos estão descritas na tabela 3.

\subsubsection{Origem da população}

Os estudos foram realizados na America do Norte (18, 19), Europa (20, 21, 22), Ásia $(23,24)$ e Continente Australiano (25). Cinco estudos incluíram homens e mulheres, dois somente mulheres e um estudo, somente homens.

\subsubsection{Seguimento}

No estudo de Sergi e cols., 135 indivíduos foram triados, 105 indivíduos preencheram os critérios de inclusão e 100 completaram todas as avaliações. No estudo de Visser e cols., a coorte original foi composta de 1509 indivíduos, dos quais 685 foram convocados para as avaliações do estudo. A avaliação basal foi realizada em 520 respondedores e 339 realizaram a segunda avaliação, sendo que 331 tinham informações completas. Informações acerca da força muscular estiveram disponíveis em 1008 indivíduos. Scott e cols. realizaram avaliação basal de massa muscular em 1009 indivíduos, destes 224 não retornaram para o exame de seguimento; dos 875 restantes, 686 tinham dados completos. No estudo de Verreault e cols., foram triados 1002 indivíduos, mas 64 estavam em uso de vitamina D e foram excluídos; dentre os outros, a dosagem de 25OHD esteve disponível em 628 indivíduos e 470 indivíduos completaram as avaliações. Dam e cols. avaliaram inicialmente 1065 indivíduos, mas 765 completaram as avaliações, sendo $99 \%$ dos casos de perda do acompanhamento por falecimento. Faulkner e cols. incluíram 389 indivíduos por amostragem simples de uma casuística inicial de 9526 indivíduos; destes, 76-80\% dos pacientes completaram as avaliações na segunda visita. Chan e cols. recrutaram 2000 pacientes, dos quais 988 tinham exames 
laboratoriais disponíveis; destes, 49 foram excluídos por estarem em uso de vitamina D ou apresentarem valores extremos de 25OHD, restando assim 714 pacientes para a análise prospectiva. Liu e cols. incluíram originalmente 3289 indivíduos, mas somente um dos centros dispunha de densitômetro por DXA, por isso 1150 indivíduos foram seguidos quanto aos exames de DXA e destes, 568 tinham dados completos para a análise prospectiva.

O tempo de seguimento médio entre os estudos foi de 3 anos, variando entre 2 a 6 anos.

\subsubsection{Dosagem de 25OHD}

Seis estudos (Sergi e cols., Scott e cols., Verreault e cols., Faukner e cols., Liu e cols. e Chan e cols.) realizaram a dosagem de $250 H D$ por radioimunoensaio. Visser e cols. utilizaram ensaio competitivo de ligação de proteínas (CBPA), utilizando kits da Nichols Diagnostics, que foram retirados do mercado posteriormente pelo fabricante. Dam e cols. utilizaram também CBPA, mas com método inhouse.

\subsubsection{Desfechos}

Todos os estudos que avaliaram a massa muscular utilizaram DXA, mas com algumas particularidades. Em quatro estudos (Sergi e cols., Visser e cols., Liu e cols. e Chan e cols.), a massa muscular esquelética apendicular (MMEA) bruta foi avaliada. Visser e cols. definiram "sarcopenia" como perda de massa muscular acima de 3\% entre a avaliação basal e de seguimento. Scott et al. avaliaram a porcentagem de MMEA em relação à massa total.

Dentre os estudos que avaliaram performance, foram utilizados diferentes métodos de avaliação, sendo o mais frequente o TCS, que foi aplicado em cinco estudos (Sergi e cols., Verreault e cols., Dam e cols., Faulkner e cols. e Chan e cols.). Em todos, a avaliação foi realizada com o mesmo método. Quatro estudos avaliaram velocidade de marcha em ritmo usual (Sergi e cols., Verreault e cols., Faulkner e cols. e Chan e cols.). Os dois primeiros verificaram a velocidade em um percurso de 4 metros e os dois últimos, em um percurso de 6 metros. O manuscrito de Sergi e cols. não descreveu a velocidade, mas esta pôde ser calculada a partir do tempo de caminhada de cada participante. Dois estudos relataram também o tempo de marcha em segundos (Sergi e cols. e Faulkner e cols.) mas, para fins desta revisão, 
104

consideramos que esse dado está estreitamente ligado à velocidade e, portanto, não foi analisado em separado. Um estudo (Dam e cols.) avaliou o TUG. Sergi e cols. realizaram as avaliações de performance com o SPPB mas, para fins desta revisão, foram utilizados os dados brutos em separado, ou seja, sem considerar a classificação numérica desse método.

Todos os estudos avaliaram força muscular, exceto o de Liu e cols. Dentre os estudos, apenas Scott e cols. não realizaram dinamometria da preensão palmar, enquanto três estudos realizaram dinamometria dos membros inferiores (Verreault e cols. Sergi e cols. e Scott e cols.). Verreault e cols. avaliaram a força isométrica flexora máxima do quadril e extensora máxima do joelho, com duas tentativas em cada membro, sendo considerada a melhor das quatro tentativas; Scott e cols. avaliaram a força isotônica máxima extensora do joelho em ambos os membros simultaneamente; Sergi e cols. avaliaram a força isotônica e isocinética máxima extensora do joelho no lado dominante. Embora utilizando métodos semelhantes, os estudos informaram medidas de associação distintas.

Nenhum estudo avaliou o desenvolvimento de sarcopenia de acordo com critérios da EWGSOP. 
Tabela 2 - estudos incluídos

\begin{tabular}{|c|c|c|c|c|c|c|c|c|c|c|}
\hline autor & $\begin{array}{l}\text { ano } \\
\text { pub }\end{array}$ & local & $\begin{array}{l}\text { delineamento } \\
\end{array}$ & população & amostragem & $\begin{array}{l}\text { exclusão } \\
\end{array}$ & n baseline & $\begin{array}{l}\text { grupos de } \\
25 \mathrm{OHD} \\
(\mathrm{nmol} / \mathrm{L})\end{array}$ & desfechos & instrumentos \\
\hline $\begin{array}{l}\text { Verreault e } \\
\text { cols. }\end{array}$ & 2002 & $\overline{E U A}$ & retrospectivo & $\begin{array}{l}\text { mulheres } \geq \\
65 \text { anos }\end{array}$ & $\begin{array}{l}\text { aleatória simples do banco de } \\
\text { dados do Medicare }\end{array}$ & uso de análogos de vitamina D & 1002 & $<25,25-52,>52$ & $\begin{array}{l}\text { Força } \\
\text { muscular }\end{array}$ & $\begin{array}{l}\text { Dinamometria isométrica de extensão do } \\
\text { quadríceps e flexão do ílio-psoas; } \\
\text { dinamometria da preensão palmar }\end{array}$ \\
\hline & & & & & & & & & $\begin{array}{l}\text { performance } \\
\text { muscular }\end{array}$ & TCS, velocidade de marcha \\
\hline \multirow[t]{2}{*}{ Visser e col } & 2003 & Holanda & prospectivo & $\begin{array}{l}\text { indivíduos } \\
\text { entre } 65 \text { e } 85 \\
\quad \text { anos }\end{array}$ & $\begin{array}{l}\text { populacional, estratificada por } \\
\text { sexo, idade e expectativa de } \\
\text { vida de } 5 \text { anos }\end{array}$ & nenhum & Massa: 331 & $\begin{array}{l}<25,25-50,50- \\
\quad 75,>75\end{array}$ & $\begin{array}{l}\text { massa } \\
\text { muscular }\end{array}$ & DXA \\
\hline & & & & & & & Força: 1008 & & $\begin{array}{l}\text { força } \\
\text { muscular }\end{array}$ & Dinamometria da preensão palmar \\
\hline \multirow[t]{2}{*}{$\begin{array}{l}\text { Faulkner e } \\
\text { cols. }\end{array}$} & 2006 & EUA & retrospectivo & $\begin{array}{l}\text { mulheres } \geq \\
65 \text { anos }\end{array}$ & Populacional, aleatória simples & $\begin{array}{l}\text { portadoras de ATQ bilateral, } \\
\text { afroamericanas, }\end{array}$ & 389 & $\begin{array}{l}15-47,4,50-62,4 \\
64,9-77,4,79,9- \\
222,1\end{array}$ & $\begin{array}{l}\text { Força } \\
\text { muscular }\end{array}$ & Dinamometria da preensão palmar \\
\hline & & & & & & $\begin{array}{l}\text { incapacidade de deambular sem } \\
\text { auxílio de outra pessoa }\end{array}$ & & & $\begin{array}{l}\text { performance } \\
\text { muscular }\end{array}$ & TCS, velocidade de marcha \\
\hline Dam e cols & 2008 & EUA & prospectivo & $\begin{array}{l}\text { Indivíduos } \geq \\
63 \text { anos }\end{array}$ & $\begin{array}{l}\text { populacional, com método } \\
\text { obscuro }\end{array}$ & nenhum & 1069 & $\begin{array}{c}\text { quartis; }<<50,50- \\
75,>75\end{array}$ & $\begin{array}{l}\text { performance } \\
\text { muscular } \\
\text { força } \\
\text { muscular }\end{array}$ & $\begin{array}{c}\text { TCS, TUG } \\
\text { Dinamometria da preensão palmar }\end{array}$ \\
\hline Scott e cols. & 2010 & Australia & prospectivo & $\begin{array}{l}\text { Indivíduos } \\
\text { entre } 50 \text { e } 75 \\
\quad \text { anos }\end{array}$ & $\begin{array}{l}\text { populacional, estratificada por } \\
\text { sexo }\end{array}$ & contraindicação à RM & 1099 & $<50,>50$ & $\begin{array}{l}\text { massa } \\
\text { muscular }\end{array}$ & DXA \\
\hline \multirow[t]{3}{*}{ Sergi e cols. } & 2011 & Itália & prospectivo & $\begin{array}{l}\text { mulheres } \geq \\
65 \text { anos }\end{array}$ & $\begin{array}{l}\text { voluntária em um programa de } \\
\text { exercícios físicos }\end{array}$ & $\begin{array}{l}\text { doenças inflamatórias, doença } \\
\text { cardiovascular ou pulmonar, }\end{array}$ & 105 & $<\mathrm{p} 50,>\mathrm{p} 50$ & $\begin{array}{l}\text { força } \\
\text { muscular } \\
\text { massa } \\
\text { muscular }\end{array}$ & $\begin{array}{c}\text { Dinamometria isotônica de extensão } \\
\text { ambos os quadríceps } \\
\text { DXA }\end{array}$ \\
\hline & & & & & & $\begin{array}{l}\text { doenças metabólicas ou } \\
\text { endócrinas "não controladas" }\end{array}$ & & & $\begin{array}{l}\text { Força } \\
\text { muscular }\end{array}$ & $\begin{array}{l}\text { Dinamometria isotônica e isocinética de } \\
\text { extensão do quadríceps dominante; } \\
\text { preensão palmar }\end{array}$ \\
\hline & & & & & & & & & $\begin{array}{l}\text { performance } \\
\text { muscular }\end{array}$ & SPPB \\
\hline Chan e cols. & 2012 & China & prospectivo & $\begin{array}{l}\text { Homens } \geq 65 \\
\text { anos }\end{array}$ & $\begin{array}{l}\text { populacional, estratificada por } \\
\text { idade }\end{array}$ & nenhum & 939 & $<50,50-75,>75$ & $\begin{array}{l}\text { massa } \\
\text { muscular }\end{array}$ & MMEA \\
\hline & & & & & & & & & $\begin{array}{l}\text { Força } \\
\text { muscular } \\
\text { performance } \\
\text { muscular }\end{array}$ & $\begin{array}{l}\text { Dinamometria da preensão palmar } \\
\text { TCS, velocidade de marcha }\end{array}$ \\
\hline Liu e cols. & 2014 & China & prospectivo & $\begin{array}{l}\text { indivíduos } \\
\text { entre } 65 \text { e } 85 \\
\quad \text { anos }\end{array}$ & $\begin{array}{l}\text { populacional, estratificada por } \\
\text { sexo e distrito de origem }\end{array}$ & $\begin{array}{c}\text { "Doenças transmissíveis", } \\
\text { doença de Alzheimer ou outras } \\
\text { demências, incapacidade } \\
\text { funcional grave, câncer, } \\
\text { "doenças psicológicas graves", } \\
\text { doença coronariana }\end{array}$ & 568 & $\begin{array}{c}<41,47,41,47- \\
57,1,>57,1\end{array}$ & $\begin{array}{l}\text { massa } \\
\text { muscular }\end{array}$ & MMEA \\
\hline
\end{tabular}

Ano pub: ano de publicação; 25OHD: 25-hidroxivitamina D. TCS: Timed Chair Stands; DXA: absorciometria por difusão de raios-X; TUG:Timed Up and Go; SPPB: Short Physical Performance

Battery; MMEA: massa muscular esquelética apendicular. ATQ: artroplastia total do quadril 
Tabela 3 - características basais dos indivíduos incluídos em cada estudo.

\begin{tabular}{|c|c|c|c|c|c|c|c|c|c|}
\hline variável & Scott e cols. 2010 & Sergi e cols. 2011 & Faulkner e cols. 2006 & Dam e cols. 2008 & Verreault e cols. 2002 & Visser e cols. 2003 & Chan e cols. 2012 & Liu e cols. 2014 & Média (DP) \\
\hline $250 \mathrm{HD}(\mathrm{nmol} / \mathrm{L})$ & $54,5(19)$ & $70,5(30,2)$ & $64,4(26,8)$ & $41,9(14,1)$ & $47,7(29)$ & & $77,9(7,1)$ & $51,5(20,1)$ & $68,0(18,8)$ \\
\hline PTH (ng/L) & & $55,4(27,4)$ & $35(23,7)$ & $50,5(25,4)$ & $49,41(1,6)$ & & 4,1 & & $38,9(20,9)$ \\
\hline $\operatorname{IMC}\left(\mathbf{k g} / \mathbf{m}^{2}\right)$ & $27,4(4,4)$ & $26,3(3,4)$ & $26,6(4,6)$ & $25,6(4,1)$ & $28,4(6,8)$ & $26,8(4) / 26,6(3,9)$ & $23,1(3,1)$ & $23,8(3,1)$ & $25,9(1,9)$ \\
\hline Idade (anos) & $61,8(7,1)$ & $70,5(4)$ & $72(5,3)$ & $74,5(10,3)$ & $77,4(8,1)$ & $74,4(6,2) / 73,9(6)$ & $72,8(5,1)$ & $57,2(5,2)$ & $66,4(10,5)$ \\
\hline Sexo feminino (\%) & 49,3 & 100 & 100 & 61 & 100 & $52,6 / 52$ & 0 & 61,1 & $67,3(36,8)$ \\
\hline Preensão palmar (KgF) & & $18,4(6,6)$ & $20,5(4,3)$ & $23,4(9,8)$ & $20,4(5,6)$ & $57,6(20,2)$ & $30,6(6,7)$ & & $28,5(14,9)$ \\
\hline MMEA (kg) & $24,7(5,3)$ & $16,2(1,93)$ & & & & $18,1(4,3)$ & $19(2,6)$ & $17,5(4)$ & $19,1(3,3)$ \\
\hline $\operatorname{TCS}(\mathrm{s})$ & & $10,4(3,8)$ & $11,9(2,5)$ & $10,9(3)$ & $15,4(4,7)$ & & 12,1 & & $12,1(1,9)$ \\
\hline Vel caminhada $(\mathrm{m} / \mathrm{s})$ & & $1,3(0,3)$ & $1,0(0,2)$ & & $0,6(0,3)$ & & $1,1(0,2)$ & & $1,0(0,3)$ \\
\hline
\end{tabular}

25OHD: 25-hidroxivitamina D; PTH: paratormônio; MMEA: massa muscular esquelética apendicular; TCS: Timed Chair Stands; vel: velocidade. No estudo de Visser e cols., o primeiro número

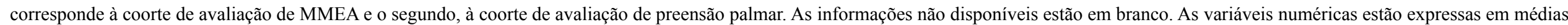
(DP). 


\subsection{Resultados dos estudos selecionados}

\subsubsection{Performance muscular}

No estudo de Dam e cols., as mulheres no primeiro quartil de 25OHD basal tiveram maior aumento percentual do TCS do que os pacientes do $4^{\circ}$ quartil e houve um aumento progressivamente maior ao longo dos quartis, nas análises ajustadas. Não houve diferenças significativas entre os homens. Em quatro estudos (Sergi e cols., Faulkner e cols., Verreault e cols. e Chan e cols.), não foram encontradas diferenças significativas entre os grupos analisados.

No estudo de Dam e cols., as mulheres no primeiro quartil de 25OHD tiveram maior aumento percentual no TUG do que as mulheres do $4^{\circ}$ quartil e houve um aumento percentual progressivamente maior ao longo dos quartis nas análises ajustadas. Não houve diferenças significativas entre os homens.

Os quatro estudos que avaliaram a velocidade de marcha (em metros/segundo) não encontraram diferenças significativas entre os grupos analisados.

\subsubsection{Massa muscular}

Visser e cols. relataram um maior OR para redução da MMEA no grupo com 25OHD basal entre 25 e $50 \mathrm{nmol} / \mathrm{L}$, em relação ao grupo com $25 \mathrm{OHD}$ basal $>50 \mathrm{nmol} / \mathrm{L}$; o grupo com $25 \mathrm{OHD}$ basal $<25 \mathrm{nmol} / \mathrm{L}$ não apresentou diferença significativa em relação ao grupo com $25 \mathrm{OHD}>50 \mathrm{nmol} / \mathrm{L}$, mas o número de indivíduos avaliados no grupo com $25 \mathrm{OHD}<25$ nmol/L foi pequeno. Scott e cols. e Chan e cols. não identificaram correlação entre os níveis de $25 \mathrm{OHD}$ basal e a perda de MMEA. Liu e cols. evidenciaram maior perda de MMEA em pacientes com menores níveis de 25OHD. Sergi e cols. não informaram os resultados da avaliação entre os grupos. Nós realizamos um teste de correlação de Spearman com os dados fornecidos por Sergi e cols. e não encontramos correlação entre 25OHD e o declínio da $\operatorname{MMEA}(\mathrm{R}=-0,14(-0,33 ; 0,05), \mathrm{p}=0,516)$.

\subsubsection{Força muscular}

Quatro estudos (Dam e cols., Sergi e cols., Verreault e cols. e Chan e cols.) não identificaram diferenças significativas entre os grupos analisados, em relação à dinamometria 
108

da preensão palmar; Visser e cols. mostraram redução mais acentuada da força de preensão palmar em indivíduos alocados no primeiro tercil de 25OHD basal em comparação ao último tercil.

O estudo de Scott e cols. mostrou correlação negativa entre níveis de 25OHD basal e perda de força isotônica extensora do joelho. Verreault e cols. e Sergi e cols. não identificaram diferenças significativas entre os grupos analisados.

A flexão do quadril avaliada pela dinamometria não mostrou diferença entre os grupos analisados (Verreault e cols.).

\subsection{Metanálise}

Os estudos trataram os dados de formas distintas, no tocante à divisão dos grupos de acordo com níveis de 25OHD, à avaliação dos desfechos como variável numérica ou dicotômica e aos métodos estatísticos. Por isso, decidimos utilizar os dados brutos para viabilizar as análises. Cinco autores responderam às solicitações (18-19, 21,22,25) permitindo agrupar os dados de quatro desfechos: dinamometria da preensão palmar, MMEA, TCS e velocidade de caminhada.

Os indivíduos nos quartis mais baixos de 25OHD foram mais idosos, mais pesados, tiveram pior avaliação basal e no seguimento nos desfechos "preensão palmar" e "velocidade de marcha"; foram mais idosos e mais pesados no desfecho "TCS"; foram mais pesados, tiveram pior avaliação basal e de seguimento no desfecho MMEA (todos com p<0,001) (tabela 4).

$\mathrm{Na}$ avaliação final, 836 indivíduos foram avaliados com a velocidade de marcha, 1373 com TCS, 1220 com dinamometria da preensão palmar e 785 com a MMEA.

A média anual do declínio da dinamometria da preensão palmar e MMEA foi de 0,28 $( \pm 1,76) \mathrm{KgF}$ e $0,43( \pm 0,54) \mathrm{kg}$, respectivamente. O TCS e velocidade de marcha tiveram incremento médio anual de $0,02( \pm 1,5)$ s e $0,01( \pm 0,09) \mathrm{m} / \mathrm{s}$, respectivamente. Os indivíduos no $1^{\circ}$ quartil de 25OHD basal tiveram maior declínio da preensão palmar do que os indivíduos no terceiro $(p=0,02)$ e quarto quartis $(p=0,001)$. Não houve diferenças entre o segundo, terceiro e quarto quartis. Não houve diferenças significativas nos outros desfechos (tabela 5).

O modelo linear generalizado não identificou associação entre a 25OHD basal e os desfechos avaliados (velocidade de marcha: $p=0.516$; TCS: $p=0.231$; preensão palmar: 
$\mathrm{p}=0.420$; MMEA: $\mathrm{p}=0.260$ ). A origem do estudo foi a única variável associada com a variabilidade ( $<<0,001$ para todos os desfechos).

Tabela 4 - Dados basais dos indivíduos participantes dos estudos incluídos, de acordo com os quartis de 25hidroxivitamina D (25OHD).

\begin{tabular}{|c|c|c|c|c|c|}
\hline \multirow{3}{*}{ Desfecho } & \multicolumn{4}{|c|}{ quartis 25OHD } & \multirow{3}{*}{$\mathrm{p}$} \\
\hline & 1 & 2 & 3 & 4 & \\
\hline & média (DP) & média (DP) & média (DP) & média (DP) & \\
\hline \multicolumn{6}{|l|}{ Preensão palmar } \\
\hline idade (anos) & $76,6(7,8)$ & $74,4(9,6)$ & $73,8(9,9)$ & $72,8(9,9)$ & $<0,001$ \\
\hline $\operatorname{IMC}\left(\mathrm{kg} / \mathrm{m}^{2}\right)$ & $28,7(6,5)$ & $26,1(4,4)$ & $25,7(4,0)$ & $25,5(3,7)$ & $<0,001$ \\
\hline preensão palmar basal (KgF) & $20,4(5,4)$ & $22,3(8,1)$ & $23,6(8,7)$ & $24,5(9,7)$ & $<\mathbf{0 , 0 0 1}$ \\
\hline preensão palmar seguimento $(\mathrm{KgF})$ & $19,1(6,5)$ & $22,0(, 6)$ & $23,6(9,2)$ & $24,8(10,3)$ & $<\mathbf{0 , 0 0 1}$ \\
\hline \multicolumn{6}{|l|}{ TCS } \\
\hline idade (anos) & $77,1(7,8)$ & $76(8,2)$ & $73,8(10)$ & $72,2(9,5)$ & $<0,001$ \\
\hline $\operatorname{IMC}\left(\mathrm{kg} / \mathrm{m}^{2}\right)$ & $28,6(6,7)$ & $27(5,4)$ & $25,9(4,3)$ & $25,5(3,6)$ & $<\mathbf{0 , 0 0 1}$ \\
\hline TCS basal (s) & $14,4(5,1)$ & $14(4,5)$ & $14,3(3,6)$ & $14,2(3,5)$ & 0,531 \\
\hline TCS seguimento (s) & $13,3(4,5)$ & $13,8(5,6)$ & $14,2(4,7)$ & $13,7(3,8)$ & 0,059 \\
\hline \multicolumn{6}{|l|}{ Vel marcha } \\
\hline idade (anos) & $77,8(7,8)$ & $75,8(7,5)$ & $75(7,2)$ & $73,9(7)$ & $<\mathbf{0 , 0 0 1}$ \\
\hline $\operatorname{IMC}\left(\mathrm{kg} / \mathrm{m}^{2}\right)$ & $29,5(7,3)$ & $28,1(6,3)$ & $27,5(5,8)$ & $26,7(4,9)$ & $<\mathbf{0 , 0 0 1}$ \\
\hline Vel basal (m/s) & $0,8(0,4)$ & $0,7(0,4)$ & $0,8(0,3)$ & $0,9(0,3)$ & $<0,001$ \\
\hline Vel seguimento $(\mathrm{m} / \mathrm{s})$ & $0,8(0,4)$ & $0,8(0,4)$ & $0,8(0,4)$ & $0,9(0,4)$ & $<0,001$ \\
\hline \multicolumn{6}{|l|}{ MMEA } \\
\hline idade (anos) & $61,9(7,8)$ & $62,2(7,2)$ & $62,2(6,7)$ & $61,1(6,8)$ & 0,444 \\
\hline IMC $\left(\mathrm{kg} / \mathrm{m}^{2}\right)$ & $28,5(5,4)$ & $27,5(4,2)$ & $27,5(3,8)$ & $26,2(3,7)$ & $<0,001$ \\
\hline MMEA basal (kg) & $22,3(5,5)$ & $23,6(5,7)$ & $25,1(5,7)$ & $23,7(5,8)$ & $<0,001$ \\
\hline MMEA seguimento (kg) & $21,3(5)$ & $22,4(5,2)$ & $23,8(5,3)$ & $22,5(5,5)$ & $<\mathbf{0 , 0 0 1}$ \\
\hline
\end{tabular}

Os quartis de 25OHD foram 53,75 e $72 \mathrm{nmol} / \mathrm{L}$ para velocidade de marcha; 52,5, 80 e $105 \mathrm{nmol} / \mathrm{L}$ para Timed Chair Stands (TCS); 53,5, 85 e 107, $5 \mathrm{nmol} / \mathrm{L}$ para preensão palmar; 38, 54 e $68 \mathrm{nmol} / \mathrm{L}$ para massa muscular esquelética apendicular (MMEA). Os dados estão divididos de acordo com cada desfecho avaliado. IMC: índice de massa corporal. Vel: velocidade. 
Tabela 5 - Comparação de médias das diferenças entre os valores de seguimento e basais dos desfechos avaliados, de acordo com os quartis de 25-hidroxivitamina D (25OHD).

\begin{tabular}{|c|c|c|c|c|c|}
\hline \multirow{3}{*}{$\Delta$ desfechos } & \multicolumn{4}{|c|}{ quartis $250 H D$} & \multirow{3}{*}{$\mathrm{p}$} \\
\hline & 1 & 2 & 3 & 4 & \\
\hline & média (DP) & média (DP) & média (DP) & média (DP) & \\
\hline Vel marcha $(\mathrm{m} / \mathrm{s})$ & $-0,2(0,1)$ & $0,00(0,1)$ & $-0,01(0,1)$ & $-0,014(0,1)$ & 0,44 \\
\hline TCS (s) & $-0,01(1,4)$ & $0,04(1,6)$ & $0,00(1,54)$ & $-0,1(1,44)$ & 0,548 \\
\hline Preensão palmar $(\mathrm{KgF})$ & $-0,5(1,58)$ & $-0,3(1,43)$ & $-0,2(1,48)$ & $-0,15(1,33)$ & $\mathbf{0 , 0 0 2}$ \\
\hline MMEA (kg) & $-0,36(0,55)$ & $-0,43(0,51)$ & $-0,5(0,56)$ & $-0,44(0,04)$ & 0,092 \\
\hline
\end{tabular}

Os quartis de 25OHD foram 53,75 e $72 \mathrm{nmol} / \mathrm{L}$ para velocidade de marcha (vel marcha); 52,5, 80 e $105 \mathrm{nmol} / \mathrm{L}$ para Timed Chair Stands (TCS); 53,5, 85 e 107, $5 \mathrm{nmol} / \mathrm{L}$ para preensão palmar; 38, 54 e $68 \mathrm{nmol} / \mathrm{L}$ para massa muscular esquelética apendicular (MMEA).

Tabela 6 - Comparação de médias de covariáveis entre os pacientes que completaram o seguimento e os que perderam.

\begin{tabular}{|c|c|c|c|}
\hline & seguimento completo & perda de seguimento & $\mathrm{p}$ \\
\hline \multicolumn{4}{|l|}{ Preensão palmar } \\
\hline basal (KgF) & $22,65(7,8)$ & $19,88(7,2)$ & $<0,001$ \\
\hline 25OHD (nmol/L) & $83,05(40,9)$ & $73,69(34,9)$ & $<0,001$ \\
\hline idade (anos) & $73,7(8,3)$ & $78,08(9,9)$ & $<0,001$ \\
\hline $\operatorname{IMC}\left(\mathrm{kg} / \mathrm{m}^{2}\right)$ & $26,87(5,2)$ & $26,15(5,4)$ & 0,008 \\
\hline \multicolumn{4}{|l|}{ TCS } \\
\hline basal (s) & $13,61(3,6)$ & $15,7(5,2)$ & $<0,001$ \\
\hline 25OHD (nmol/L) & $84,35(41,9)$ & $74,85(35,5)$ & $<0,001$ \\
\hline idade (anos) & $73,64(7,3)$ & $76,34(11,3)$ & $<0,001$ \\
\hline $\mathrm{IMC}\left(\mathrm{kg} / \mathrm{m}^{2}\right)$ & $26,72(5)$ & $26,71(5,9)$ & 0,952 \\
\hline \multicolumn{4}{|l|}{ Vel marcha } \\
\hline basal (m/s) & $0,89(0,3)$ & $0,66(0,3)$ & $<0,001$ \\
\hline 25OHD (nmol/L) & $58,79(29,4)$ & $53,61(25,7)$ & 0,006 \\
\hline idade (anos) & $74,18(6,8)$ & $77,99(8)$ & $<0,001$ \\
\hline IMC $\left(\mathrm{kg} / \mathrm{m}^{2}\right)$ & $27,93(6,2)$ & $27,43(5,9)$ & 0,239 \\
\hline
\end{tabular}

No desfecho massa muscular esquelética apendicular, os dados de pacientes com perda de seguimento não estiveram disponíveis. Basal: valor de cada variável dependente aferido na primeira avaliação. TCS: Timed Chair Stands. Vel: velocidade.

Foi realizada comparação de médias post hoc, com teste t de Student, de covariáveis entre os pacientes que completaram o seguimento e os que perderam, nas quatro casuísticas avaliadas (tabela 6). No desfecho MMEA, não tivemos acesso aos dados de pacientes com perda de seguimento. Os pacientes com perda de seguimento apresentaram, em média, menores valores de 25OHD, maior idade e piores valores basais, em todos os desfechos 
avaliados. No desfecho "preensão palmar", além das diferenças descritas acima, os pacientes apresentaram menores valores de IMC.

\section{Discussão}

Nos últimos anos, novos estudos sobre sarcopenia foram publicados, o que culminou com a definição de critérios classificatórios pela EWGSOP em 2010 (1). A adoção desses critérios tem permitido uma homogeneidade na realização de estudos observacionais e ensaios clínicos randomizados.

Os estudos selecionados para a presente revisão foram, de certa forma, homogêneos no que diz respeito aos instrumentos de avaliação utilizados, o que permitiu aos revisores proceder metanálises com dados de quatro desfechos.

A avaliação transversal mostrou associação entre 25OHD basal e características clínicas que podem representar um pior estado de saúde. No entanto, o modelo de efeitos aleatórios não apontou uma relação independente entre $25 \mathrm{OHD}$ e a variação das variáveis avaliadas, sugerindo que baixos níveis de $25 \mathrm{OHD}$ não teriam relação de causalidade com o desenvolvimento de sarcopenia.

Três estudos (Verreault e cols., Faulkner e cols., e Chan e cols.) incluíram poucos indivíduos nos estratos mais baixos de 25OHD. Isso ocorreu no estudo de Verreault e cols., apesar de ter sido selecionado o tercil de indivíduos mais incapacitados e de terem sido excluídos os indivíduos em uso de suplementação de vitamina D. Tal configuração pode ser justificada pelo fato de os pacientes que não realizaram dosagem de $25 \mathrm{OHD}$ ( $33 \%$ dos casos) terem sido mais idosos, com menor índice de massa corporal e maior incapacidade nas atividades de vida diária. Faulkner e cols. excluíram afroamericanos, com a justificativa de que estes têm risco baixo de fraturas; tal grupo étnico apresenta menores níveis de 25OHD em comparação com a população caucasiana (26). Chan e cols. incluíram voluntários, que provavelmente correspondem a indivíduos mais saudáveis, com maiores níveis de 25OHD. Em síntese, em todos esses estudos, não foram comparados pacientes com valores extremos de 25OHD, o que pode ter acarretado em erro tipo I.

Os estudos tiveram perdas de seguimento entre 5 e $51 \%$. Chan e cols. descreveram que os pacientes que não completaram o seguimento eram, em média, mais idosos, tinham menor Índice de Qualidade Alimentar, mais sedentários, tinham menor nível de atividade física, 
112

MMEA mais baixa e com maior número de comorbidades crônicas. Tais perdas podem ter homogeneizado a amostra, causando o mesmo efeito descrito acima.

Apenas dois estudos que avaliaram performance muscular incluíram homens $(22,23)$.

Somente Dam e cols. identificaram piora do TCS nos grupos com níveis mais baixos de 25OHD, mas somente na população feminina. As diferenças entre os estudos podem ser explicada pelos diferentes métodos de amostragem. No estudo de Dam e cols., os homens tiveram menor declínio do TCS por ano, por isso o tempo de seguimento desses indivíduos pode ter sido insuficiente para verificar diferenças entre os grupos. A metanálise não mostrou associação entre 25OHD e o declínio do TCS.

Dam e cols. foram os únicos que avaliaram o TUG. Nesse estudo, somente as mulheres tiveram diferenças entre os estratos de 25OHD. Outros estudos são necessários para confirmar esse achado.

Visser e cols. identificaram maior declínio da preensão palmar em pacientes com níveis mais baixos de 25OHD, o que não foi confirmado pelos outros estudos. Isso poderia ter mudado o resultado encontrado na metanálise, se seus dados tivessem sido incluídos. Sergi e cols. incluíram voluntários de um programa de exercícios físicos, o que poderia ter minimizado o declínio da preensão palmar, atenuando as diferenças entre os grupos. Contudo, isso não aconteceu de fato, pois a média do declínio da preensão palmar dos indivíduos de Sergi e cols. não diferiu das outras casuísticas. Os pacientes no primeiro quartil de 25OHD basal tiveram maior declínio anual da preensão palmar na análise dos dados agrupados, mas o modelo de efeitos aleatórios mostrou apenas efeito da origem do estudo na variabilidade dos dados, o que sugere que a vitamina $\mathrm{D}$ pode ter diferentes efeitos na força muscular, de acordo com a população estudada.

O declínio da força muscular nos membros inferiores foi avaliado em três estudos $(18,21,25)$, mas o único que demostrou maior declínio da força muscular em estratos mais baixos de 25OHD foi o de Scott e cols., o que pode ter ocorrido por heterogeneidade entre os métodos de medição, conforme descrito acima, ou por diferenças populacionais.

Os estudos tiveram resultados contraditórios em relação à 25OHD e perda de massa muscular. Alguns desses estudos não estiveram disponíveis para a metanálise, o que limitou as conclusões.

A análise dos indivíduos que perderam o seguimento identificou que esse grupo possui diferenças clínicas significativas em relação ao restante da casuística. Os achados sugerem 
que as perdas de seguimento não são aleatórias, mas provavelmente estão relacionadas a uma pior condição clínica, como foi descrito em Dam e cols. (22).

No nosso conhecimento, esta é a primeira revisão sistemática de coortes que avaliou o declínio da força, massa e performance muscular ao longo do tempo considerando a dosagem sérica de 25OHD como variável independente.

Até a data da busca nas bases de dados descrita acima, nenhuma coorte avaliando o desenvolvimento de sarcopenia definida pelos critérios da EWGSOP, de acordo com os níveis de 25OHD, havia sido publicada.

Esta revisão tem limitações. Primeiro, o paratormônio (PTH) pode ser preditor para o desenvolvimento de perda de massa muscular, por isso não podemos descartar a possibilidade de os indivíduos nos estudos terem diferentes níveis séricos de PTH, já que a relação entre PTH e 25OHD não é linear. Segundo, os estudos incluídos representam populações de vários continentes, o que permite certa generalização dos resultados em países desenvolvidos, porém países em desenvolvimento não foram representados.

Concluindo, a associação entre os níveis de 25OHD basais e o declínio de performance muscular não foi identificada quando medida pelo TCS e pela velocidade de caminhada e esteve presente quando medida pelo TUG, em um único estudo. Não foi encontrada associação independente entre 25OHD e o declínio da força de preensão palmar. Não está clara a associação entre $25 \mathrm{OHD}$ e a perda de força nos membros inferiores. A avaliação da associação entre 25OHD e declínio da MMEA avaliada por DXA foi inconclusiva.

Sugerimos a realização de novos estudos prospectivos para avaliar a relação entre vitamina D e sarcopenia, preferencialmente multicêntricos, incluindo países em desenvolvimento, utilizando estratégias para minimizar o viés das perdas de seguimento dos indivíduos em pior condição clínica.

\section{Referências}

1. Cruz-Jentoft AJ, Baeyens JP, Bauer JM, Boirie Y, Cederholm T, Landi F, et al. Sarcopenia: European consensus on definition and diagnosis: Report of the European Working Group on Sarcopenia in Older People. Age Ageing. 2010;39(4):412-23.

2. Fielding RA, Vellas B, Evans WJ, Bhasin S, Morley JE, Newman AB, et al. Sarcopenia: an undiagnosed condition in older adults. Current consensus definition: 
114

prevalence, etiology, and consequences. International working group on sarcopenia. J Am Med Dir Assoc. 2011;12(4):249-56.

3. MacLaughlin J, \& Holick MF. Aging decreases the capacity of human skin to produce vitamin D3. J Clin Invest. 1985;76(4):1536-8.

4. Saraiva GL, Cendoroglo MS, Ramos LR, Araujo LM, Vieira JG, Maeda SS, et al. Prevalência da deficiência, insuficiência de vitamina $\mathrm{D}$ e hiperparatiroidismo secundário em idosos institucionalizados e moradores na comunidade da cidade de Sao Paulo, Brasil. Arq Bras Endocrinol Metab. 2007;51(3):437-42.

5. Bhan A, Rao AD, Rao DS. Osteomalacia as a result of vitamin D deficiency. Rheum Dis Clin North Am. 2012 Feb;38(1):81-91, viii - ix.

6. Roth SM, Zmuda JM, Cauley JA, Shea PR, Ferrell RE. Vitamin D receptor genotype is associated with fat-free mass and sarcopenia in elderly men. J Gerontol A Biol Sci Med Sci. 2004;59(1):10-5.

7. Onder G, Capoluongo E, Danese P, Settanni S, Russo A, Concolino P, et al. Vitamin D receptor polymorphisms and falls among older adults living in the community: results from the ilSIRENTE study. J Bone Min Res. 2008;23(7):1031-6.

8. Tagliafico AS, Ameri P, Bovio M, Puntoni M, Capaccio E, Murialdo G, et al. Relationship between fatty degeneration of thigh muscles and vitamin $\mathrm{D}$ status in the elderly: a preliminary MRI study. Am J Roentgenol. 2010;194(3):728-34.

9. Sato Y, Iwamoto J, Kanoko T, Satoh K. Low-dose vitamin D prevents muscular atrophy and reduces falls and hip fractures in women after stroke: a randomized controlled trial. Cerebrovasc Dis. 2005;20(3):187-92.

10. Dhesi JK, Jackson SH, Bearne LM, Moniz C, Hurley M V, Swift CG, et al. Vitamin D supplementation improves neuromuscular function in older people who fall. Age Ageing. 2004;33(6):589-95.

11. Pfeifer M, Begerow B, Minne HW, Suppan K, Fahrleitner-Pammer A, Dobnig H. Effects of a long-term vitamin D and calcium supplementation on falls and parameters of muscle function in community-dwelling older individuals. Osteoporos Int. 2009;20(2):31522.

12. Murad MH, Elamin KB, Abu Elnour NO, Elamin MB, Alkatib AA, Fatourechi MM, et al. Clinical review: The effect of vitamin D on falls: a systematic review and meta-analysis. $\mathrm{J}$ Clin Endocrinol Metab. 2011;96(10):2997-3006.

13. Liberati A, Altman DG, Tetzlaff J, Mulrow C, Gotzsche PC, Ioannidis JP, et al. The PRISMA statement for reporting systematic reviews and meta-analyses of studies that evaluate health care interventions: explanation and elaboration. J Clin Epidemiol. 2009;62(10):e1-34. 
14. Wells GA., Shea B., O'Connell D., Peterson J., Welch V., Losos V., et al. The Newcastle-Ottawa Scale (NOS) for assessing the quality of nonrandomised studies in metaanalyses. Ottawa Hospital Research Institute; 2010. Disponível em: http://www.ohri.ca/programs/clinical_epidemiology/oxford.asp.

15. Cunha BM, Maria Henrique da Mota L, Dos Santos-Neto LL. Risk of orthopedic surgical site infections in patients with rheumatoid arthritis treated with antitumor necrosis factor alfa therapy. Int J Rheumatol. 2012:369565.

16. Zhao Y, Sun Y, Ji H-F, Shen L. Vitamin D levels in Alzheimer's and Parkinson's diseases: a meta-analysis. Nutrition. 2013;29(6):828-32.

17. Opara JA. Activities of daily living and quality of life in Alzheimer disease. J Med Life. $2012 ; 5(2): 162-7$.

18. Verreault R, Semba RD, Volpato S, Ferrucci L, Fried LP, Guralnik JM. Low serum vitamin d does not predict new disability or loss of muscle strength in older women. J Am Geriatr Soc. 2002;50(5):912-7.

19. Faulkner K, Cauley J, Zmuda JM, Landsittel DP, Newman B, Studenski S, et al. Higher 1,25-dihydroxyvitamin D3 concentrations associated with lower fall rates in older community-dwelling women. Osteoporos Int. 2006;17(9):1318-28.

20. Visser M, Deeg DJ, Lips P. Low vitamin D and high parathyroid hormone levels as determinants of loss of muscle strength and muscle mass (sarcopenia): the Longitudinal Aging Study Amsterdam. J Clin Endocrinol Metab. 2003;88(12):5766-72.

21. Sergi G, Sarti S, Mosele M, Ruggiero E, Imoscopi A, Miotto F, et al. Changes in healthy elderly women's physical performance: a 3-year follow-up. Exp Gerontol. 2011;46(11):929-33.

22. Dam TT, von Muhlen D, Barrett-Connor EL. Sex-specific association of serum vitamin D levels with physical function in older adults. Osteoporos Int. 2009;20(5):751-60.

23. Chan R, Chan D, Woo J, Ohlsson C, Mellström D, Kwok T, et al. Not all elderly people benefit from vitamin D supplementation with respect to physical function: results from the Osteoporotic Fractures in Men Study, Hong Kong. J Am Geriatr Soc. 2012;60(2):290-5.

24. Liu G, Lu L, Sun Q, Ye X, Sun L, Liu X, et al. Poor vitamin D status is prospectively associated with greater muscle mass loss in middle-aged and elderly Chinese individuals. J Acad Nutr Diet. 2014;114(10):1544-51.e2.

25. Scott D, Blizzard L, Fell J, Ding C, Winzenberg T, Jones G. A prospective study of the associations between 25-hydroxy-vitamin $\mathrm{D}$, sarcopenia progression and physical activity in older adults. Clin Endocrinol. 2010;73(5):581-7.

26. Kant AK, Graubard BI. Race-ethnic, family income, and education differentials in nutritional and lipid biomarkers in US children and adolescents: NHANES 2003-2006. Am J Clin Nutr. 2012;96(3):601-12. 
APÊNDICE B

\section{COORTE SARAR: ATIVIDADE DE DOENÇA, CAPACIDADE FUNCIONAL E DANO RADIOLÓGICO NA ARTRITE REUMATOIDE DE LONGA EVOLUÇÃO}

Cunha BM, Oliveira SB, Santos-Neto LL

Publicado na Revista Brasileira de Reumatologia na edição de setembro/outubro de 2015

\section{Resumo}

Objetivos: avaliar fatores clínicos e laboratoriais que estão associados à atividade de doença, capacidade funcional e dano radiológico em pacientes com artrite reumatoide (AR) submetidos a artroplastias de quadril e joelho. Métodos: estudo transversal, com coleta de dados em revisão de prontuário. Resultados: 32 pacientes foram incluídos, com tempo médio de início da doença de 240 meses e intervalo médio entre o início e o diagnóstico de 27 meses. Foi encontrada correlação positiva entre dose máxima de metotrexato (MTX) durante a evolução e Clinical Disease Activity Index (CDAI) $(\mathrm{R}=-0,46, \mathrm{p}=0,011)$ e negativa com Simplified Erosion and Narrowing Score (SENS) $(\mathrm{R}=-0,58, \mathrm{p}=0,004)$. Valores de SENS foram maiores nos pacientes com fator reumatoide $(\mathrm{FR})(\mathrm{p}=0,005)$ e anti-CCP3 positivo $(p=0,044)$, nos com maiores títulos de FR $(p=0,037)$ e Anti-CCP3 $(p=0,025)$ e menores nos pacientes com história de familiar de AR $(p=0,009)$. Valores de HAQ foram maiores em pacientes mais idosos $(\mathrm{p}=0,031)$. Na regressão linear múltipla, somente as variáveis “dose máxima de MTX" e "história familiar" permaneceram com associação significativa. O modelo final explicou aproximadamente $73 \%$ da variabilidade de SENS. No modelo que avaliou a variável independente "CDAI", apenas "dose máxima de MTX" permaneceu com associação significativa $\left(\mathrm{r}^{2}=0,35, \mathrm{p}=0,016\right)$. Conclusão: fatores clínicos e laboratoriais estiveram relacionados à atividade de doença, capacidade funcional e dano radiológico, de forma semelhante a estudos que avaliaram pacientes com menor tempo de doença.

Palavras-chave: artrite reumatoide, artroplastia, dano radiológico, capacidade funcional, atividade de doença 


\section{Introdução}

A artrite reumatoide (AR) é doença comum no Brasil, acometendo 0,2 a 1\% da população brasileira ${ }^{1}$. As diretrizes brasileiras de tratamento da artrite reumatoide recomendam o uso precoce de pelo menos uma droga modificadora do curso da doença (DMCD), associada ou não ao uso de corticosteroides, no tratamento da doença, desde o seu início $^{2}$. O objetivo principal é evitar ou ao menos retardar a progressão das lesões osteoarticulares, que podem levar a deformidades e grande incapacidade funcional, com redução da qualidade de vida e capacidade laboral. No entanto, o tratamento da AR é ainda, muitas vezes, subótimo em nosso meio ${ }^{3}$ e, com isso, muitos pacientes evoluem com osteoartrite secundária, necessitando de tratamento cirúrgico com artroplastia total, o que aumenta significativamente os custos de assistência à saúde ${ }^{4}$.

A Rede SARAH é um centro de referência em reabilitação no Brasil, com unidades em várias unidades da federação, incluindo o Distrito Federal. A instituição dá enfoque ao tratamento de pacientes portadores de AR ou artrite idiopática juvenil (AIJ) em fase avançada, com sequelas permanentes da doença, por meio de cirurgias ortopédicas e reabilitação.

A coorte SARAR é composta por pacientes com AR ou AIJ que participam de programa de reabilitação e fazem acompanhamento ortopédico para as sequelas da doença no hospital SARAH-Brasília. O objetivo dessa coorte é avaliar a evolução desses pacientes após serem submetidos a cirurgias articulares.

As características clínicas dos pacientes com AR candidatos a cirurgias ortopédicas podem ter influência no grau de incapacidade funcional e instabilidade no trabalho ${ }^{5}$, atividade inflamatória e dano radiológico ${ }^{6}$. Por isso, o objetivo deste estudo é avaliar o perfil clínico, radiológico e laboratorial dos pacientes com AR que são encaminhados por serviços de reumatologia e ortopedia e avaliar quais fatores estão associados à atividade de doença, capacidade funcional e dano radiológico.

\section{Métodos}

\subsection{Delineamento}

Análise transversal de dados da coorte SARAR, com aproveitamento de dados gerados na assistência ao paciente. 


\subsection{Critérios de inclusão e exclusão}

Foram incluídos todos os pacientes com idade maior ou igual a 18 anos, internados na enfermaria de Ortopedia e Neurocirurgia Adulto, para se submeterem a artroplastia total de quadril (ATQ) ou joelho (ATJ) no hospital Sarah-Brasília, portadores de AR com diagnóstico firmado a partir dos critérios da American College of Rheumatology ${ }^{7}$. A inclusão ocorreu entre outubro de 2008 e janeiro de 2013.

Foram excluídos os portadores de AR com indicação de artroplastia por necrose óssea avascular, portadores de doenças inflamatórias que justificassem o quadro articular melhor do que a AR, pacientes submetidos a artroplastia prévia no período de inclusão e portadores de AIJ.

\subsection{Coleta de dados}

A avaliação padronizada foi realizada por meio de revisão de dados do prontuário eletrônico, complementada com entrevista ao paciente quando necessário. Foram registrados os seguintes dados: tempo de doença; intervalo de tempo entre o início dos sintomas e o diagnóstico correto; data do início do tratamento com drogas modificadoras do curso da doença (DMCD) com descrição das medicações em uso prévio e atual, incluindo a dose; tempo de acompanhamento com reumatologista; diagnóstico ortopédico pré-operatório; comorbidades autoimunes associadas; história de tabagismo; história familiar de AR; dosagem do fator reumatoide e do anti-CCP3, ambos por ELISA, quando disponíveis, sendo considerado o exame de data mais recente no prontuário.

A atividade inflamatória foi avaliada com o Clinical Disease Activity Index (CDAI) ${ }^{8}$, que leva em consideração, para seu cálculo, a contagem de articulações dolorosas e edemaciadas, o escore de avaliação global de saúde realizada pelo paciente e pelo médico, por meio de escala visual analógica. Neste estudo, foram utilizadas escalas contínuas.

A capacidade funcional pré-operatória foi avaliada com o Health Assessment Questionnaire - Disability Index (HAQ) traduzido e validado para a língua portuguesa, autoaplicado 9,10 .

O dano articular estabelecido foi avaliado com radiografias digitais simples das mãos e pés utilizando o Simplified Erosion Narrowing Score (SENS) ${ }^{11}$, que contabiliza o número de articulações nas quais há a presença de redução do espaço articular e/ou erosões. Para essa 
120

avaliação, foi utilizado o software Efilm Workstation versão 2.1.2, sendo permitido o uso de recursos de ampliação de imagem.

O estudo foi aprovado pelo Comitê de Ética em Pesquisa da Rede SARAH, com registro na Plataforma Brasil número 07477412.2.0000.0022.

\subsection{Análise estatística}

Foi realizada análise descritiva dos dados. Os valores de FR e Anti-CCP3 foram divididos em quatro categorias, sendo os primeiros de acordo com os quartis e os segundos em negativo, positivo fraco, positivo moderado e positivo forte, de acordo com as referências do fabricante. Foram realizados testes de correlação de Spearman entre as variáveis independentes contínuas e as variáveis dependentes (CDAI, HAQ e SENS). Foi realizado o teste U de Mann-Whitney para comparação entre variáveis dependentes contínuas e independentes com duas categorias e o teste $\mathrm{H}$ de Kruskal-Wallis para comparação entre variáveis dependentes contínuas e independentes com mais de duas categorias.

Análise de subgrupos foi realizada, entre os pacientes submetidos a ATQ e ATJ.

Modelo de regressão linear múltipla em etapas foi elaborado, incluindo as variáveis independentes com associação significativa, assumindo uma distribuição normal dos dados.

Para verificar a variabilidade intraexaminador da avaliação das radiografias, foi calculado coeficiente de correlação intraclasse, modelo $3,1^{12}$ e realizado teste t pareado incluindo 10 pacientes, que foram selecionados de forma aleatória, computadorizada, dentre a amostra do estudo.

Os pacotes estatísticos utilizados foram o SOFA versão 1.4.0 e o SPSS versão 21.

\section{Resultados}

As características clínicas dos pacientes estão descritas nas tabelas $\mathbf{1}$ e 2. Trinta e dois casos foram incluídos. Os pacientes encaminhados por serviços do SUS perfizeram $44 \%$ dos casos sendo que, dentre os pacientes oriundos de fora do Distrito Federal, apenas um tinha acompanhamento em serviço público. Cinco pacientes não estavam em acompanhamento regular com reumatologista. Quarenta e oito por cento dos pacientes haviam perdido o acompanhamento com reumatologista durante algum período, desde o primeiro contato com o 
especialista. Dentre os pacientes que tiveram intervalos sem acompanhamento reumatológico, a média de tempo sem acompanhamento foi de 45,6 meses (0-432).

MTX foi utilizado em $84 \%$ dos casos durante a evolução, mas somente $41 \%$ estavam em tratamento corrente. A dose máxima utilizada no curso da doença foi, em média, de 15,1 mg (2,5-20). Cinco pacientes nunca foram tratadas com MTX, uma delas com 115 meses de duração da doença. Apenas dois pacientes não usaram antimalárico durante a evolução. Leflunomida foi usada em $66 \%$ dos casos, sulfassalazina em $31 \%$ e sais de ouro em $22 \%$. Dentre os biológicos (em uso em 31\% dos casos), os mais frequentes foram o etanercepte e adalimumabe, com quatro casos cada. Oitenta e sete por cento dos casos estavam em atividade inflamatória (39\% atividade leve, 23\% moderada e 26\% grave). O FR foi positivo em 51\% dos casos, com valor médio de $371 \mathrm{U} / \mathrm{ml}$ (29-3140). O anti-CCP3 foi positivo em $62 \%$ dos casos, sendo positivo fraco em $3 \%$, moderado em $9 \%$ e forte em $50 \%$. Dentre as comorbidades autoimunes, a única presente foi a doença autoimune da tireoide (com hipo ou hipertireoidismo), em $34 \%$ dos casos.

Tabela 1. Drogas modificadoras de curso da doença (DMCD) em uso corrente.

\begin{tabular}{lcccc}
\hline \multicolumn{1}{c}{ DMCD } & n & \multicolumn{3}{c}{ dose } \\
\cline { 3 - 5 } & & média & DP & min-max \\
\hline metotrexato (mg/dia) & 13 & 14,4 & 2,9 & $2,5-20$ \\
leflunomida (mg/dia) & 15 & 20 & 0 & 20 \\
sulfassalazina (mg/dia) & 2 & 750 & 350 & $500-1000$ \\
cloroquina (mg/dia) & 5 & 250 & 0 & 250 \\
hidroxicloroquina (mg/dia) & 3 & 333,3 & 115,5 & $200-400$ \\
infliximabe (mg/dose) & 1 & 200 & 0 & 200 \\
etanercepte (mg/semana) & 2 & 50 & 0 & 50 \\
adalimumabe (mg/dose) & 3 & 40 & 0 & 40 \\
rituximabe (mg/dose) & 2 & 2000 & 0 & 2000 \\
abatacepte (mg/dose) & 1 & 500 & 0 & 500 \\
\hline
\end{tabular}

O resultado da avaliação das variáveis independentes numéricas está detalhado na tabela 3. Quando analisada a variável dependente "CDAI", Foi encontrada correlação negativa com tempo de início da doença e positiva com a dose máxima de MTX. Na análise da variável dependente "HAQ", foi encontrada correlação positiva com a idade. Quando analisada a variável dependente "SENS", foi encontrada correlação positiva com a dose máxima de MTX. 
Os resultados da avaliação das variáveis independentes categóricas estão detalhados na tabela 4. Quando avaliada a variável dependente "CDAI" e "HAQ", não foram encontradas associações significativas. Na análise da variável dependente "SENS", foi encontrada associação positiva com a presença de FR e Anti-CCP3 e negativa com tabagismo e história familiar de AR. Foi realizada análise entre as categorias de FR e Anti-CCP, sendo que as de títulos mais elevados foram associados a maiores valores de SENS.

Tabela 2. Características gerais dos pacientes

\begin{tabular}{lccc}
\hline \multicolumn{1}{c}{ variável } & n & média & DP \\
\hline idade (anos) & 32 & 59,1 & 10,2 \\
tempo início (meses) & 31 & 240,2 & 148,2 \\
$\Delta$ t início-diag (meses) & 31 & 27 & 64,6 \\
medicações em uso & & & \\
metotrexato (mg) & 13 & 14,4 & 2,9 \\
leflunomida (mg) & 15 & 20 & 0 \\
sulfassalazina (mg) & 2 & 0,75 & 0,35 \\
cloroquina (mg) & 5 & 250 & 0 \\
hidroxicloroquina (mg) & 3 & 333,3 & 115,5 \\
infliximabe (mg/dose) & 1 & 200 & 0 \\
etanercepte (mg/sem) & 2 & 50 & 0 \\
adalimumabe (mg/dose) & 3 & 40 & 0 \\
rituximabe (mg/dose) & 2 & 2000 & 0 \\
abatacepte (mg/dose) & 1 & 500 & 0 \\
rigidez matinal (min) & 31 & 25,2 & 53,6 \\
HAQ & 31 & 1,8 & 0,6 \\
CDAI & 31 & 14,7 & 13,4 \\
SENS & 28 & 34,8 & 19,9 \\
\hline
\end{tabular}

$\Delta \mathrm{t}$ início-diag: tempo decorrido entre o início dos sintomas e o diagnóstico. HAQ: Health Assessment Questionnaire. CDAI: Clinical Disease Activity Index. SENS: Simplified Erosion Narrowing Score.

O modelo de regressão linear múltipla incluiu as variáveis clínicas e laboratoriais com associação significativa com SENS e CDAI. Em relação à variável dependente "SENS", foram construídos dois modelos, um incluindo o FR e anti-CCP3 como variáveis categóricas (presente ou ausente) e outro como variáveis ordinais escalares (de acordo com o título). Em ambos, somente as variáveis "dose máxima de MTX" e "história familiar" permaneceram com associação significativa ( $\mathrm{p}<0,001 \mathrm{em}$ ambas as variáveis). O modelo final explicou aproximadamente $73 \%$ da variabilidade de SENS. No modelo que avaliou a variável independente "CDAI", apenas "dose máxima de MTX” permaneceu com associação significativa $\left(r^{2}=0,35, p=0,016\right)$. 
Não houve diferenças significativas entre pacientes submetidos a ATQ e ATJ, em relação a CDAI, HAQ e SENS.

O coeficiente de correlação intraclasse para a avaliação de 10 radiografias foi de 0,92 (IC 95\% 0,73-0,98) e a diferença média entre os pares de avaliações foi de 3,4 (DP 7,2), não sendo encontrada diferença significativa $(\mathrm{p}=0,169)$.

Tabela 3. Testes de correlação de Spearman entre as variáveis independentes contínuas, Health Assessment Questionnaire (HAQ), Clinical Disease Activity Index (CDAI) e Simplified Erosion Narrowing Score (SENS).

\begin{tabular}{lccc} 
& \multicolumn{3}{c}{ CDAI } \\
\cline { 2 - 4 } idade & $\mathrm{R}$ & $\mathrm{IC}$ & $\mathrm{p}$ \\
\cline { 2 - 4 } tempo início & $-0,04$ & $-0,39 ; 0,32$ & 0,816 \\
$\Delta$ tempo-diag & $-0,46$ & $-0,70 ;-0.12$ & $\mathbf{0 , 0 1 1}$ \\
Dose máx MTX & 0,17 & $-0.20 ; 0.50$ & 0,365 \\
& 0,55 & 0,$22 ; 0.77$ & $\mathbf{0 , 0 0 3}$ \\
\hline & \multicolumn{3}{c}{ HAQ } \\
\cline { 2 - 4 } & $\mathrm{R}$ & $\mathrm{IC}$ \\
idade & 0,39 & 0,$04 ; 0,65$ & $\mathbf{0 , 0 3 1}$ \\
tempo início & 0,07 & $-0,3 ; 0,42$ & 0,704 \\
$\Delta$ início-diag & 0,08 & $-0,29 ; 0,43$ & 0,676 \\
Dose máx MTX & 0,01 & $-0,37 ;-0,39$ & 0,957 \\
& \multicolumn{3}{c}{ SENS } \\
\cline { 2 - 4 } & $\mathrm{R}$ & $\mathrm{IC}$ & $\mathrm{p}$ \\
\cline { 2 - 4 } idade & $-0,09$ & $-0,45 ; 0,29$ & 0,653 \\
tempo início & 0,32 & $-0,07 ; 0,62$ & 0,101 \\
$\Delta$ início-diag & 0,16 & $-0.23 ; 0.51$ & 0,431 \\
Dose máx MTX & $-0,58$ & $-0,80 ;-0,22$ & $\mathbf{0 , 0 0 4}$ \\
\hline
\end{tabular}

Tempo início: tempo entre o início da doença e a data da coleta de dados. $\Delta$ início-diag: tempo decorrido entre o início da doença e o diagnóstico de artrite reumatoide. 
Tabela 4. Comparação entre grupos com presença ou ausência de variáveis clínicas e laboratoriais.

\begin{tabular}{lccc}
\hline \multicolumn{1}{c}{ variável } & CDAI & HAQ & SENS \\
\hline & 0,563 & 0,611 & $\mathbf{0 , 0 0 5}$ \\
FR positivo & 0,532 & 0,181 & $\mathbf{0 , 0 3 7}$ \\
FR classe $(1 \mathrm{a} 4)$ & 0,351 & 0,301 & $\mathbf{0 , 0 4 4}$ \\
Anti-CCP3 + & 0,575 & 0,458 & $\mathbf{0 , 0 2 5}$ \\
Anti-CCP3 classe (1 x 4) & 0,86 & 0,616 & 0,87 \\
gênero & 0,936 & 0,054 & 0,08 \\
tabagismo & 0,58 & 0,406 & $\mathbf{0 , 0 0 9}$ \\
história familiar AR & 0,724 & 0,204 & 0,674 \\
uso MTX & 0,833 & 0,611 & 0,51 \\
uso LFN & 0,151 & 0,719 & 0,811 \\
uso SSZ & 0,127 & 0,778 & 0,964 \\
uso antimalárico & 0,108 & 0,124 & 0,466 \\
uso ouro & 0,057 & 0,33 & 0,98 \\
uso biológico & 0,776 & 0,109 & 0,502 \\
ATJ & &
\end{tabular}

Foram empregados os testes de Mann-Whitney ou Kruskal Wallis, de acordo com o número de categorias. HAQ: Health Assessment Questionnaire. CDAI: Clinical Disease Activity Index. SENS: Simplified Erosion Narrowing Score. FR: fator reumatoide - as classes de FR foram divididas de acordo com os quartis. Anti-CCP: anti-peptídeo cíclico citrulinado as classes de Anti-CCP foram divididas em negativo, positivo fraco, positivo moderado e positivo forte. MTX: metotrexato. LFN: leflunomida. SSZ: sulfassalazina. ATJ: artroplastia total do joelho.

\section{Discussão}

A coorte SARAR é constituída de pacientes adultos com doença de longa evolução, de todas as faixas etárias, com grande incapacidade funcional e extenso dano radiológico, em acompanhamento no serviço de Ortopedia do hospital SARAH-Brasília. Nossos resultados identificaram possíveis aperfeiçoamentos na condução dos pacientes com AR que são encaminhados para reabilitação e cirurgia. Chama a atenção o pequeno número de pacientes que estava em uso corrente de MTX, a droga-âncora do tratamento da AR. Isso pode ser explicado em parte por se tratar de pacientes de longa evolução, que em muitos casos foram expostos à medicação por longo tempo, o que pode aumentar a chance de descontinuação da medicação por efeitos adversos ${ }^{13,14}$, principalmente hepáticos ${ }^{15}$. Além disso, alguns pacientes possivelmente não tiveram boa resposta à medicação. Por outro lado, $49 \%$ dos casos estavam em atividade inflamatória moderada a grave, o que consideramos uma situação inadequada no contexto peroperatório. Tal fato não pode ser justificado somente pela gravidade dos casos, 
uma vez que vários pacientes estavam com dose subótima de DMCD. Articulações com lesões avançadas podem ter inflamação persistente. Se o tratamento medicamentoso estivesse otimizado, os pacientes em atividade de doença poderiam manifestar menos sintomas álgicos na articulação em que se indicou o procedimento cirúrgico, podendo ter a indicação cirúrgica postergada. Além disso, a atividade de doença torna os pacientes mais incapacitados, o que pode reduzir a adesão às atividades de reabilitação.

A frequência de positividade de FR e anti-CCP3 foi menor do que o descrito na literatura internacional, mas semelhante à encontrada na coorte Brasília ${ }^{16}$, composta de pacientes com AR inicial, cujos primeiros exames foram colhidos pré-tratamento. Nesse estudo, os títulos de FR aumentaram após um ano, o que pode justificar o título médio de FR ter sido muito superior em nossa casuística. Tais dados contrastam com a descrição de Bos e cols., em que se observou redução dos níveis de FR ou mesmo negativação do exame em uma parcela dos casos após início do tratamento com adalimumabe ${ }^{17}$ e com o estudo de Vaz e cols., em que houve redução significativa dos títulos de anti-CCP durante tratamento com infliximabe ${ }^{18}$. Esses achados podem estar relacionados a características específicas da droga em questão.

À semelhança deste estudo, outros grupos não encontraram correlação da positividade ou dos títulos de FR com a medida de capacidade funcional e atividade de doença ${ }^{19,20}$. A associação entre FR e progressão radiológica é conhecida, principalmente em pacientes com doença inicial ${ }^{21,22}$, porém não se sabe de que forma as lesões articulares se acumulam ao longo de décadas. Neste estudo, não foi encontrada correlação independente entre FR e SENS, mas foram avaliados pacientes com média de 20 anos de início da doença, com muitas lesões articulares acumuladas. Chama a atenção o fato de que não foi encontrada correlação entre idade e dano radiológico. Isso sugere que o surgimento de lesões pode se estabilizar ao longo do tempo, em grupos com fatores prognósticos distintos.

Foi encontrada correlação positiva entre idade e capacidade funcional, independentemente do grau de dano radiológico, o que sugere que outros fatores estejam influenciando o HAQ, como por exemplo, o processo natural do envelhecimento ${ }^{23}$, com o desenvolvimento de osteoartrite primária.

Ainda não está bem definido na literatura o papel do tabagismo na progressão radiológica. Os resultados deste estudo contrastam com os do estudo prospectivo de Vesperini e cols, que demonstrou recentemente menor risco de progressão em pacientes com AR 
126

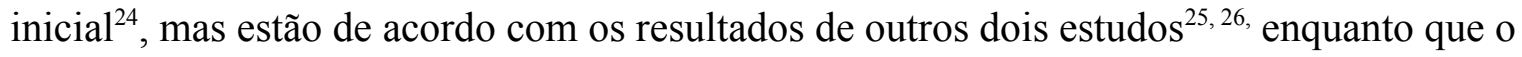
estudo de Ruiz-Esquide e cols. demonstrou maior progressão radiográfica em tabagistas ${ }^{27}$.

Em relação à história familiar de $\mathrm{AR}$, os resultados deste estudo vão de encontro aos de Rojas-Villajaga e cols., que demonstrou que pacientes portadores de AR inicial com história familiar desenvolviam mais rapidamente lesões radiográficas, embora não tenha sido avaliado o dano cumulativo ${ }^{28}$. Fatores como diferenças étnicas, tempo de doença, diferenças no tratamento com DMARD e métodos de avaliação radiográfica podem ser a origem de tais disparidades.

Pacientes com atividade de doença mantida por mais tempo apresentam maior dano radiológico acumulado ${ }^{29}$, o que pode explicar o uso de maiores doses de MTX nos pacientes com maiores valores de SENS e CDAI, pois provavelmente têm atividade de doença de mais difícil controle.

A coorte SARAR, de certa forma, faz um contraponto interessante com a coorte Brasília, uma vez que se trata de pacientes com doença avançada, originários da mesma região do Brasil. No nosso conhecimento, este é o primeiro estudo no Brasil que avaliou atividade de doença, capacidade funcional e dano radiológico em pacientes com AR de tão longa evolução, o que é interessante em um momento em que todas as atenções estão voltadas para pacientes com AR inicial. No momento, está sendo planejada uma mudança na avaliação e condução dos pacientes com AR em reabilitação no hospital SARAH-Brasília, motivada pelos resultados deste estudo, de forma que tais pacientes sejam agrupados para reabilitação em um serviço especializado.

Este estudo tem limitações. Trata-se de um estudo transversal, cujas conclusões necessitam de confirmação em estudos prospectivos; os dados temporais e as doses máximas de DMCD foram referidos pelos pacientes por meio de resgate da memória, o que pode levar a grandes imprecisões, considerando o tempo prolongado de doença; as dosagens de fator reumatoide tiveram grande variação temporal antecedendo a internação, por isso em alguns casos elas podem não ter representado o estado imunológico corrente dos pacientes; por motivos técnicos, inerentes à bidimensionalidade das radiografias, não foi possível avaliar o SENS de um paciente com deformidades graves, o que excluiu um caso extremo da análise.

Em resumo, pacientes com AR, operados no hospital SARAH-Brasília, receberam diagnóstico de AR tardiamente em seus serviços de origem. Cerca de metade dos pacientes estava em atividade inflamatória moderada a grave, com tratamento em desacordo com o consenso da Sociedade Brasileira de Reumatologia ${ }^{2}$ e com as recomendações da campanha 
Treat To Target ${ }^{30}$. Pacientes com história familiar de AR tiveram menor dano radiológico, enquanto pacientes com uso de maior dose máxima de MTX tiveram maior dano radiológico. Pacientes mais idosos tiveram maior incapacidade funcional. A dose máxima de MTX durante a evolução foi associada com maior atividade de doença.

\section{Agradecimentos}

Luiz Guilherme Nadal Nunes, pela assistência no planejamento dos testes estatísticos para avaliação da variabilidade intraexaminador na análise das radiografias.

\section{Referências}

1. Marques-Neto J, Gonçalves E, Langen L, Cunha M, Radominski S, Oliveira S, et al. Estudo multicêntrico da prevalência da artrite reumatoide do adulto em amostras da população brasileira. Rev Bras Reumatol. 1993;33(5):169-73.

2. Mota LMH, Cruz BA, Brenol CV, Pereira IA, Rezende-Fronza LS, Bertolo MB, et al. Consenso 2012 da Sociedade Brasileira de Reumatologia para o tratamento da artrite reumatoide. Rev Bras Reumatol. 2012;52:152-74.

3. Medeiros MMC, Ferraz MB, Vilar MJP, Santiago MB, Xavier RM, Levy RA, et al. Condutas usuais entre os reumatologistas brasileiros: levantamento nacional. Rev Bras Reumatol. 2006;46:82-92.

4. Robinson JC, Pozen A, Tseng S, Bozic KJ. Variability in costs associated with total hip and knee replacement implants. JBJS (American volume). 2012 19;94(18):1693-8.

5. Macedo A, Oakley S, Gullick N, Kirkham B. An examination of work instability, functional impairment, and disease activity in employed patients with rheumatoid arthritis. $\mathrm{J}$ Rheumatol. 2009;36(2):225-30.

6. Mota LMH, Cruz BA, Brenol CV, Pereira IA, Fronza LSR, Bertolo MB, et al. Consenso da Sociedade Brasileira de Reumatologia 2011 para o diagnóstico e avaliação inicial da artrite reumatoide. Rev Bras Reumatol. 2011;51:207-19.

7. Arnett FC, Edworthy SM, Bloch DA, McShane DJ, Fries JF, Cooper NS, et al. The American Rheumatism Association 1987 revised criteria for the classification of rheumatoid arthritis. Arthritis rheum. 1988;31(3):315-24.

8. Aletaha D, Smolen J. The Simplified Disease Activity Index (SDAI) and the Clinical Disease Activity Index (CDAI): a review of their usefulness and validity in rheumatoid arthritis. Clin exp rheumatol. 2005;23(5 Suppl 39):S100-8. 
9. Ferraz MB, Oliveira LM, Araujo PM, Atra E, Tugwell P. Crosscultural reliability of the physical ability dimension of the health assessment questionnaire. J rheumatol.

1990;17(6):813-7.

10. Costa G, Confiabilidade da autoaplicação do Health Assessment Questionnaire Modificado (HAQ-M) em uma população de portadores de artrite reumatoide no Brasil. Brasília-DF. Dissertação [Mestrado em Ciencias Médicas]. Universidade de Brasília; 2006.

11. Heijde D, Dankert T, Nieman F, Rau R, Boers M. Reliability and sensitivity to change of a simplification of the Sharp/van der Heijde radiological assessment in rheumatoid arthritis. Rheumatology (Oxford). 1999;38(10):941-7.

12. Weir JP. Quantifying test-retest reliability using the intraclass correlation coefficient and the SEM. J Strength Cond Res. 2005;19(1):231-40.

13. Gilani ST, Khan DA, Khan FA, Ahmed M. Adverse effects of low dose methotrexate in rheumatoid arthritis patients. J Coll Physicians Surg Pak. 2012;22(2):101-4.

14. McWilliams DF, Kiely PD, Young A, Walsh DA. Baseline factors predicting change from the initial DMARD treatment during the first 2 years of rheumatoid arthritis: experience in the ERAN inception cohort. BMC Musculoskelet Disord. 2013;14:153.

15. Alves JA, Fialho SC, Morato EF, Castro GR, Zimmermann AF, Ribeiro GG, et al. Liver toxicity is rare in rheumatoid arthritis patients using combination therapy with leflunomide and methotrexate. Rev Bras Reumatol. 2011;51(2):141-4.

16. Mota LMH, Santos Neto LL, Pereira IA, Burlingame R, Ménard HA, Laurindo IMM. Autoanticorpos na artrite reumatoide inicial: coorte Brasília - resultados de uma análise seriada de três anos. Rev Bras Reumatol. 2011;51:564-71.

17. Bos WH, Bartelds GM, Wolbink GJ, Koning MH, Stadt RJ, Schaardenburg D, et al. Differential response of the rheumatoid factor and anticitrullinated protein antibodies during adalimumab treatment in patients with rheumatoid arthritis. J Rheumatol. 2008;35(10):19727.

18. Vaz JLP, Abreu MM, Levy RA. Changes in anti-ctrullinated antibody titers following treatment with infliximab foi rheumatoid arthritis. IMAJ. 2014;16:17-9.

19. Mota LMH, Santos Neto LL, Burlingame RW, Ménard HA, Pereira IA, Carvalho JF, et al. Incapacitação e qualidade de vida não são influenciadas pela prevalência de autoanticorpos em pacientes com artrite reumatoide inicial - resultados da Coorte Brasília. Rev Bras Reumatol. 2012;52:824-9.

20. Teixeira RCA, Gabriel Júnior A, Martino MCD, Martins LC, Lopes AC, Tufik S. Marcadores de ativação endotelial e auto-anticorpos na artrite reumatóide. Rev Bras Reumatol. 2007;47:411-7. 
21. Mota LMH, Santos Neto LL, Burlingame R, Laurindo IMM. Comportamento distinto dos sorotipos do fator reumatoide em avaliação seriada de pacientes com artrite reumatoide inicial. Rev Bras Reumatol. 2009;49:223-35.

22. Heijde DM, Riel PL, Rijswijk MH, Putte LB. Influence of prognostic features on the final outcome in rheumatoid arthritis: a review of the literature. Sem Arthritis Rheum. 1988;17(4):284-92.

23. Cho SK, Sung YK, Choi CB, Cha HS, Choe JY, Chung WT, et al. Do patients with elderly-onset rheumatoid arthritis have severe functional disability? Sem Arthritis Rheum. 2012 Aug;42(1):23-31.

24. Vesperini V, Lukas C, Fautrel B, Le Loet X, Rincheval N, Combe B. Association of tobacco exposure and reduction of radiographic progression in early rheumatoid arthritis: results from a French multicenter cohort. Arthritis Care Res. 2013;65(12):1899-906.

25. Finckh A, Dehler S, Costenbader KH, Gabay C. Cigarette smoking and radiographic progression in rheumatoid arthritis. Ann Rheum Dis. 2007;66(8):1066-71.

26. Westhoff G, Rau R, Zink A. Rheumatoid arthritis patients who smoke have a higher need for DMARDs and feel worse, but they do not have more joint damage than non-smokers of the same serological group. Rheumatology (Oxford). 2008;47(6):849-54.

27. Ruiz-Esquide V, Gomez-Puerta JA, Canete JD, Graell E, Vazquez I, Ercilla MG, et al. Effects of smoking on disease activity and radiographic progression in early rheumatoid arthritis. J Rheumatol. 2011;38(12):2536-9.

28. Rojas-Villarraga A, Diaz FJ, Calvo-Paramo E, Salazar JC, Iglesias-Gamarra A, Mantilla RD, et al. Familial disease, the HLA-DRB1 shared epitope and anti-CCP antibodies influence time at appearance of substantial joint damage in rheumatoid arthritis. $\mathrm{J}$ Autoimmun. 2009;32(1):64-9.

29. Hetland ML, Ejbjerg B, Horslev-Petersen K, Jacobsen S, Vestergaard A, Jurik AG, et al. MRI bone oedema is the strongest predictor of subsequent radiographic progression in early rheumatoid arthritis. Results from a 2-year randomised controlled trial (CIMESTRA). Ann Rheum Dis. 2009;68(3):384-90.

30. Smolen JS, Aletaha D, Bijlsma JW, Breedveld FC, Boumpas D, Burmester G, et al. Treating rheumatoid arthritis to target: recommendations of an international task force. Ann Rheum Dis. 2010;69(4):631-7. 


\title{
TERMO DE CONSENTIMENTO LIVRE E ESCLARECIDO
}

\author{
$\mathrm{O}(\mathrm{A})$ Sr.(a) está sendo convidado(a) para participar da pesquisa intitulada:
}

\begin{abstract}
“Capacidade funcional e análise de marcha no pós-operatório de artroplastia total do quadril em pacientes com hipovitaminose D”, realizada no hospital SARAH Brasília. A pesquisa terá duração de 1 ano, com o término previsto para maio de 2013.
\end{abstract}

O(A) Sr.(a) foi selecionado(a), mas sua participação não é obrigatória. Sua participação é voluntária, isto é, a qualquer momento, o(a) Sr.(a) pode recusar-se a responder qualquer pergunta ou desistir de participar e retirar seu consentimento. Sua recusa não trará nenhum prejuízo em sua relação com o pesquisador ou com a instituição.

O objetivo deste estudo é verificar se há correlação entre os níveis de vitamina $\mathrm{D}$ no sangue e o resultado da reabilitação após a artroplastia total de quadril. Serão utilizados para tal os dados colhidos de rotina pela equipe de terapia funcional no pré e pós-operatório. Sua participação nesta pesquisa consistirá em responder as perguntas a serem realizadas sob a forma de questionário e será realizada coleta de amostra de sangue e urina para dosagem de vitamina $\mathrm{D}$, paratormônio, cálcio e fósforo, cujos resultados serão passados para o(a) Sr.(a) 3 meses após a cirurgia.

$\mathrm{O}(\mathrm{A}) \operatorname{Sr}(\mathrm{a})$ não terá nenhum custo ou quaisquer compensações financeiras. Não há nenhum risco adicional relacionado com sua participação no estudo, além dos relacionados ao procedimento cirúrgico. O benefício relacionado com a sua participação é a possibilidade de ser diagnosticado como portador de hipovitaminose D (ou seja, vitamina D baixa no sangue), uma condição frequente na população e que, quando não diagnosticada e tratada, pode levar a prejuízo da saúde óssea.

Suas respostas serão tratadas de forma anônima e confidencial, isto é, em nenhum momento será divulgado o seu nome em qualquer fase do estudo. Os dados coletados serão utilizados apenas em pesquisas e os resultados divulgados em eventos e/ou revistas científicas.

$\mathrm{O}(\mathrm{A}) \mathrm{Sr}$.(a) receberá uma cópia deste termo onde consta o telefone e o endereço institucional do pesquisador principal e o endereço eletrônico, podendo tirar suas dúvidas sobre o projeto e sua participação, agora ou a qualquer momento. 
Bernardo Matos da Cunha

CRM-DF 16753

Hospital SARAH Brasília

SMHS Quadra 301 Bloco A

70.335-901 - Brasília - DF

Telefone: 0xx61 - 33191111

Email: bmcunha@sarah.br

Declaro estar ciente do inteiro teor deste TERMO DE CONSENTIMENTO e estou de acordo em participar do estudo proposto, sabendo que dele poderei desistir a qualquer momento, sem sofrer qualquer punição ou constrangimento.

(assinatura) 


\section{ÍNDICE WOMAC DE AVALIAÇÃO DO QUADRIL TRADUZIDO E VALIDADO PARA A LÍNGUA PORTUGUESA}

Extraído de: Fernandes MI. Tradução e validação do questionário de qualidade de vida específico para osteoartrose WOMAC (Western Ontario McMaster Universities) para a lingua portuguesa. Reumatologia. [São

Paulo]: Universidade Federal de São Paulo - Escola Paulista de Medicina; 2003.

As perguntas a seguir se referem à INTENSIDADE DA DOR que você está atualmente sentindo devido a artrite de seu quadril. Para cada situação, por favor, coloque a intensidade da dor que sentiu nas últimas 72 horas (3 dias)

Pergunta: Qual a intensidade da sua dor?

1-Caminhando em um lugar plano.

Nenhuma Pouca Moderada Intensa Muito intensa

2- Subindo ou descendo escadas.

Nenhuma Pouca Intensa Muderada intensa

3- A noite deitado na cama.

Nenhuma Pouca Moderada Intensa Muito intensa

4-Sentando-se ou deitando-se.

Nenhuma Pouca Intensa Muito intensa

5. Ficando em pé.

Nenhuma Pouca Moderada Intensa Muito intensa

TOTAL:

As perguntas a seguir se referem a intensidade de RIGIDEZ nas junta (não dor), que você está atualmente sentindo devido a artrite em seu quadril nas últimas 72 horas. Rigidez é uma sensação de restrição ou dificuldade para movimentar suas juntas.

1- Qual é a intensidade de sua rigidez logo após acordar de manhã?

Nenhuma Pouca Moderada Intensa Muito intensa

2- Qual é a intensidade de sua rigidez após se sentar, se deitar ou repousar no decorrer do dia?

Nenhuma Pouca Moderada Intensa Muito intensa

TOTAL:

As perguntas a seguir se referem a sua ATIVIDADE FÍSICA. Nós chamamos atividade física, sua capacidade de se movimentar e cuidar de você mesmo(a). Para cada uma das atividades a seguir, por favor, indique o grau de dificuldade que você está tendo devido à artrite em seu quadril durante as últimas 72 horas.

Pergunta: Qual o grau de dificuldade que você tem ao:

1 - Descer escadas.

Nenhuma Pouca Moderada Intensa $\quad$ Muito intensa

2- Subir escadas.

Nenhuma Pouca Moderada Intensa Muito intensa

3- Levantar-se estando sentada. 


\begin{tabular}{|c|c|c|c|c|}
\hline Nenhuma & Pouca & Moderada & Intensa & Muito intensa \\
\hline \multicolumn{5}{|l|}{ 4- Ficar em pé. } \\
\hline Nenhuma & Pouca & Moderada & Intensa & Muito intensa \\
\hline \multicolumn{5}{|c|}{ 5- Abaixar-se para pegar algo. } \\
\hline Nenhuma & Pouca & Moderada & Intensa & Muito intensa \\
\hline \multicolumn{5}{|c|}{ 6- Andar no plano. } \\
\hline Nenhuma & Pouca & Moderada & Intensa & Muito intensa \\
\hline \multicolumn{5}{|c|}{ 7- Entrar e sair do carro. } \\
\hline Nenhuma & Pouca & Moderada & Intensa & Muito intensa \\
\hline \multicolumn{5}{|c|}{ 8- Ir fazer compras. } \\
\hline Nenhuma & Pouca & Moderada & Intensa & Muito intensa \\
\hline \multicolumn{5}{|c|}{ 9- Colocar meias. } \\
\hline Nenhuma & Pouca & Moderada & Intensa & Muito intensa \\
\hline \multicolumn{5}{|c|}{ 10- Levantar-se da cama. } \\
\hline Nenhuma & Pouca & Moderada & Intensa & Muito intensa \\
\hline \multicolumn{5}{|c|}{ 11- Tirar as meias. } \\
\hline Nenhuma & Pouca & Moderada & Intensa & Muito intensa \\
\hline \multicolumn{5}{|c|}{ 12- Ficar deitado na cama. } \\
\hline Nenhuma & Pouca & Moderada & Intensa & Muito intensa \\
\hline \multicolumn{5}{|c|}{ 13- Entrar e sair do banho. } \\
\hline Nenhuma & Pouca & Moderada & Intensa & Muito intensa \\
\hline \multicolumn{5}{|l|}{14 - Se sentar. } \\
\hline Nenhuma & Pouca & Moderada & Intensa & Muito intensa \\
\hline \multicolumn{5}{|c|}{ 15- Sentar e levantar do vaso sanitário. } \\
\hline Nenhuma & Pouca & Moderada & Intensa & Muito intensa \\
\hline \multicolumn{5}{|c|}{ 16- Fazer tarefas domésticas pesadas. } \\
\hline Nenhuma & Pouca & Moderada & Intensa & Muito intensa \\
\hline
\end{tabular}

17- Fazer tarefas domésticas leves.

$\begin{array}{llll}\text { Nenhuma } & \text { Pouca } & \text { Moderada } & \text { Intensa }\end{array}$

TOTAL:

\section{Pontuação}

Nenhuma 0

Pouca $1 \quad$ Moderada 2

Intensa 3

Muito intensa 


\title{
APROVAÇÃO PELO COMITÊ DE ÉTICA EM PESQUISA DA REDE SARAH DE HOSPITAIS DE REABILITAÇÃO
} \\ Comité de Ética em Pesquisa da Associaçăo das Pioneiras Sociais
}

\section{CERTIDÃO}

Declaramos que o trabalho intitulado Capacidade funcional e análise de marcha no pos-operatónio de artroplastia total do quadril em pacientes com hipovitaminose $D$, de Bernardo Matos da Cunha, Medico, foi apreciado e considerado correto sob o ponto de vista ético pelo Comite de Ética em Pesquisa da Rede SARAH de Hospitais de Reabilitaçăo, em dez de novembro de 2011.

Brasilia-DF, 11 de junho de 2012.

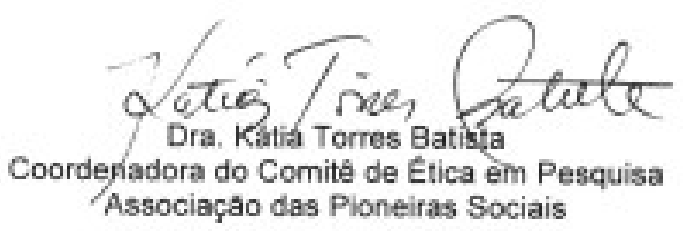

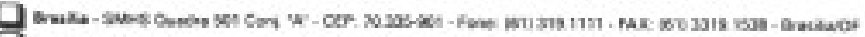

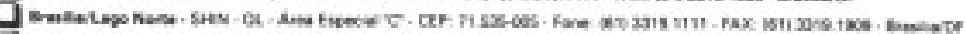

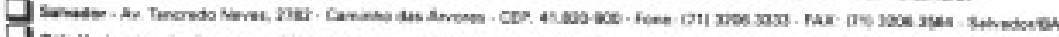

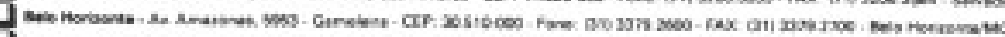

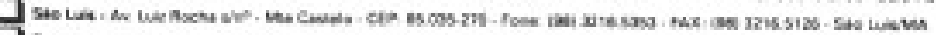

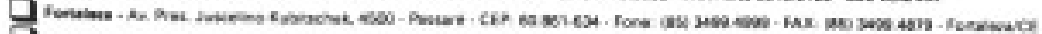

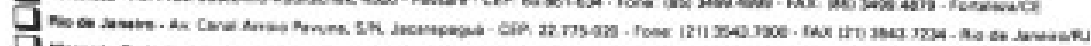

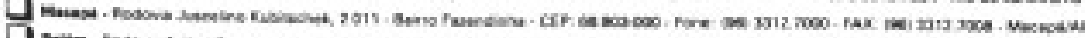

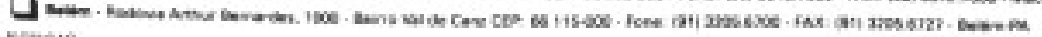

